University of Redlands

\title{
A Web-Based Atlas of Environmental Justice for Coachella Valley, Southern California
}

A Major Individual Project submitted in partial satisfaction of the requirements

for the degree of Master of Science in Geographic Information Systems

by

Joseph Munyao

Fang Ren, Ph.D., Committee Chair

Mark Kumler, Ph.D.

December 2014 
A Web-Based Atlas of Environmental Justice in the Coachella Valley, Southern California

Copyright (C) 2014

by

Joseph Munyao 
The report of Joseph Munyao is approved.

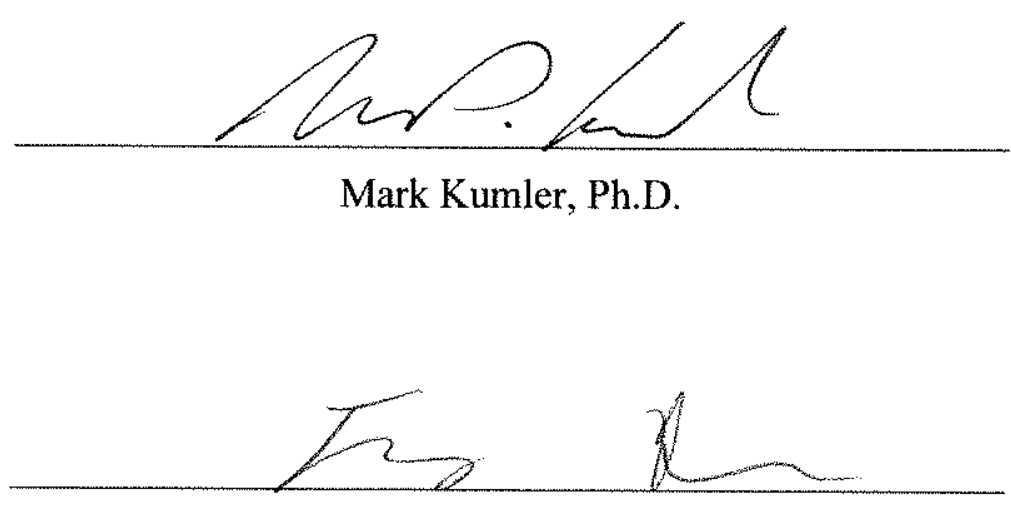

Fang Ren, Ph.D., Committee Chair

December 2014 



\section{Acknowledgements}

First, I thank the Almighty God, to whom I pay allegiance, for granting me the opportunity to be part of His creation, giving me a sound mind, and enabling me by His grace to come this far. Many appreciations to Morrison Family Foundation Trust for the grant to enable me join a grad school. To my advisor Fang Ren, Ph.D., your contribution to this project was unmeasurable. I highly appreciate your input towards making my graduate schoolwork successful. To my dear parents, Mr. \& Mrs. Peter M. Mbuvi, it is with utmost gratitude that I celebrate the fruits of your tearful sweat. You always made sure that I got that which was relevant so that my life can be meaningful. I honor you, Mum and Dad, for you taught me the basics of education, discipline, and life. To my fiancé, Victoria Mueni, you are beyond a line of appreciation from my heart. Though painful and as hard as it was, you let me fly miles away and leave you behind so that I can advance my education. Your support and encouragement kept me going through the hard times away from home. May the Almighty God favor and bless you in abundance. Peter, thanks for introducing me to the MS GIS program and mentoring me. Loderay, you ensured that I was happy, well, and strong to do that that pertains to my being in the foreign land. Thanks Raynah for trusting me and keeping me on my toes as far as far as positivity is concerned. Every single slap was worth towards making me a good boy. For sure, you are beyond a sister to me Raynah. Many thanks to Lane and Greg Lane, my USA mum and dad, for the support you accorded me. Great thanks to Nate and Shilpi for helping me with my code; you always knew where it was breaking. Cohort 25 , \& 24, you will live long in my memories for the fun-filled moments we shared. I cannot mention all but, in whichever way you made me go through the program, I surely appreciate. 



\begin{abstract}
A Web-Based Atlas of Environmental Justice in Coachella Valley, Southern California

by

Joseph Munyao

The US Environmental Protection Agency (2014) defines environmental justice as "the fair treatment and meaningful involvement of all people regardless of race, color, national origin, or income with respect to the development, implementation, and enforcement of environmental laws, regulations, and policies." Environmental issues caused by human practices affect human life in numerous ways. As a result, different regions exhibit varying interactions between the environment and the corresponding human practices. The lack of an adequate communication medium for the existing environmental justice issues has left the residents of Coachella Valley with unattended and overlooked environmental hazards. Although the victims are aware of the problems, other members of the society and government agencies need to realize the effects of the deadly hazards on the Valley residents. This project examined the vulnerability of different communities to environmental hazards based on their linguistic, ethnic, and racial diversities. To target a broader audience, GIS and Web technologies have proven to be effective in exploring the spatial interactions between residents and geographic contexts. Thus, the project adapted an interactive Web-based solution to enable visualization of the spatial patterns between environmental and social factors. Considering the environmental factors, including pesticide use, water distribution, housing, green spaces, and waste facilities and dumpsites, an interactive Web application was developed using ArcGIS API for JavaScript.
\end{abstract}





\section{Table of Contents}

Chapter 1 - Introduction ............................................................................................... 1

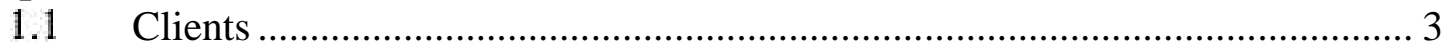

1.2 Problem Statement ........................................................................... 3

1.3 Proposed Solution .............................................................................. 3

1.3.1 Goals and Objectives ............................................................................. 3

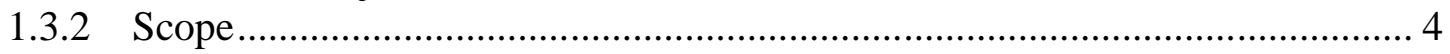

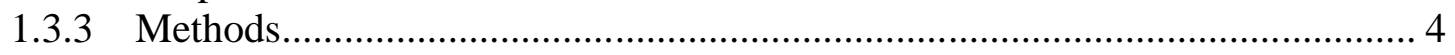

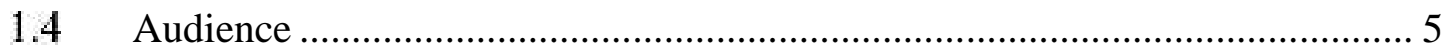

1.5 Overview of the Rest of This Report ....................................................... 5

Chapter 2 - Background and Literature Review ............................................................ 7

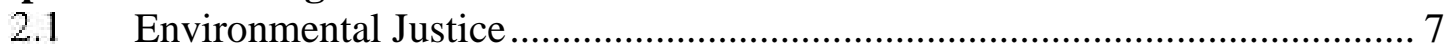

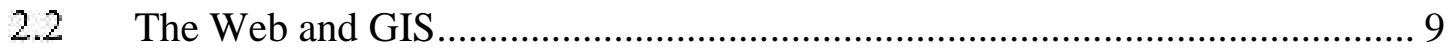

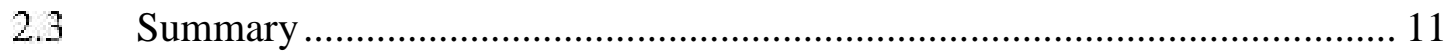

Chapter 3 - Systems Analysis and Design........................................................................... 13

$3.1 \quad$ Problem Statement .................................................................................. 13

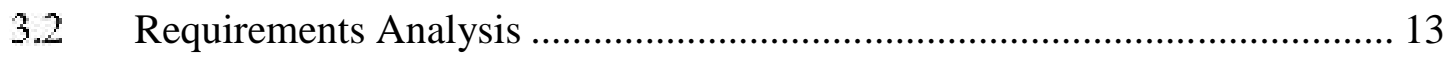

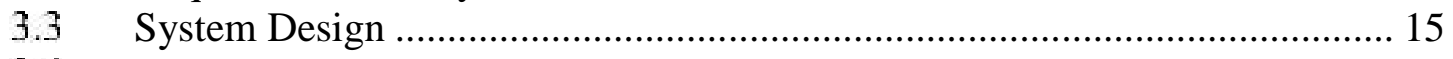

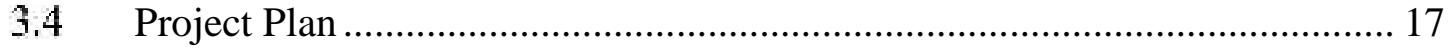

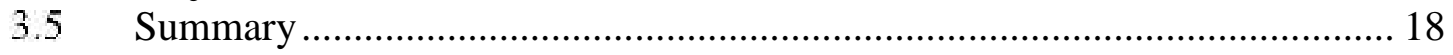

Chapter 4 - Database Design........................................................................................... 19

4.1 Conceptual Data Model ................................................................... 19

4.2 Logical Data Model ………………………….................................... 24

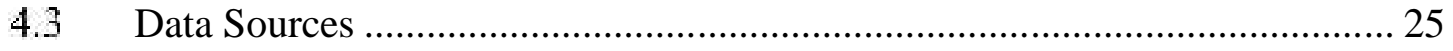

4.4 Data Scrubbing and Loading ……………………............................. 25

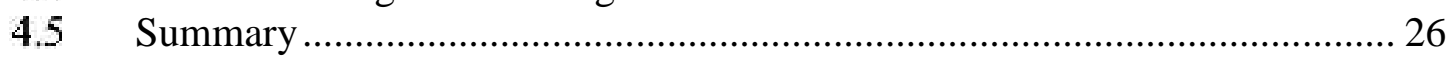

Chapter 5 - Implementation.................................................................................................... 27

$5.1 \quad$ Publishing Maps and Services ............................................................... 27

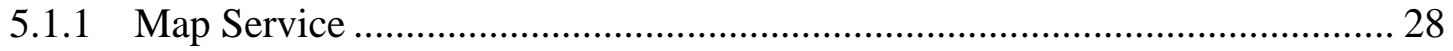

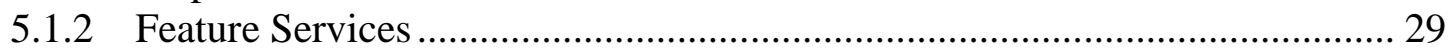

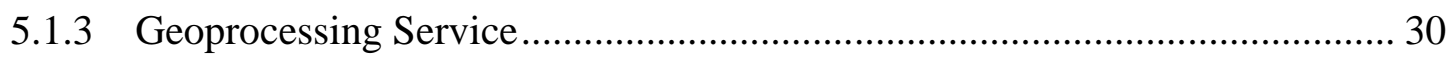

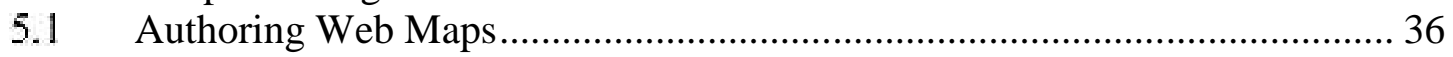

$5.2 \quad$ Web Application Development................................................................... 38

5.2.1 Public Web Application Version ............................................................... 38

5.2.2 Clients Web Application Version .................................................................... 40

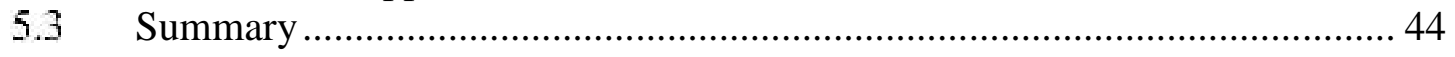

Chapter 6 - Results and Analysis............................................................................ 45

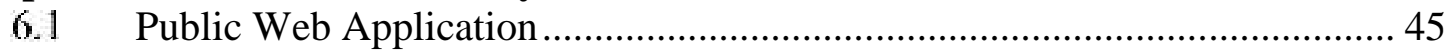

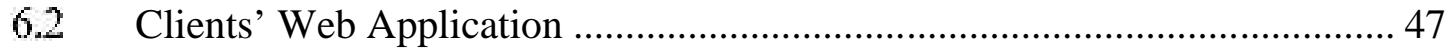

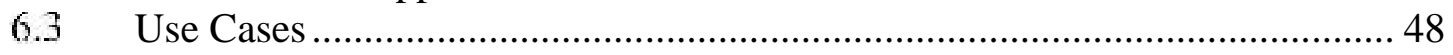

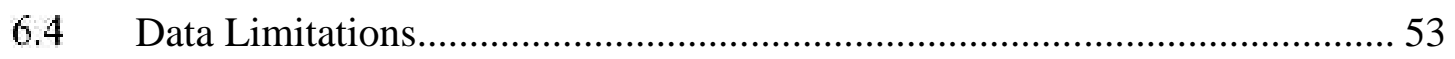

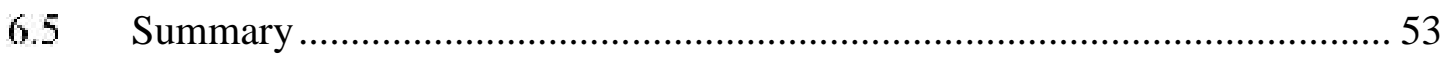


Chapter 7 - Conclusions and Future Work .................................................................... 55

Works Cited ........................................................................57

Appendix A. Sample Code in Aptana Studio 3 ...................................................... 59

Appendix B. Sample CSS .......................................................................................................... 64

Appendix C. Geoprocessing Code ..................................................................66 6

Appendix D. Environmental Justice Maps.................................................................. 69 


\section{Table of Figures}

Figure 1.1: Coachella Valley in Riverside County, CA.............................................. 1

Figure 1.2: Location of the project area in Riverside County, Southern California ....2

Figure 1.3: Project workflow ............................................................................. 5

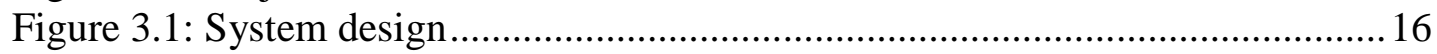

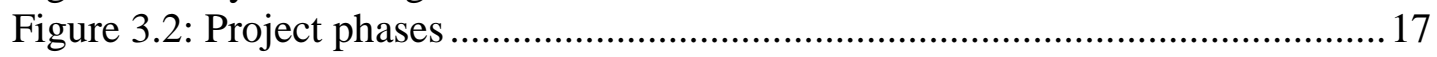

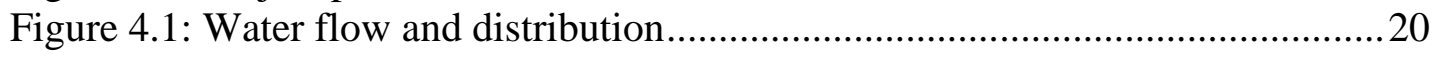

Figure 4.2: Interactions of water and pesticides ............................................. 21

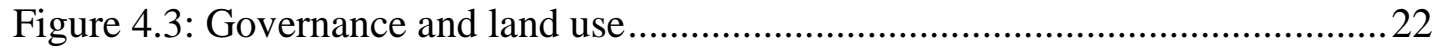

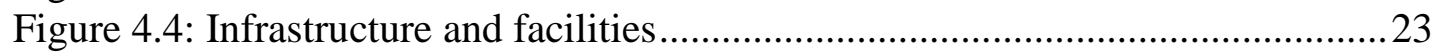

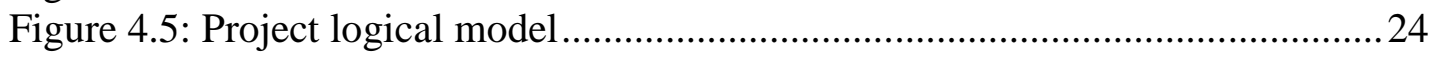

Figure 5.1: Setting up the ArcGIS Server ...........................................................2

Figure 5.2: Database connection to the enterprise database server .........................28

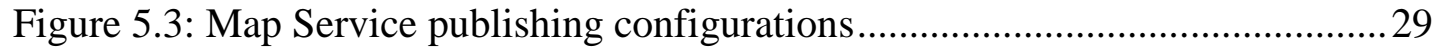

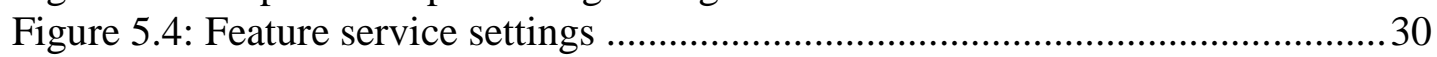

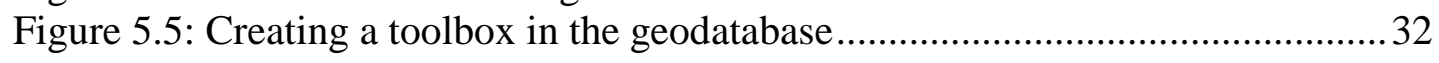

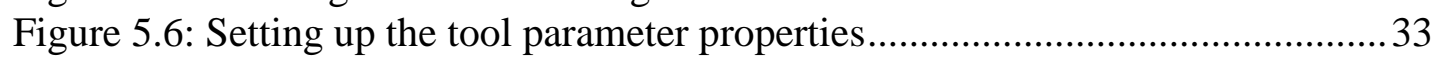

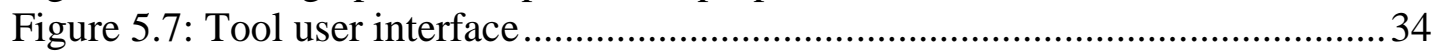

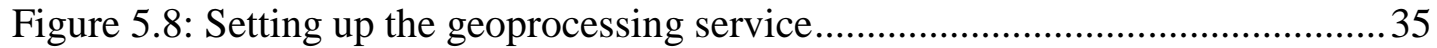

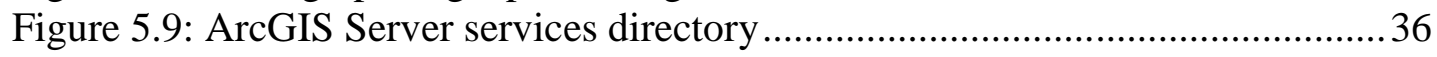

Figure 5.10: Environmental justice issues based on Hispanic population percentages

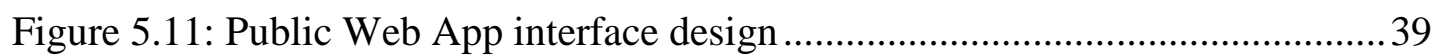

Figure 5.12: Using the Measurement widget on the application ..............................39

Figure 5.13: Characteristics of population based on ethnicity in a Tract .................40

Figure 5.14: Clients' Web application interface .................................................. 41

Figure 5.15: Edit window for the feature services ............................................. 42

Figure 5.16: Edit settings window in ArcMap.................................................. 43

Figure 5.17: Geoprocessing service interface to enter parameters ..........................44

Figure 6.1: Public Web application interface ................................................... 45

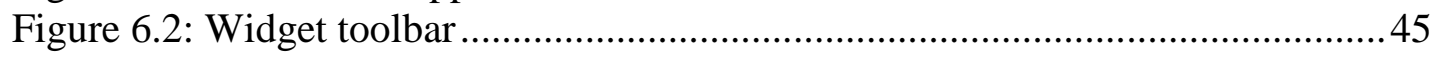

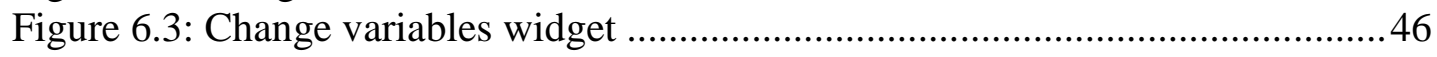

Figure 6.4: Clients' Web application interface ................................................. 47

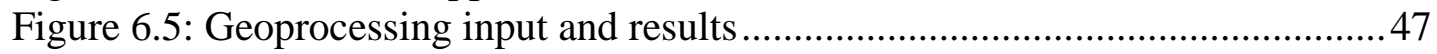

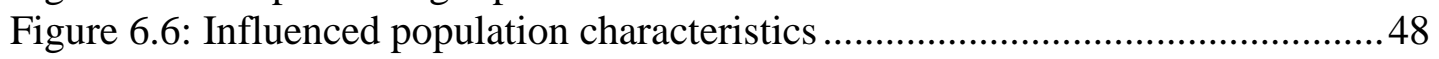

Figure 6.7: Population density in Coachella Valley ...............................................49

Figure 6.8: Percentages of Hispanic population per tract in Coachella Valley ..........50

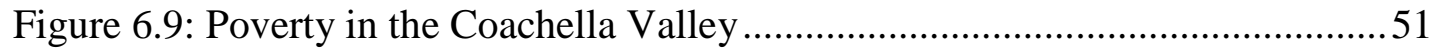

Figure 6.10: Poor English speaking abilities by the population .............................51

Figure 6.11: Water distribution based on percentages of Hispanic population ..........52

Map 1: Use of pesticides against percentages of Hispanic population .....................69

Map 2: Distribution of green spaces against percentages of Hispanic population .... 70

Map 3: Waste disposal practices against percentages of Hispanic population ...........70

Map 4: Housing infrastructure against percentages of Hispanic population ............. 71 
Map 5: Pesticides and waste disposal facilities against poverty levels

Map 6: Distribution of green spaces against poverty levels ................................. 72

Map 7: Water distribution and access against poverty levels ................................ 72

Map 8: Housing infrastructure against poverty levels........................................ 73

Map 9: Waste disposal facilities and pesticides usage against English speaking abilities

Map 10: Water infrastructure and green spaces against English speaking abilities .. 74

Map 11: Housing infrastructure against English speaking abilities

74 


\section{List of Tables}

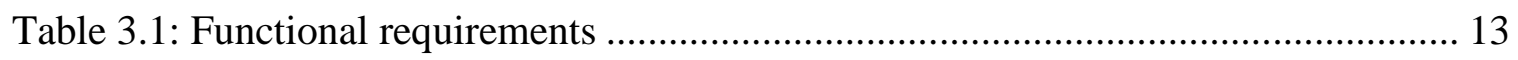

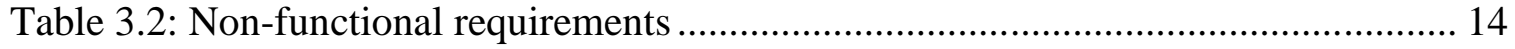

Table 5.1: Project themes and respective feature services............................................ 37 



\section{List of Acronyms and Definitions}

$\begin{array}{ll}\text { AGOL } & \text { ArcGIS Online } \\ \text { API } & \text { Application Programming Interface } \\ \text { ArcSDE } & \text { Arc Spatial Database Engine } \\ \text { AWAB } & \text { ArcGIS Web App Builder } \\ \text { CCD } & \text { Census County Division } \\ \text { CCWD } & \text { Coachella Valley Water District } \\ \text { CSS } & \text { Cascading Style Sheet } \\ \text { ECV } & \text { East Coachella Valley } \\ \text { EPA } & \text { Environmental Protection Agency } \\ \text { EVST } & \text { Environmental Design Studio } \\ \text { HTML } & \text { Hyper Text Markup Language } \\ \text { IDE } & \text { Integrated Development Environment } \\ \text { IIS } & \text { Internet Information Services } \\ \text { JS } & \text { JavaScript } \\ \text { KML } & \text { Keyhole Markup Language } \\ \text { MAUP } & \text { Modifiable Area Unit Problem } \\ \text { MXD } & \text { Map Document } \\ \text { PPGIS } & \text { Public Participatory GIS } \\ \text { TRI } & \text { Toxic Releases Inventory } \\ \text { TSDF } & \text { Treatment Storage and/or Disposal Facilities } \\ \text { URL } & \text { Universal Resource Locator } \\ \text { WCV } & \text { West Coachella Valley }\end{array}$





\section{Chapter 1 - Introduction}

The US Environmental Protection Agency (2014) defined environmental justice as "the fair treatment and meaningful involvement of all people regardless of race, color, national origin, or income with respect to the development, implementation, and enforcement of environmental laws, regulations, and policies." Failure to maintain environmental justice in daily lives has led to a high compromise of the standards of living in different societies. The project area, Coachella Valley, is a metropolitan area at the foothills of the San Bernardino Mountains in Riverside County, California (Figure 1.1).

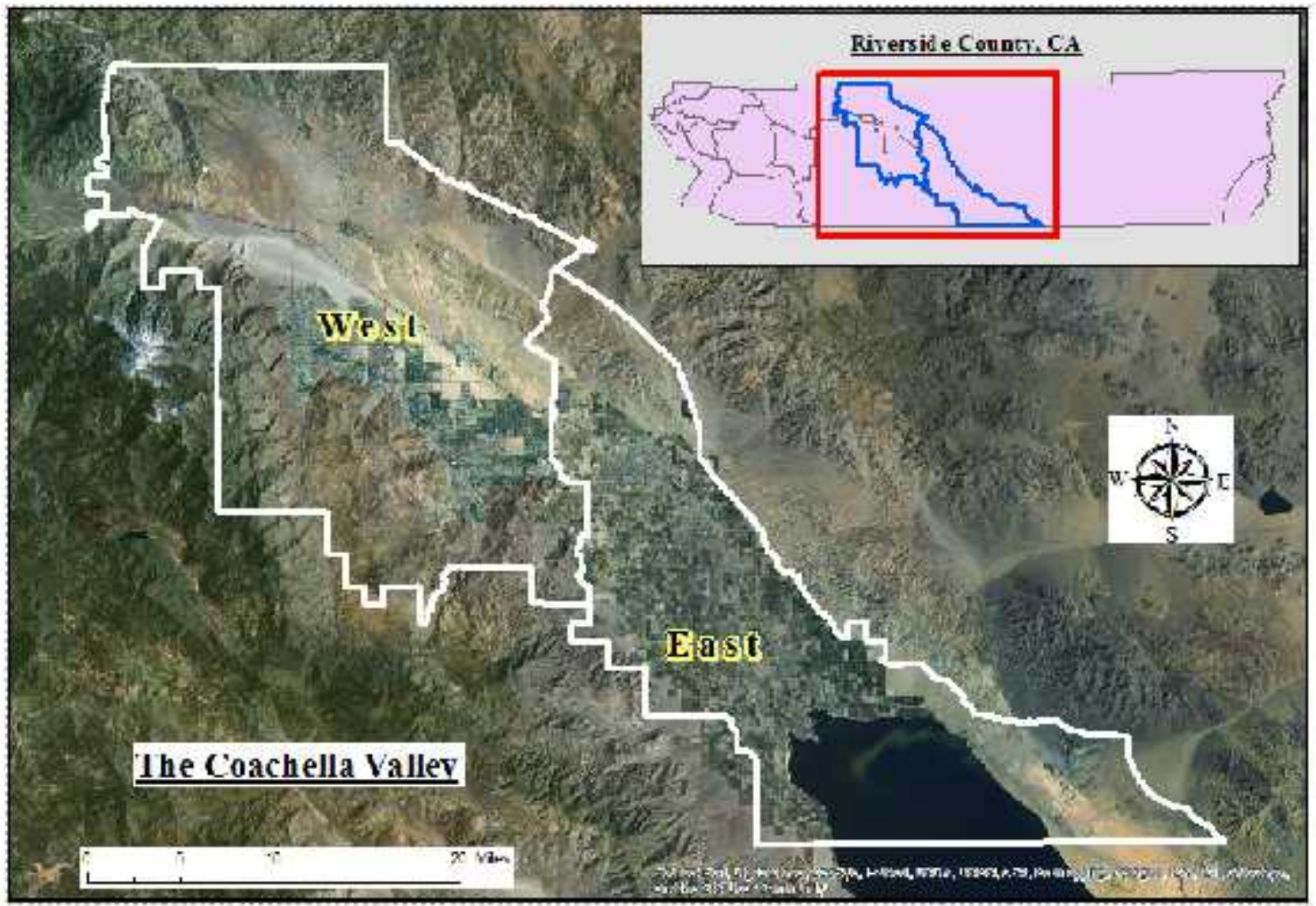

Figure 1.1: Coachella Valley in Riverside County, CA

Riverside County is located in the southern part of California. Figure 1.2 illustrates the geographical locations of the project area and Riverside County in the State of California, USA. The County consists of 17 Census County Divisions (CCD) among which four form the project area, Coachella Valley. These four CCDs forming the project area include the Coachella Valley, Cathedral City-Palm Desert, Desert Hot Springs, and 
Palm Springs. The first CCD constitutes the Eastern region while the latter three constitute the Western region.

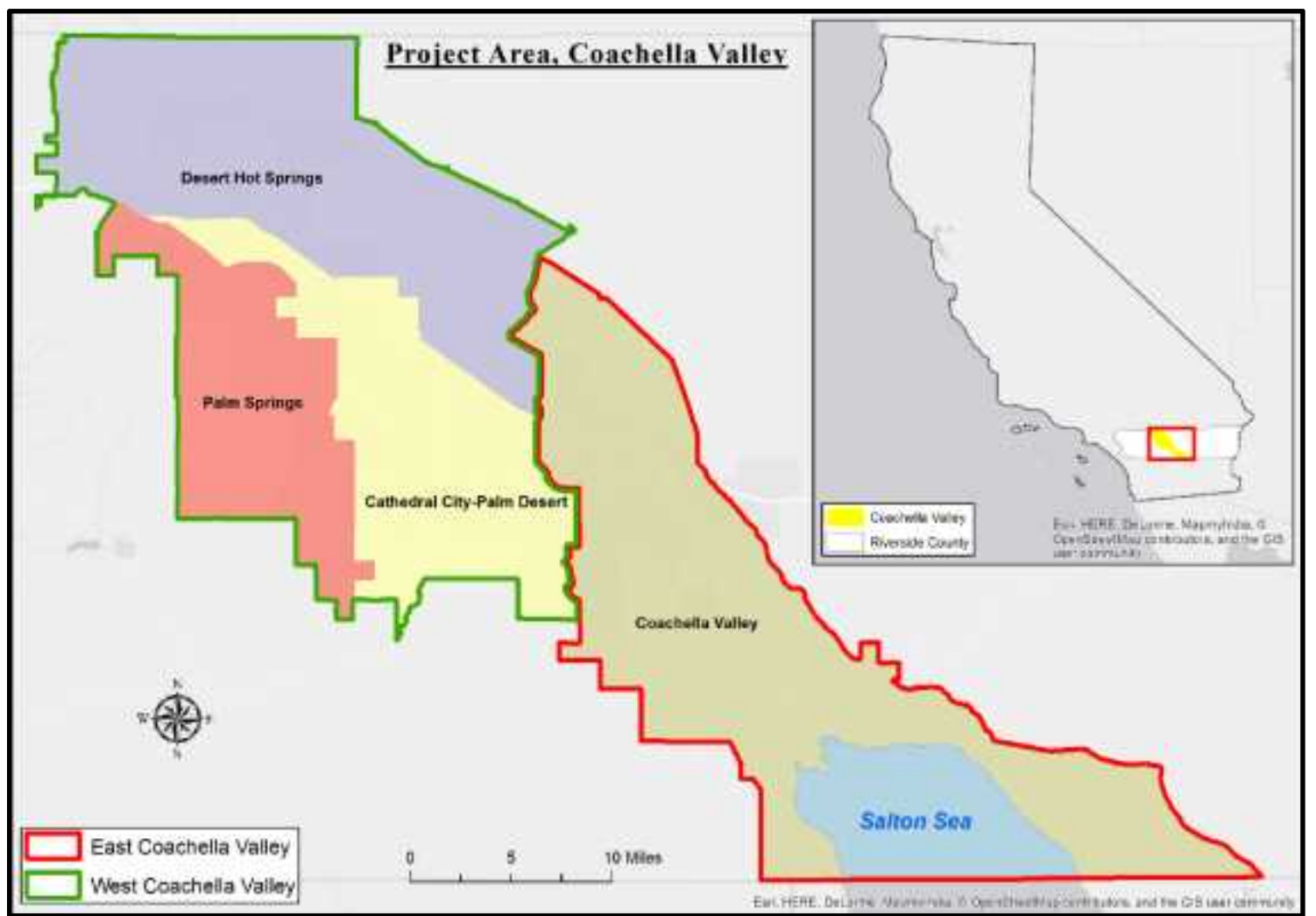

Figure 1.2: Location of the project area in Riverside County, Southern California

A wide racial and ethnic diversity characterizes the regional demographics with a total population of more than 320,000 people. Rising environmental issues ascribed to various human practices disproportionately affect these diverse communities. The susceptibility to these environmental issues categorizes the valley into two distinct regions: East and West Coachella Valley regions (Figure 1.1). The low-income residents of the Eastern Coachella Valley (ECV) are more vulnerable to the environmental hazards as compared to the high-income residents in the Western Coachella Valley (WCV).

Hosting unincorporated communities, the Valley faces a myriad of issues including poor access to health facilities, poor transportation infrastructure, contaminated drinking water, failing sewer connections, excessive exposure to pesticides, lack of political voice, haphazard illegal dumping sites, and polluted air, among other hazards (London, Greenfield, \& Zagofsky, 2013). The vulnerability to these issues is disproportional between ECV and WCV residents and the majority of the local residents were not aware of it. Although previous research was conducted to reveal the issue, the findings are available on print media, which is not readily available to all residents due to the costs of accessing these materials. To raise the awareness of these issues to a broader audience, the clients sought to use GIS and Web technologies. 


\subsection{Clients}

The clients for the project were Dr. Russell Weaver and Dr. Daniel Klooster, professors at the University of Redlands. Dr. Weaver has carried out research that seeks to understand urban changes in relation to social issues and human rights. Dr. Klooster's research focuses on sustainable community development with particular interest in rural community livelihood in Latin America and social justice in the United States.

The primary contact person, Dr. Weaver, provided all the project data. The clients wished to use GIS and Web technologies to illustrate the complex environmental justice issues in a simpler way to a broader audience. In particular, they wanted to show how the distributions of environmental hazards vary between ECV and WCV. They also wanted the final output to be a supplemental instruction material for the Environmental Design Studio (EVST 250) course in the undergraduate program at the University of Redlands.

\subsection{Problem Statement}

The lack of an adequate communication medium to convey the existing environmental justice issues has left the residents of Coachella Valley with unattended and overlooked environmental hazards. In particular, a skewed susceptibility to these environmental hazards is evident between Eastern Coachella Valley and Western Coachella Valley. Although the victims are aware of the problems, other members of the society and government agencies need to realize the effects of the deadly hazards on the Valley residents. Without a public platform to reveal these disproportionate hazards susceptibility, local communities in Eastern Coachella Valley will continue to suffer from the deteriorating environment.

\subsection{Proposed Solution}

To enhance public awareness of the environmental justice issues in the Coachella Valley, an interactive Web-based platform solution was proposed. With the capability to reveal complex spatial distributions and relationships among the phenomena of interest, GIS was chosen to divulge the spatial patterns of environmental justice issues in the Coachella Valley.

\subsubsection{Goals and Objectives}

The primary goal of the project was to reveal the complex environmental justice issues in a simplified manner to a broad audience using GIS and Web technologies. The three specific objectives implemented to achieve the goal were:

a. to design a geodatabase for the environmental and social themes addressed in the project,

b. to author and publish environmental and social feature services and thematic Web maps,

c. and to develop an interactive Web applications using ArcGIS API for JavaScript and ArcGIS Web App Builder to display Web maps and facilitate spatial analysis. 


\subsubsection{Scope}

Environmental issues that affect the lives of people are numerous and vary in space. This project only focused on the Coachella Valley region in Riverside County, Southern California. The project addressed five themes of environmental justice including pesticides application, waste disposal, housing infrastructure, water accessibility, and green spaces. To explain these environmental factors in the context of environmental justice, three social indicators were considered including ethnicity, English language proficiency, and poverty.

Since the project targeted a broad audience with minimal to no GIS skills, the Web atlas was designed for browsing purpose only. The audience should be able to view and change the interested environmental themes and social indicators in an intuitive way such as clicking a button or checking a box. In addition, other functions such as locating a specific address, sharing the map via social media, and printing the map were also included in the public Web atlas.

On the other hand, the project product would also be used to supplement the teaching material for the EVST 250 course at the University of Redlands. This audience has GIS skills, which called for some advanced functions on the application. To take care of this without complicating the public Web application, an advanced version of the Web application was designed. This advanced version was intended to provide editing and geoprocessing capabilities to the user.

\subsubsection{Methods}

Web GIS technology was the key to the implementation of the project and Esri products were chosen to implement the Web GIS. Figure 1.3 illustrates how the different Esri products were put together to develop the solution. The use of ArcSDE technology enabled the building of a SQL server enterprise geodatabase to host the project data. From the ArcGIS desktop environment, ArcMap and ArcCatalog applications were used to clean up the data and load it into the enterprise geodatabase. The final project database was comprised of the three social indicators and environmental variables measuring the selected environmental justice themes. These datasets were set to Web Mercator spatial reference. PyScripter Integrated Development Environment was used to develop a Python script that was then published to the ArcGIS Server as geoprocessing services for spatial analysis on the Web. ArcGIS Server hosted the feature, map, and geoprocessing services published from ArcGIS desktop environment. These feature and map services were then used to author thematic Web maps on ArcGIS Online (AGOL) environment representing the five environmental justice themes and three social indicators. Lastly, ArcGIS API for JavaScript and ArcGIS Web App Builder were the development platforms for the two versions of the Web application solutions. The two versions were important due to the difference in GIS skills of the target audience and database integrity. 


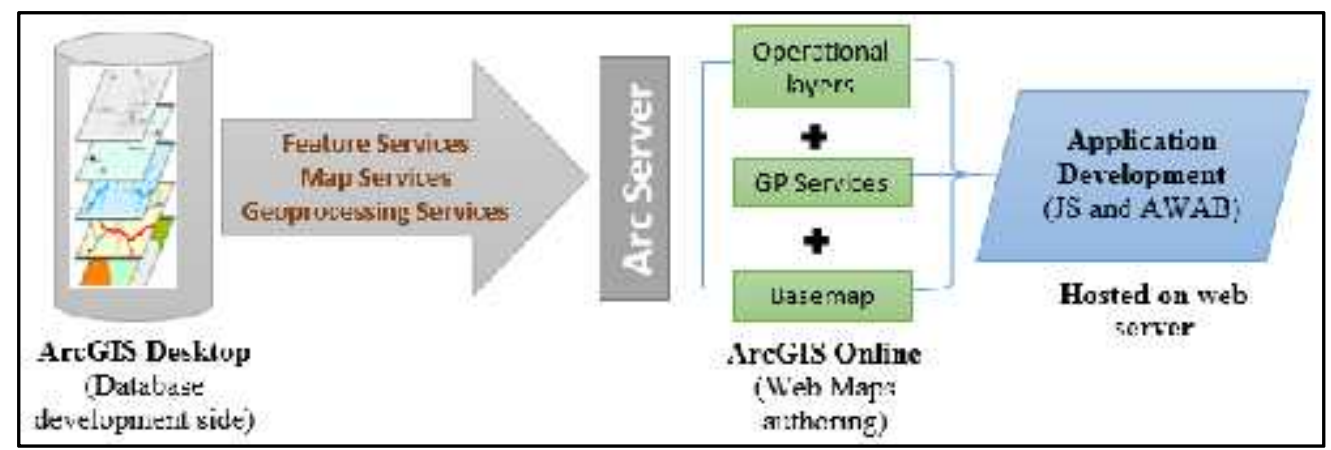

Figure 1.3: Project workflow

\subsection{Audience}

The project targeted a broad audience with minimal to no GIS skills. This audience included the Coachella Valley communities and administration, high school students, environmental advocacy organizations, environmental activists, human rights activists, government agencies, and students of Environmental Design Studio at the University of Redlands. The public were also included as part of the targeted audience.

\subsection{Overview of the Rest of This Report}

The rest of this report consists of six chapters. These chapters provide details on previous work related to this project, implementation workflows, and recommendations for future studies to advance this work. Chapter 2 covers the previous work and studies conducted by researchers in the domain of environmental justice. In addition, the chapter examines the application of GIS and Web technologies in various projects from different disciplines and the successes recorded from these studies. Chapter 3 addresses the project requirements, system design and task execution in relation to schedule and plan of the project. Chapter 4 expounds on database designs and structures, while chapter 5 is about implementation. Chapters 6 and 7 are about project results and conclusions respectively. Chapter 7 also highlights possible advancements of this work. 



\section{Chapter 2 - Background and Literature Review}

This chapter provides a broad overview of environmental justices' research and Web GIS technology. Section 2.1 examines the previous research as pertains to environmental justice issues and it was found that different social groups experience disproportional environmental threatens. In addition, this chapter reviews the effectiveness of the Web as a medium of communicating environmental justice issues to a broad audience (Section 2.2). The chapter ends with a summary in Section 2.3.

\subsection{Environmental Justice}

The U.S. EPA advocates for healthy, sustainable, and equitable communities through the implementation of environmental justice practices. Various factors, including housing, transportation, health, research, environment, federal agency contacts, training, and capacity building, affect environmental justice among different social groups. Key relationships exist among these vital pillars and thus lack of one might influence others, either directly or indirectly. According to EPA (2014), minority communities suffer more in the society due to inadequacy or lack of these basic resources. For example, Massey (2004) examined a common perception where better environmental protection was associated with social groups of higher economic, political, and social status in the society. Massey depicted how poor communities became victims of environmentally related diseases and other hazards. This was the case whether or not these poor communities were responsible for the hazards caused by the human practices. The findings suggested that the effects of these hazards worsened among the low-income communities considering their limited economic power to afford better health care services and other basic facilities.

Similar conclusions were also observed in Faber and Krieg (2005). In this study, environmental injustice vulnerabilities were found to be related to political power, race, environmental awareness, and economic power in the State of Massachusetts. Massachusetts had more than 30,750 hazardous waste sites designated by Department of Environmental Protection, of which 3,741 sites were very hazardous. There were 31 sites included in the EPA Superfund list. According to EPA (2014), a superfund site is "an uncontrolled or abandoned place where hazardous waste is located, possibly affecting local ecosystems or people". The striking finding was that most of the hazardous sites clustered in the areas inhabited by low-income and non-white communities. This was an indicator of disproportional spatial distribution of the environmental hazards based on social diversity. For instance, areas with residents earning up to $\$ 39,524$ per year were recorded with an average of 19.2 hazardous sites per square mile as compared to 4.6 sites per square mile for the localities whose population earned $\$ 65,876$ or above annually.

Race seemed to be another important factor affecting environmental injustice. An average of 2.1 hazardous waste sites per square mile were found in the areas with less than five percent of non-white communities, while the areas with 25 percent or above of non-white populations had an average of 48.3 hazardous waste sites per square mile. The report further revealed more bias toward non-white communities in reference to chemical releases. Between 1990 and 2002, the mean cumulative industrial release of hazardous 
chemical was 19,435 per square mile in areas with less than five percent of non-white communities, as contrasted with an average of 198,479 per square mile in areas with 25 percent and above of non-white population. They also found that minority communities with less economic power were unduly disadvantaged in resource allocation and access to quality living.

Swarthmore College students (2006) used maps to display the existing spatial patterns of environmental hazards in their quest to understand environmental justice issues in Delaware County, Ohio. They found salient contrasts that existed in the county as indicated by the income, race, and education disparities among the county communities. According to their report, the less-educated and low-income populations lived in the areas with major pollution sources. It seemed that the political, social, and economic power among the populations determined their vulnerability levels to the environmental hazards, with minority communities disproportionately disadvantaged (Swarthmore College, 2006).

Further evidences on disparities in exposure of communities to environmental hazards are found in other two studies carried out in Southern California by MorelloFrosch, Pastor, Porras, and Sadd (2002). They examined the spatial distribution of Treatment Storage and/or Disposal Facilities (TSDF) in relation with the race, economy, and land use variables of the communities in Los Angeles. They found that communities in the tracts hosting or within one-mile radius from TSDF had higher percentages in Latino population, low per capita income and household incomes, and low proportion in registered voters. Similar findings were again evident in their second study where they examined how the Toxic Releases Inventory (TRI) facilities were distributed in Ventura, Los Angeles, Orange, San Bernardino, and Riverside Counties. Latino communities followed by African Americans were found very proximal to highly carcinogenic TRI facilities, which could be linked to the lifetime cancer risk levels of the various communities within these counties.

London, Greenfield, \& Zagofsky (2013) considered three environmental indicators -pesticides, drinking water, and water bodies -- to measure environmental hazards in the Coachella Valley. To show the environmental vulnerability patterns, they compared the demographics of Eastern Coachella Valley (ECV), Western Coachella Valley (WCV), and the Riverside County and found that the ECV had the highest percentage of population that were people of color, low-income, unemployed, limited English speakers.

Using the statistical methods, they analyzed the differences in pesticide usage, water contaminants, and impaired water bodies among the three regions. The results indicated that ECV proved to be more vulnerable, exhibiting higher scores than the other regions in pesticide usage, contaminants in drinking water and higher number of impaired water bodies (London, Greenfield, \& Zagofsky, 2013).

GIS has also been applied to study environmental justice from a spatial perspective. A case study by Mennis (2002) in the Pennsylvania region used the U.S. Bureau Census and U.S. Environmental Protection Agency datasets to evaluate how different populations are affected by or exposed to environmental injustices. According to Mennis, multi-scale analysis enabled by GIS facilitated the generation of statistical surfaces showing the environmental justice in Pennsylvania. To determine the effect and influence of the various environmental hazards on the populations, three methods were brought forth by Mennis (2002): polygon, buffer, and centroid containment. He found 
that populations were affected differently based on the method used for the evaluation. A common result from the three methods was that the increasing of hazardous waste facilities is associated with the decreasing of socioeconomic status of the population.

In general, the findings from previous research consistently indicated environmental injustices existed among minority communities in all study areas. Race, income, and language diversities were found to be important indicators that characterize the population at disadvantage.

\subsection{The Web and GIS}

Since its inception, GIS has been an instrumental tool in many disciplines enabling the study of spatial relationships within phenomena. According to Kraak (2004), a GIS has the capabilities to assimilate diverse spatial datasets and perform various analyses that enable users to derive spatial characteristics, behaviors, and meaning of phenomena. This capability enables people to use GIS to simplify and understand complex characteristics and spatial relationships within phenomena. Fu \& Sun (2011) emphasized, "GIS offers a rich set of analytical functions that can reveal hidden relationships, patterns, and trends that are not readily apparent, enabling people to think spatially to solve problems and make better decisions" (p. 6). In spite of the strengths of GIS, Kraak (2004) pointed out that GIS utility had remained within the GIS-skilled personnel for meaningful decisionmaking processes, analyses, and results.

Environmental justice is not an exception. Being a spatial domain topic in nature, environmental studies have increasingly relied on GIS technology to reveal spatial patterns of environmental hazards within communities in diverse regions. Besides the capability of integrating spatial and non-spatial environmental and population variables, GIS involves various spatial analytic techniques and provides visual presentations of complex patterns and relationships. An example of GIS application in environmental justice is the study by Sheppard, Leitner, Mcmaster, \& Tian (1999) in the city of Minneapolis, Minnesota. They conducted a proximity analysis of environmental hazards against population characteristics and pollution sources in the city. Zonal and buffer statistical analysis indicated disproportionate exposures of minority communities to effects of hazardous sites. GIS enabled them to compare the results at various geographic scales (zip codes, census tracts, block-groups) and spatial resolution. Recently, these capabilities of GIS began moving from the desktop environment to the Web-based platforms opening up the technology for even wider applications.

Longley, Goodchild, Maguire, \& Rhind (2010) argued that since its invention in 1980 by Tim Berners-Lee, the World Wide Web (WWW) or simply the Web had grown at a faster rate than any other innovation. This was because the Web attracted 1.4 billion users by the year 2008. The Web platform has transformed human lives in numerous ways, including communication, business, planning, education, and governance. Additionally, the Web has become the most common platform of information dissemination as its penetration to the society continues to grow, reaching even the remote communities. The platform has become a rich source of all kind of information, thus forming a central portal used by many for such purposes as research, education, communication, and entertainment. Based on the Web platform, new technologies like social media and email have been used to connect people across the globe, the world into a global village (Longley, Goodchild, Maguire, \& Rhind, 2010). 
With the numerous Internet-based information portals, the Web platform provides a bi-directional communication interface from which users can interactively query and upload information in these portals (Longley, Goodchild, Maguire, \& Rhind, 2010). Fu and Sun (2011) asserted that the platform had eased many transactions in today's society by enabling sharing of content in a more cost-effective manner. The platform has outgrown the wired connections to a wider spread wireless connection following the advancement of technology in mobile devices and Wi-Fi. The Web has become the ultimate medium for quick dissemination of information and content to a broader audience without worrying about geographical constraints (Fu \& Sun, 2011).

Among various applications on the Web, the GIS applications on the Web have grown tremendously as Web GIS provides powerful online spatial contexts for the audience. With the ease of information exchange, Web GIS brought a new paradigm in the geospatial field by changing the development, processing, management, presentation, and sharing of geospatial information (Fu \& Sun, 2011). It has simplified and deployed most desktop GIS functions and operations to a simple click from a browser. Voluntary community mapping has also become possible with Web GIS. Clifford Okembo (2012) argued that public participation in mapping and reporting of various incidences around world - Public Participatory GIS (PPGIS) - was one of the many ways that Web GIS unlocked the power of GIS. In particular, this approach helped to bring grassroots communities aboard to participate in decision-making processes in matters that affected their daily lives.

Because of the strength of Web-based GIS, it has widely been implemented lately in numerous projects. For example, Okembo (2012) developed a Web atlas for Highland Library in the City of Highland, CA, to educate people on environmental planning. Using ArcGIS API for JavaScript, he created an application used by the library visitors to learn about various environmental issues affecting the society and implement these things for their surroundings. Within the same city, Hutsel (2012) used Web GIS to help the City departments centralize their property's database and allow decentralized accessing, updating, and viewing of the database. Unlike Okembo (2012), Hutsel (2012) used ArcGIS API for Flex to build an application that the City departments use to make informed decision for their day-to-day processes. Web GIS solution particularly suits the people who do not have backgrounds or expertise on GIS technology as they only need to know how to operate a browser.

Epperson's (2010) study on Internet GIS as a historic place-making tool presented the power of Web GIS in incorporating the public to information collection and enrichment. She developed a Web GIS tool that helped communities provide narrative descriptions, photographs, and manuscripts of past places and events for Mammoth Cave National Park (MCNP) in Central Kentucky. This tool greatly helps the park staff to acquire information not only available in academic documentation but also in the hands of private collectors. This study proves that data gathering and dissemination become more efficient and effective through a Web environment, which is supported by other studies. For example, Sugumaran \& Sugumaran (2007) argued that HTML, Internet programs, computational models, and geographic databases could be integrated to deploy spatial analytical functions to the people through Web-based decision support systems. Using server-side (database and server technology) and client-side (Web browser) approaches, they realized that spatial and non-spatial data can be mashed-up together and 
various analysis can be performed to inform decision making processes in an organization.

However, findings from Sugumaran \& Sugumaran (2007) show various limitations faced by this technological advancement. First, performance was indicated as the greatest issue of concern. They attributed this to the voluminous data in form of vector and raster formats, which need to be processed through networked systems thus slower in task executions. Second in their list were technological integrations where they indicated that most of the Web GIS applications are built using costly softwares and environments, which are limited to few people. They advocated for open source developments, which would open up the technologies to wider range of users. Security and privacy was a concern noted in their findings considering that some geographical datasets are private. In addition, the Web sharing of content opened up data and networked systems to virus attack, hackers, and network jam risks. Other limitations they identified included laxity by some organizations to adopt change as well as policy issues within different stakeholders.

\subsection{Summary}

Many studies indicate unjust exposure of minority communities to environmental hazards, which translates to environmental injustice. Communities unduly subjected to environmental risks are often low-income, non-white, non-English speakers who possess weaker political and social power. This disparity violates the pillar of environmental justice where social diversities should not dictate environmental safety of communities. Despite all these findings by different researchers, the general awareness of these issues is still low among the public and even responsible agencies. Paper maps and reports were used to communicate most of these results to the audience. These media could only reach a limited audience and not the targeted audience at the end.

GIS and the Web technologies have been fused and used in various disciplines with convincing results in accessing broader audiences including remote area users. Environmental justice is not an exception. Advocates want inclusion of all people irrespective of socio-economic diversities for equitable treatment. With the power and capabilities of Web GIS, it is the unmatched and most reliable medium of communicating the environmental justice issues to a broader audience. 



\section{Chapter 3 - Systems Analysis and Design}

This chapter discusses the system design that provides an overview of the components required for the project execution. Section 3.1 expounds on the project problem, followed by the requirements analysis in Section 3.2. Section 3.3 outlines the system design and Section 3.4 explains the various phases of the project with their respective tasks. The chapter ends with a summary in Section 3.5.

\subsection{Problem Statement}

Being home to numerous unincorporated communities, the Valley faces myriad challenges including poor access to health facilities, poor transportation infrastructure, contaminated drinking water, failing sewer connections, excessive exposure to pesticides, lack of political voice, haphazard illegal dumping sites, and polluted air. Uncontrolled pollution and unregulated development projects carried out without the knowledge of regulatory agencies have rendered the minority groups susceptible to associated hazards. Unfortunately, disproportional vulnerabilities of communities to environmental hazards in the Valley have escaped the attention of responsible environmental regulators for too long. Because the local communities did not have effective communication media that can unveil these environmental justice issues to a broad audience, only the victims and a few others recognized the issues.

\subsection{Requirements Analysis}

For any successful project, the clients' needs and problem take center stage in the solution development. Project requirements analysis must precede the implementation so that the solution developed suits the clients' needs. Deliberations with the clients yielded system requirements, which fall into two categories: functional and non-functional. Table 3.1 summarizes the project functional requirements.

\section{Table 3.1: Functional requirements}

\begin{tabular}{|l|l|}
\hline Requirement & Description \\
\hline Editing of feature services & $\begin{array}{l}\text { This provided room for future updating of the datasets } \\
\text { to reflect new mapped features on the ground. This edit } \\
\text { capability was restricted to the client and EVST 250 } \\
\text { course students due to data integrity issues. The editing } \\
\text { could be done from the Web App (Advanced version) or } \\
\text { ArcMap application }\end{array}$ \\
\hline Geoprocessing service & $\begin{array}{l}\text { The clients and the EVST 250 students could perform } \\
\text { spatial analysis on the app to determine the population } \\
\text { influenced by a certain facility or hazard }\end{array}$ \\
\hline
\end{tabular}




\begin{tabular}{|c|c|}
\hline Requirement & Description \\
\hline Toggle layers functionality & $\begin{array}{l}\text { This enabled the audience to toggle various layers on } \\
\text { and off from the Web application and see just the } \\
\text { desired layers. In addition, only one social indicator } \\
\text { could be seen at a time and thus toggling helped the } \\
\text { audience compare the spatial patterns of hazards against } \\
\text { the social variable, one at a time }\end{array}$ \\
\hline $\begin{array}{l}\text { Information template (Pop } \\
\text { up window) }\end{array}$ & $\begin{array}{l}\text { Popup window activated through clicking of individual } \\
\text { features provided more details about the features } \\
\text { chosen. The social indicators included graphs to help the } \\
\text { audience with quick visual comparisons }\end{array}$ \\
\hline Print services support & Users should export and print maps from the application \\
\hline Measure Widget & $\begin{array}{l}\text { Users can use the measure tool to measure distances, } \\
\text { area, and coordinates on the application. }\end{array}$ \\
\hline Toggle basemaps & $\begin{array}{l}\text { The Esri ArcGIS Online basemap services were } \\
\text { included in the application to help the audience change } \\
\text { the basemaps at will. Users were required to click on the } \\
\text { basemap button on the application and choose the } \\
\text { desired basemap }\end{array}$ \\
\hline Share maps widget & $\begin{array}{l}\text { Users could share the web maps via social media and } \\
\text { email. }\end{array}$ \\
\hline
\end{tabular}

The functional requirements entail the various operations, activities, or functions that the system performs as the audience uses the product. For this class of requirements, the user needed to click or initiate the processes and then the system responds accordingly dependent on the command from the user side. Table 3.2 illustrates the non-functional requirements of the project.

Table 3.2: Non-functional requirements

\begin{tabular}{|l|l|}
\hline Requirement & Description \\
\hline $\begin{array}{l}\text { Environmental justice } \\
\text { themes }\end{array}$ & $\begin{array}{l}\text { Web maps represented how people of different social } \\
\text { characteristics were exposed to environmental justice } \\
\text { issues. }\end{array}$ \\
\hline
\end{tabular}




\begin{tabular}{|l|l|}
\hline Requirement & Description \\
\hline Three social indicators & $\begin{array}{l}\text { The spatial distribution of the various hazards and } \\
\text { facilities were compared against three social indicators - } \\
\text { ethnic, English proficiency, and poverty - represented } \\
\text { as layers in all the Web maps }\end{array}$ \\
\hline $\begin{array}{l}\text { Descriptive summary } \\
\text { interpretation }\end{array}$ & $\begin{array}{l}\text { Each Web map on the application contained a } \\
\text { descriptive summary that served to interpret the map in } \\
\text { the context of environmental justice to enhance better } \\
\text { and quicker understanding to the audience }\end{array}$ \\
\hline Public access & The application should be accessible to the public \\
\hline Coordinate system & $\begin{array}{l}\text { The Web Mercator coordinate system was used for all } \\
\text { datasets to help make them compatible with the already } \\
\text { existing Web services like google and Esri basemaps }\end{array}$ \\
\hline ArcGIS Desktop 10.2.2 & $\begin{array}{l}\text { Platform for organization of data, editing and publishing } \\
\text { of services }\end{array}$ \\
\hline ArcSDE & Database server for hosting the database \\
\hline Major browsers support & $\begin{array}{l}\text { The Web application was accessible by anyone using at } \\
\text { least any of the four major browsers i.e. Chrome, } \\
\text { Firefox, Safari, and Internet Explorer }\end{array}$ \\
\hline Simple user interface & $\begin{array}{l}\text { With the target audience having no GIS experience, the } \\
\text { user interface needed to be relatively easy and simple to } \\
\text { use and understand }\end{array}$ \\
\hline $\begin{array}{l}\text { Application Programming Interface used to develop the } \\
\text { Web application }\end{array}$ \\
\hline
\end{tabular}

The non-functional requirements address the technical and operational functions that would support the execution of the functional requirements. These non-functional requirements are background processes that aid the smooth running of the functional requirements. They serve to make the system respond as expected while the users are using the product.

\subsection{System Design}

The system was comprised of four major components: geodatabase, services, Web application, and the Web browser (Figure 3.1). 


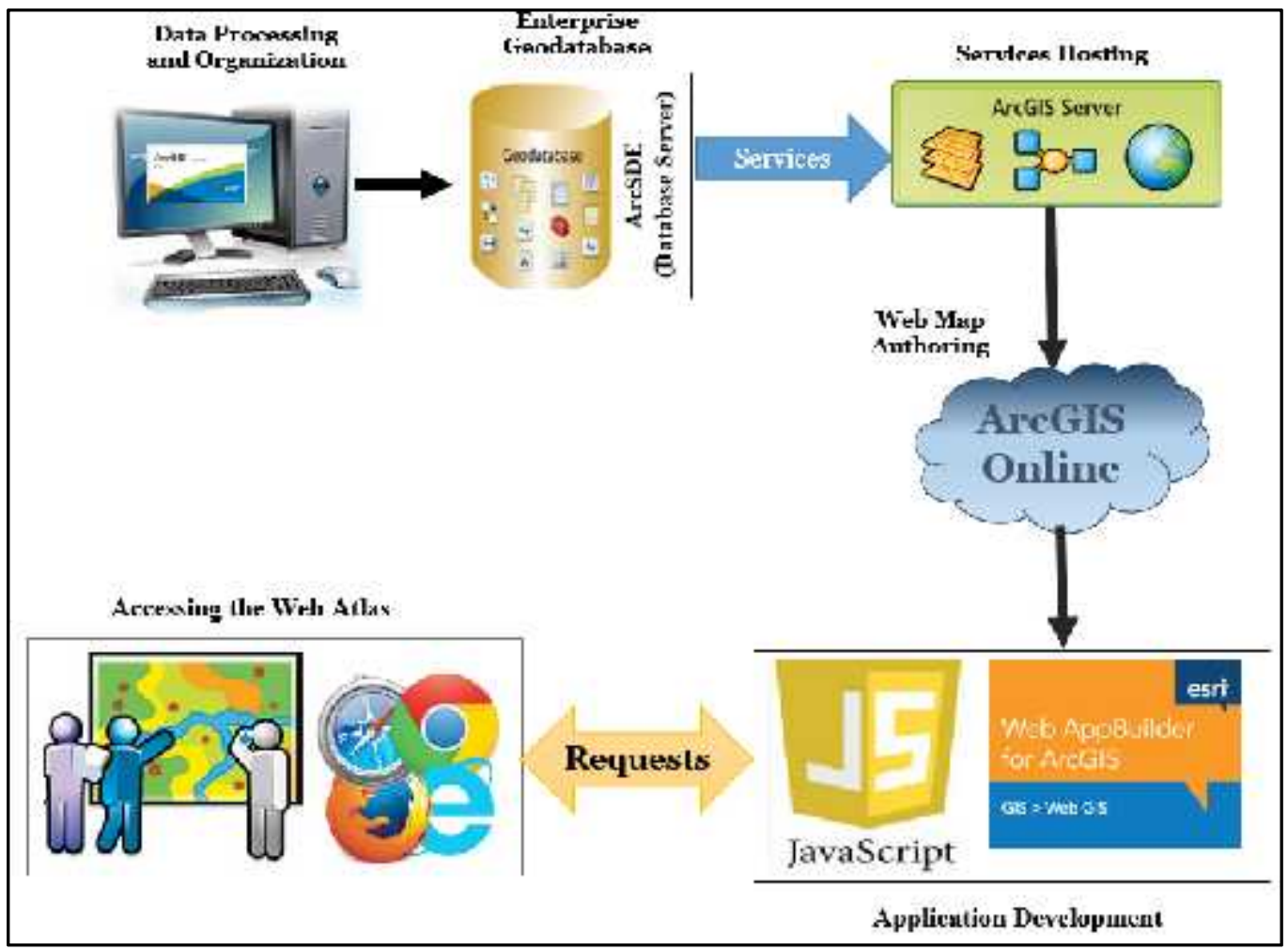

Figure 3.1: System design

The geodatabase component involved data cleaning and processing within the ArcGIS desktop 10.2.2 environment. An enterprise geodatabase designed in ArcSDE environment would host all the social indicators and environmental variables of the project. The social indicators included ethnicity, poverty, and language indicators. Environmental themes considered in the project included: water access; pesticides usage; waste disposal; green spaces; and housing infrastructure. Feature classes representing these five themes comprised of public water lines, water wells, licensed waste facilities, unregulated dumpsites, tribal lands, mobile home parks, incorporated communities, pesticides usage, and recreational sites. From the ArcGIS desktop environment, map and feature services were published to the ArcGIS server. The ArcGIS online platform was used to author the thematic Web maps using the services residing in the server.

Thematic Web maps were authored on the ArcGIS online platform using the services residing on the ArcGIS server. Two versions of Web applications were built: a public and private Web application. The public version was to be availed to the public to enable them to view the Web atlas. The private version was to be used by the clients to view the Web atlas, edit the data, and perform geoprocessing analysis. JavaScript and ArcGIS Web App Builder were used to develop the public and private Web applications respectively. These web applications would be accessed from a Web browser. All these components were put together to deliver the desired Web atlas to the audience on a Web browser. 


\subsection{Project Plan}

The project involved five major phases: project initiating, design, development and testing, deployment, and closing. Quality control measures were implemented from the design stage to the project-closing phase to keep the project in check. Figure 3.2 shows an overview of these project phases.

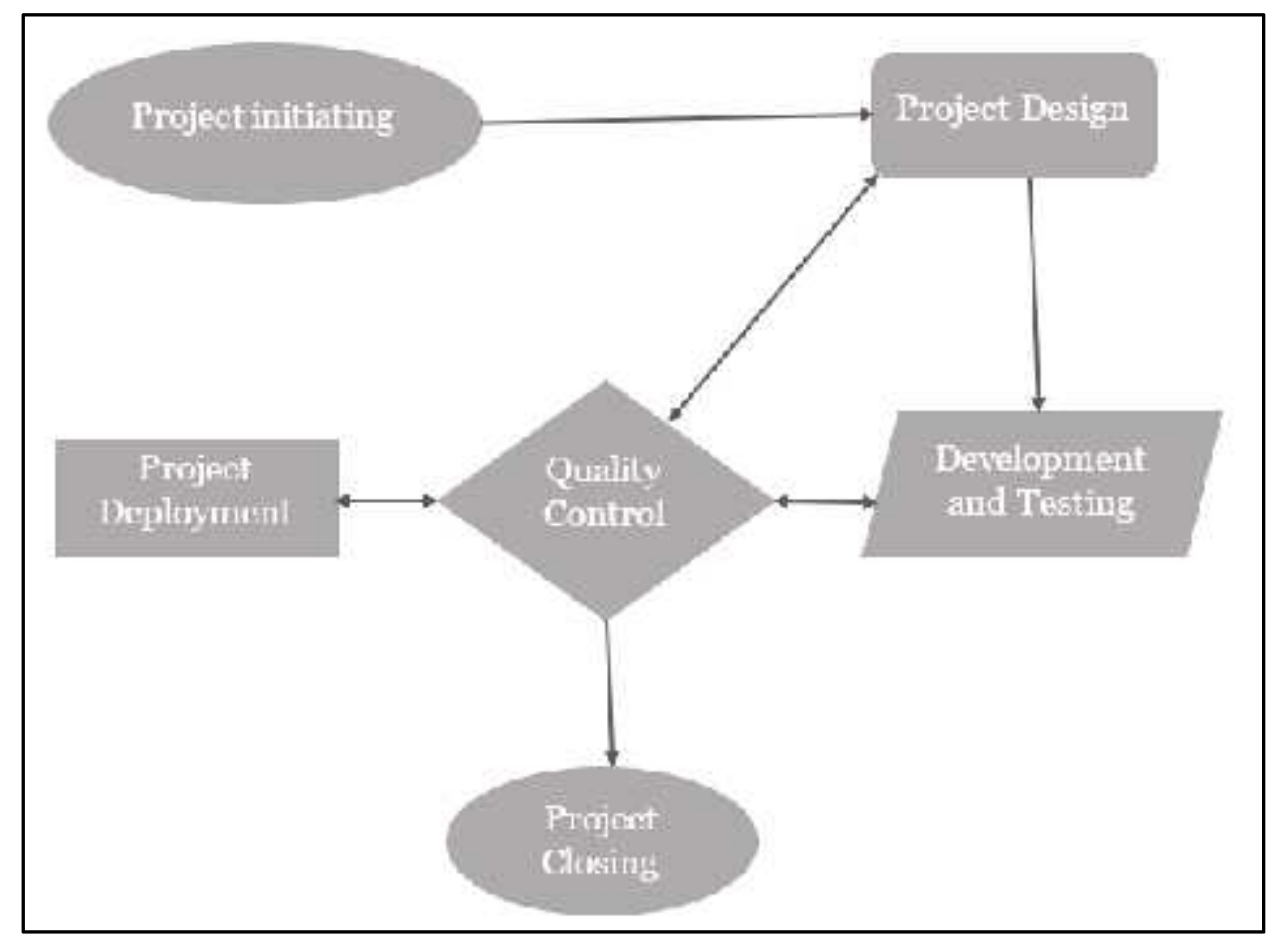

Figure 3.2: Project phases

Each of the phases was comprised of various tasks, which were carried since the project inception. In the project initiating phase, the project scope was defined. This involved identification of the overall project goal, specific objectives and the spatial extent of the project area. A solution was proposed and the implementation methodology designed. Extensive discussions were done with the clients to ensure that the proposed solution and methodologies best suited their needs. The clients provided the first phase of the data to be used in the project. These data were examined to understand the formats and the attribution. The second phase, Project Design, began by examining the previous studies in environmental justice and Web GIS. This yielded the various social indicators of environmental justice from where three indicators were chosen for the project. These three indicators formed the basis of evaluating the vulnerability of the communities to environmental hazards. The data were inspected for their sufficiency in reference to attribution and information. A preliminary geodatabase was built and the various quality checks performed on the data to ensure that it complied with the schema and was sufficient to represent the environmental justice issues. All the errors that arose from the data loading into the geodatabase schema were fixed at this phase.

Development and testing phase begun in June 2014 where the final geodatabase was built and the project system architecture designed. This was followed by authoring of 
feature, map, and geoprocessing services. The Web applications were developed and testing on the different Web browsers performed to ensure broad audience access. The failures, errors, and recommendations from the testing process were implemented to polish the application. When the development was completed, quality assurance was performed for compliance purposes to the project requirements. Project deployment was the next phase. This involved testing and reviews of the Web application by the client and the project committee as well as the delivery of the final product to the clients. The proposed amendments from these reviews were implemented. This was then followed by the project closure phase. In this phase, the project documentation comprised of the metadata and the project document were done. Defense was then done as well as the final project document and poster submitted. The whole project lifetime was between March and December 2014.

\subsection{Summary}

This chapter discussed the system implementation, requirements, and the plan of the project. The project requirements as agreed upon with the clients guided the system design for the most appropriate solution. The project requirements were compromised of two major categories: functional and non-functional requirements. The project involved five major phases, namely project initiating, design, development and testing, deployment and closing. In addition, this chapter explained the various tasks involved in each project phase. 


\section{Chapter 4 - Database Design}

This project utilized various datasets to model the spatial relationships between identified environmental issues and the social indicators. A database design provides a framework of how these datasets were put together to reveal the spatial patterns. Section 4.1 illustrates the conceptual model of the project database. To bring out the descriptive and detailed architecture of the five environmental themes and three social factors, a logical model was necessary. Section 4.2 discusses the logical model designed for the project. Other key elements of the database discussed in this chapter include data sources in Section 4.3 and the procedures followed in data scrubbing and loading as described in section 4.4. The chapter ends with a summary in Section 4.5.

\subsection{Conceptual Data Model}

The project addressed five themes of environmental justice measured against three social indicators. A conceptual model was crucial to model how human practices result into environmental hazards, and how the environmental hazards in turn affect the health and vary among different social groups in space. Four conceptual models, Figure 4.1 to Figure 4.4, show these spatial interactions and relationships. 


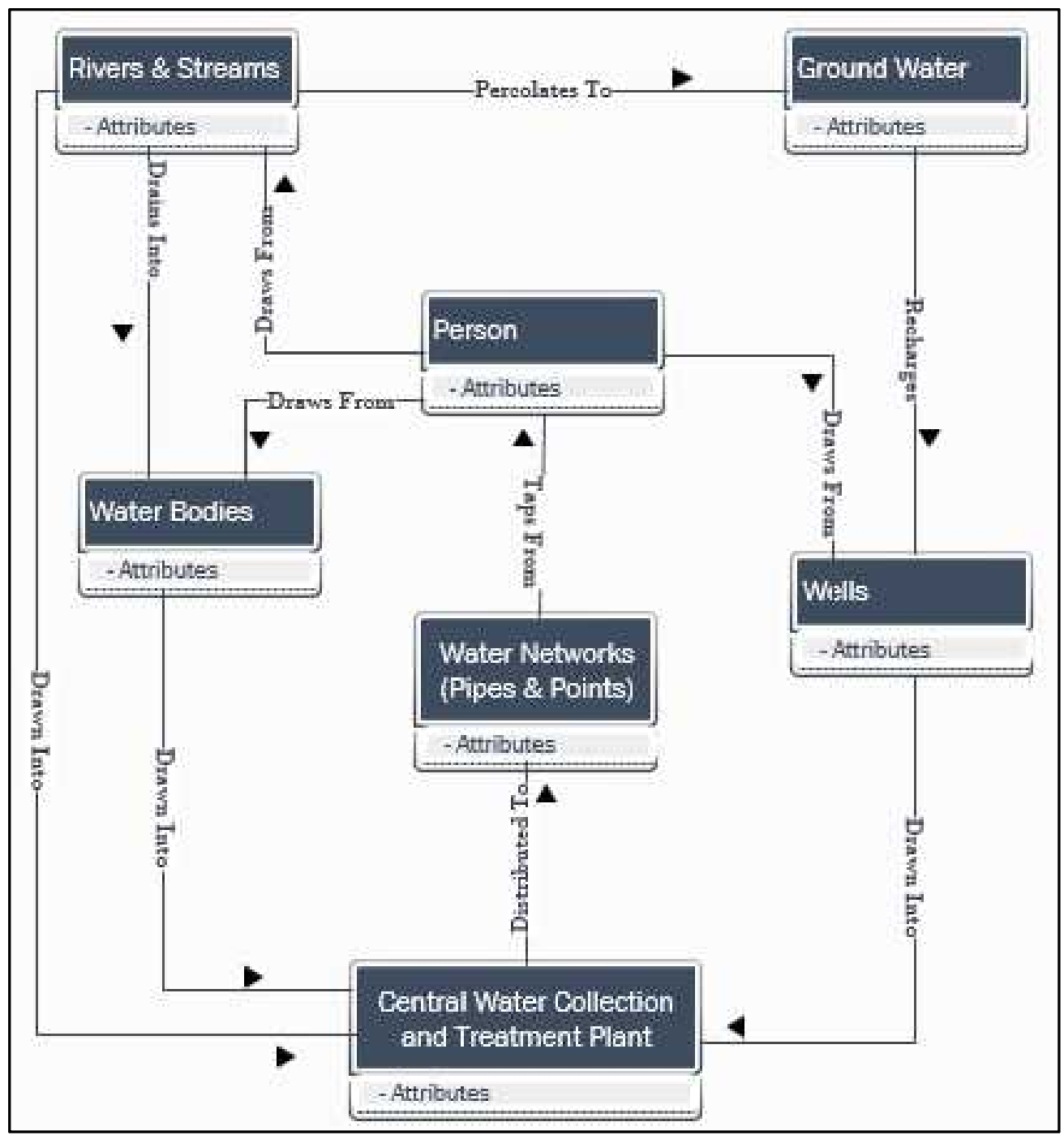

Figure 4.1: Water flow and distribution

Figure 4.1 illustrates how distribution of water might affect residents' health. Ground and surface water exist in the project area and serve as major sources for human use. The Coachella Valley Water District (CVWD) is responsible for the water distribution infrastructure (Water lines and connection points). Water treatment processes precede the distribution of the water by the CVWD to residents. Thus, the water distributed by the CDWD is safe for drinking purposes. People outside the water grid acquire their water from wells, water bodies, rivers, and streams. Any contamination of these sources exposes the residents to environmental risks including water-borne diseases. 


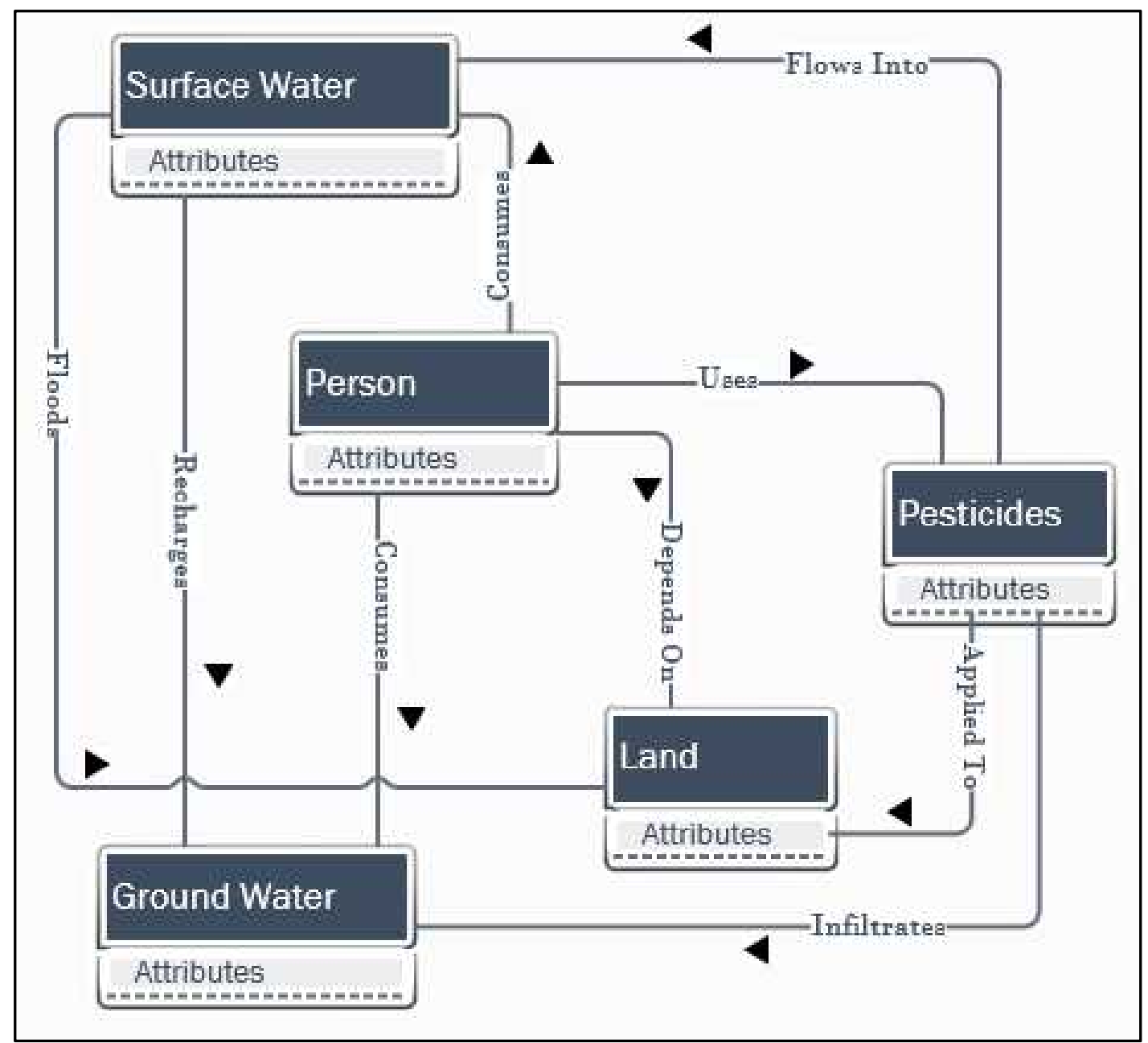

\section{Figure 4.2: Interactions of water and pesticides}

Figure 4.2 models the interactions between water and pesticides used in the Valley. The East Coachella Valley (ECV) is an agricultural hub where pesticide application is the norm. Because of insufficient rain in the project area, the agricultural processes are highly dependent on irrigation, which aids the transfer of these pesticides into ground and surface water sources.

The developmental practices carried out within the project area are subject to the regulations and policies governing the Valley. Unlike in Western Coachella Valley (WCV) communities, which are incorporated, most development and economic activities are not regulated in the ECV. This leaves individuals with more room to undertake developments that pose hazards to the less disadvantaged communities. 


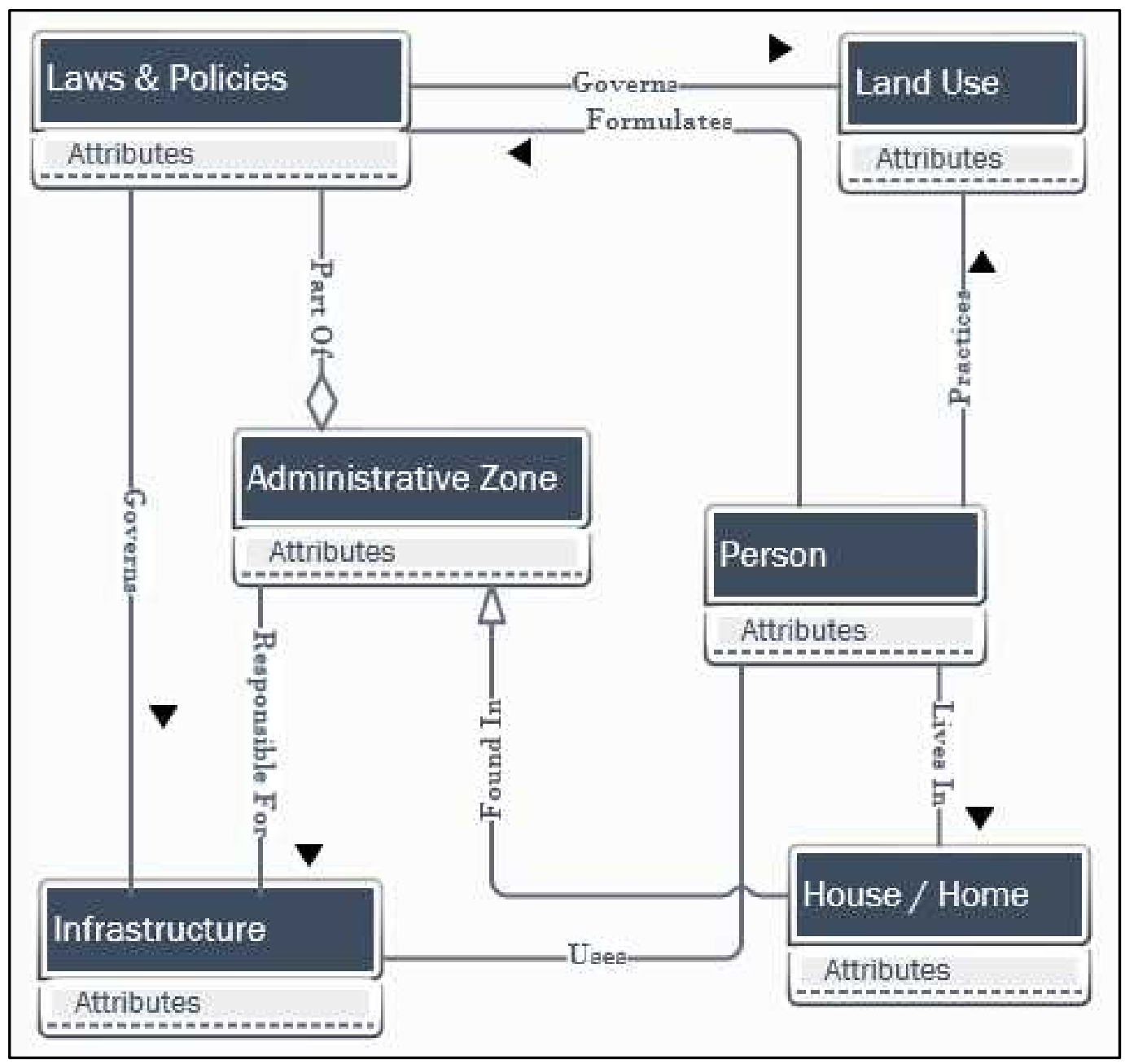

Figure 4.3: Governance and land use

Figure 4.3 shows the relationship between land use and governance of a region. Being unincorporated, the ECV depends on the Riverside County government for enactment and implementation of laws and policies for the area. Being far away from the direct watch of the County government and lacking an influential political voice, land use in the ECV mainly depends on the good will of the people of high social class who own the land. Presence of tribal lands in the project area is an issue of concern. This is because these lands are not subject to control of the government and thus the land practices in these lands are therefore unregulated. The law and policies that govern land usage do not apply to the tribal lands. This exemption renders the full mandate of the owners to practice any activity as they wish to. Any activity that is dangerous or poses hazardous risks to the residents is thus a concern, as the law cannot be used to regulate these activities. Agriculture is highly practiced in the project area. This requires fertilizers and pesticides for economical production in the region. Since this land use is not closely regulated, residents are at risk to pollution that comes from these agricultural parcels.

Infrastructure is key in any area inhabited by people as these facilitate how people acquire services in their daily lives. Figure 4.4 illustrates the infrastructural facilities in the project area. 


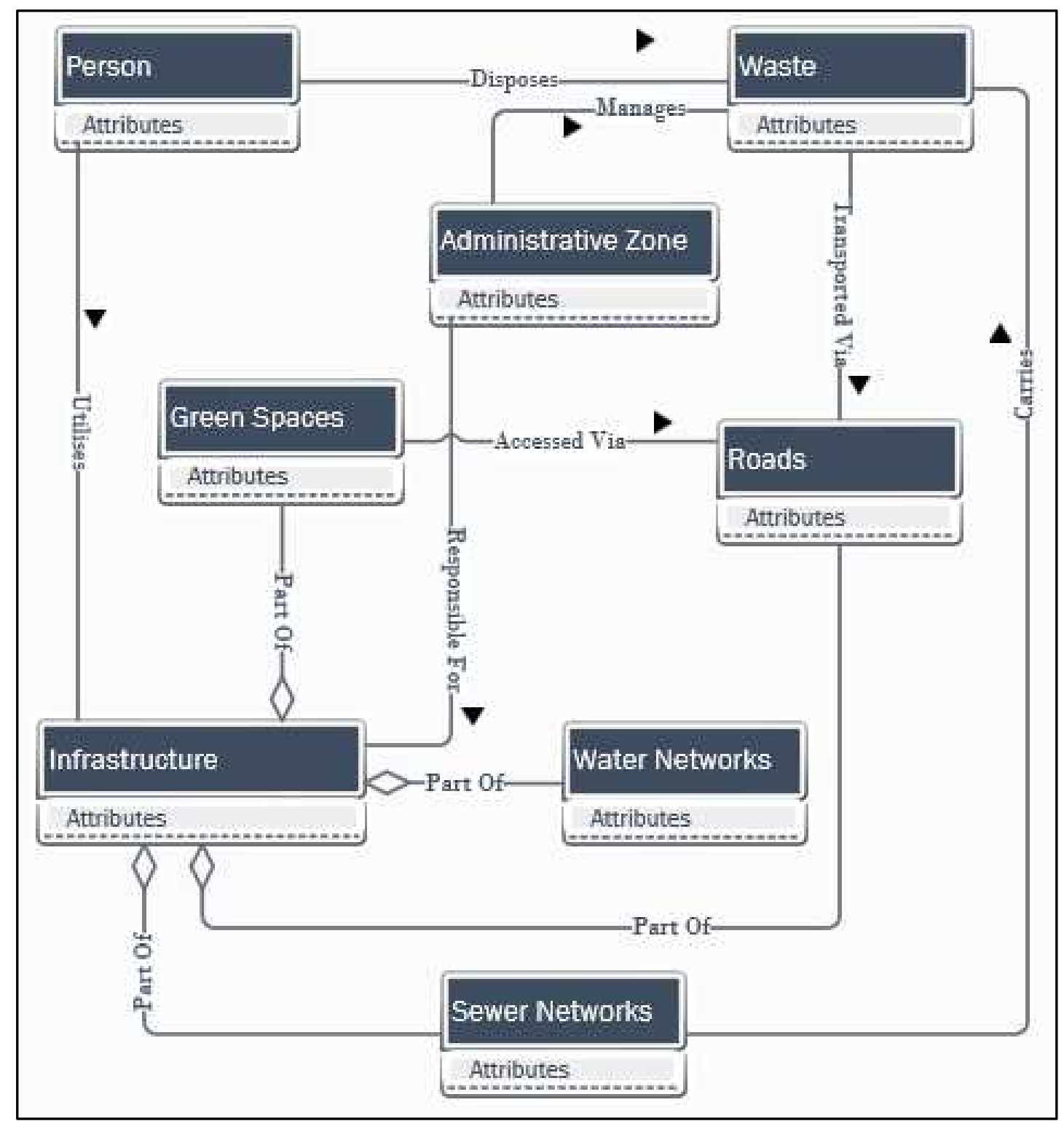

\section{Figure 4.4: Infrastructure and facilities}

The governance structures are mainly responsible for the allocation of resources for the development of these infrastructures to aid humane living within their administration zones. Key infrastructural facilities include waste management, water distribution, roads, and green spaces. Sewer and waste facilities should be managed well to ensure that they do not become sources of health risks. Green spaces are very necessary to help communities live healthily. Absence or mismanagement of these facilities inhibits people from exercise, which is related to health conditions like obesity. Road networks facilitate the movement of people from place to the other. The lack or poor conditions of these infrastructural facilities pose significant risks to the residents. These conceptual models focused mainly on the themes addressed in the project. They serve to illustrate how various human practices can alter the environment and affect people. Most of these 
practices are subject to the law but due to differences in governance and policies, varied exposure to the effects is evident.

\subsection{Logical Data Model}

The logical model is a more detailed structure of the project database showing the relationships inherent among the data. The project implemented the Esri enterprise geodatabase format that is scalable, versatile, and easy to load and exchangeable with other data formats. There were two major categories of datasets used in the geodatabase: environmental and social variables (Figure 4.5).

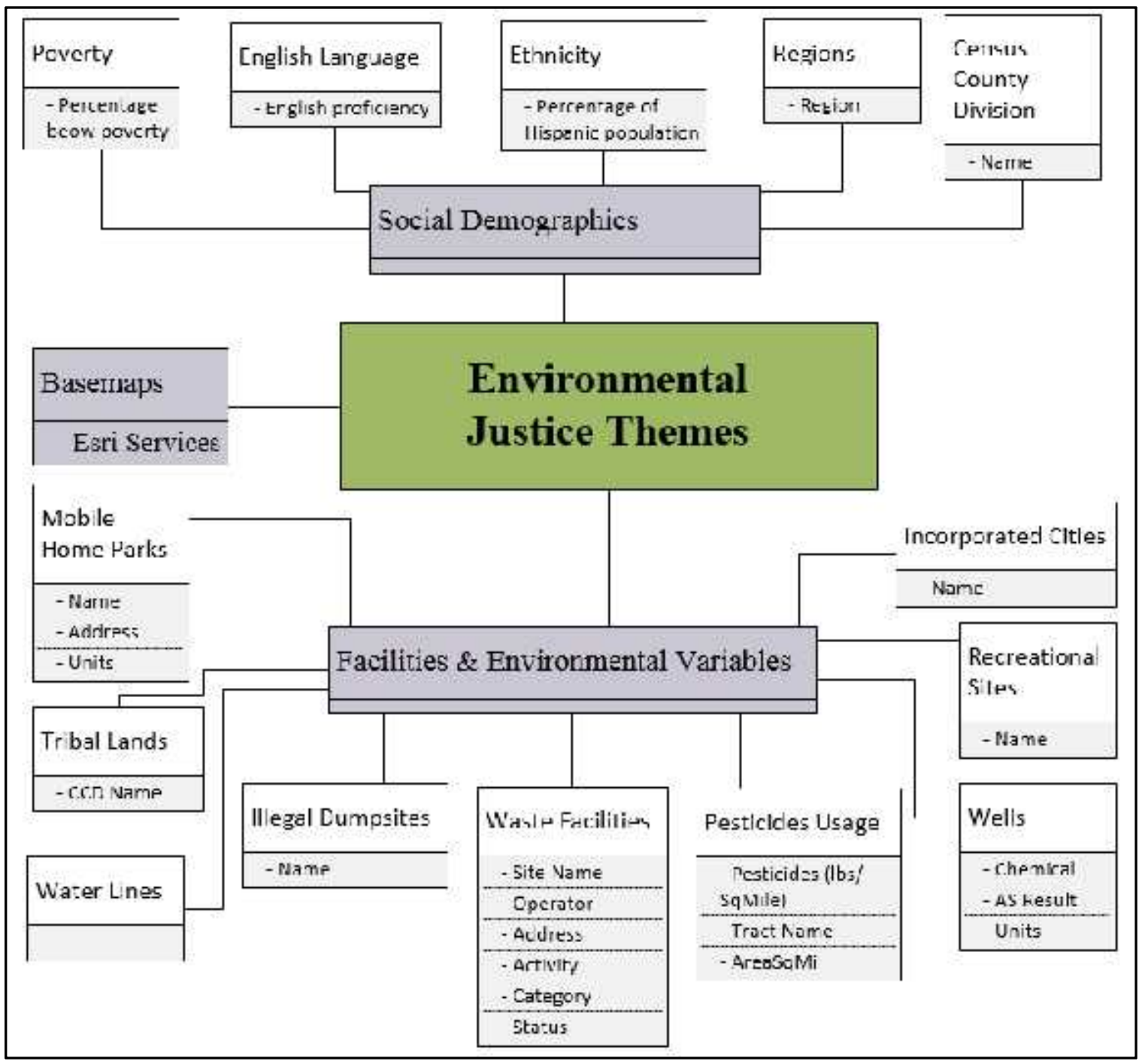

Figure 4.5: Project logical model

The social variables, including poverty, English language proficiency, and ethnicity, were contained in the same feature dataset called Social Demographics. These variables were represented at the census tract level. For the purposes of having these data as light as possible on the Web application, individual feature classes were used instead of a 
single feature class with all the fields for the social indicators. The fields containing information about the feature class were retained. The project took advantage of the existing online Esri basemap services. These were virtual components of the project database as they were used as they were from ArcGIS Online platform.

Based on the conceptual model, ten environmental variables were considered in the project, including water wells, mobile home parks, incorporated cities, waste facilities, unregulated dumpsites, recreational parks, water lines, tribal lands, and pesticides usage. These environmental variables represented the five themes considered in the project and individual feature classes represented them. The feature classes had attributes that provided more details of the feature class. For the pesticides, the amount of pesticides was quantified in pounds per square mile from which the average amount of pesticides used on the agricultural farms per tract can be derived. Other attributes in this feature class included the tract name and the area in square miles. The Mobile home parks contained the name, address and the number of units (number of mobile temporary houses) represented by each trailer park. The Tribal Lands feature class had one attribute, county census division (CCD) name, to show where it belongs among the four Coachella Valley CCDs. The Water Lines feature class did not have any attributes apart from the object ID. The unregulated dumpsites feature class has a name field to identify each dumpsite. The Waste Facilities' attributes include the site name, operator, address, activity, category, and the status of the facility. Wells feature class has information about the chemical (Arsenic substance) in the wells and the level of contamination in milligrams per liter $(\mathrm{mg} / \mathrm{L})$. A name attribute is available for the Incorporated Cities and Recreational Parks feature classes. These environmental variables represented the five themes considered in the project.

\subsection{Data Sources}

The project's primary contact person, Dr. Weaver, provided most of the data used in the project in the file geodatabase format. These datasets were found from the U.S. Census 5Year American Community Survey (2008 -2012), Riverside County Land Information System, U.S. Decennial Census 2010, CalEnvironScreen 2.0, Desert Mirage High School, and Dr. Ryan Sinclair of Loma Linda University. However, the project needed more information to represent the environmental justice issues more explicitly. Thus, more data were obtained from the Coachella Valley Water District (CVWD) and the Groundwater Ambient Monitoring and Assessment Program (GAMA). The data from the last two sources were downloaded from the websites as provided by contact people.

\subsection{Data Scrubbing and Loading}

The data delivered by the clients required minimal processing since they were already in the file geodatabase format. Although transferring these data to the enterprise geodatabase was straightforward, data integrity and compliance called for inspection, polishing and minor processing. For example, the Census County Divisions (CCDs) feature class was created by dissolving the tract census feature classes based on the CCD name. Similarly, dissolving the CCD's feature class based on the region ID field formed the Coachella Valley Regions feature class. Data downloaded from other sources other than the clients were received in the form of Excel files. These files had Latitude and 
Longitude fields, which enabled conversion of these datasets into feature classes with their correct geographical positions. The "Display XY" tool in ArcMap was used to make event layers form the Excel files and then exported as a geodatabase feature class.

Unnecessary fields were then deleted from the feature class. Following the Web sharing standards of common services like Esri basemaps and Google Maps, the Web Mercator coordinate system was adopted for all the feature layers. Finally, simple loader was used to load the datasets into the developed project geodatabase schema to make the final project geodatabase.

\subsection{Summary}

This chapter expounded on the various database development procedures for the project. Conceptual and logical models were discussed and illustrated to show how the datasets were put together to reveal the spatial relationships between the environmental and social factors. The chapter also expanded on data sources, collection methods, and data cleaning and loading processes for preparing the final project database. 


\section{Chapter 5 - Implementation}

The anticipated product of this project was a Web atlas showing environmental justice issues in the Coachella Valley. This atlas was meant to promote awareness of the issues for public and environmental regulators. Due to various constraints, the project scope narrowed down to five environmental thematic areas: waste disposal, housing infrastructure, water distribution and infrastructure, green spaces, and pesticides usage. To realize this, two Web applications were built. The first application provides map viewing functions to the public. The second application supports advanced functions for the clients, including spatial analysis and editing. This chapter elaborates on the various implementation stages: publishing services (Section 5.1), authoring thematic maps (Section 5.2), and developing the Web applications (Section 5.3). Finally, Section 5.4 provides a summary of the chapter.

\subsection{Publishing Maps and Services}

This project utilized three types of services: feature, map, and geoprocessing services. The feature services are comprised of nine variables: wells, unregulated dumpsites, licensed waste facilities, tribal lands, pesticides, recreational sites, mobile home parks, and incorporated communities. The map service consists of the social demographic data and public water lines. To publish these services, ArcGIS desktop, ArcGIS Server, and database connection to the enterprise database server (ArcSDE) are required. The ArcGIS server allows the publishing of the Web services from the ArcGIS desktop environment. Figure 5.1 shows the set up window of the ArcGIS server established in this project in the ArcGIS desktop platform. Since the Web application would be available to the public, the ArcGIS server was configured to allow public access to the services.

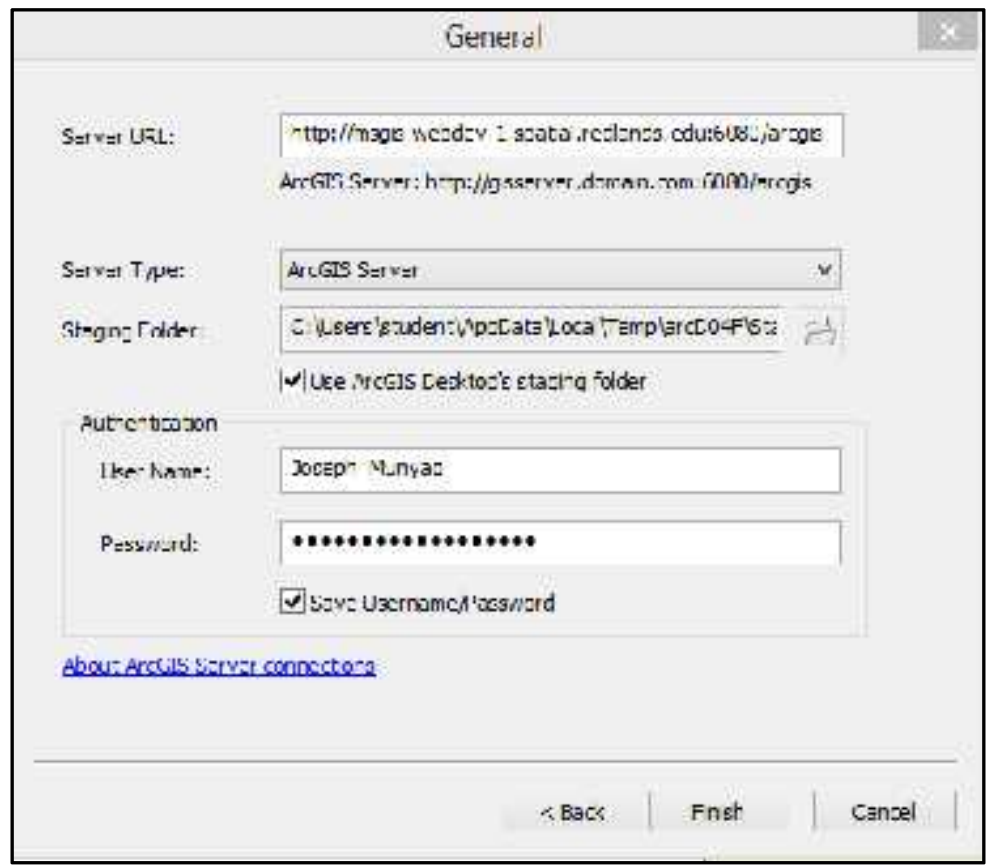

Figure 5.1: Setting up the ArcGIS Server 
An enterprise database server (SQL database server) was used to host the project database. To access and store the data on this server, an ArcSDE connection was built (Figure 5.2), which ensures that the database could support multi-use functionality while maintaining full security integrity of the data.

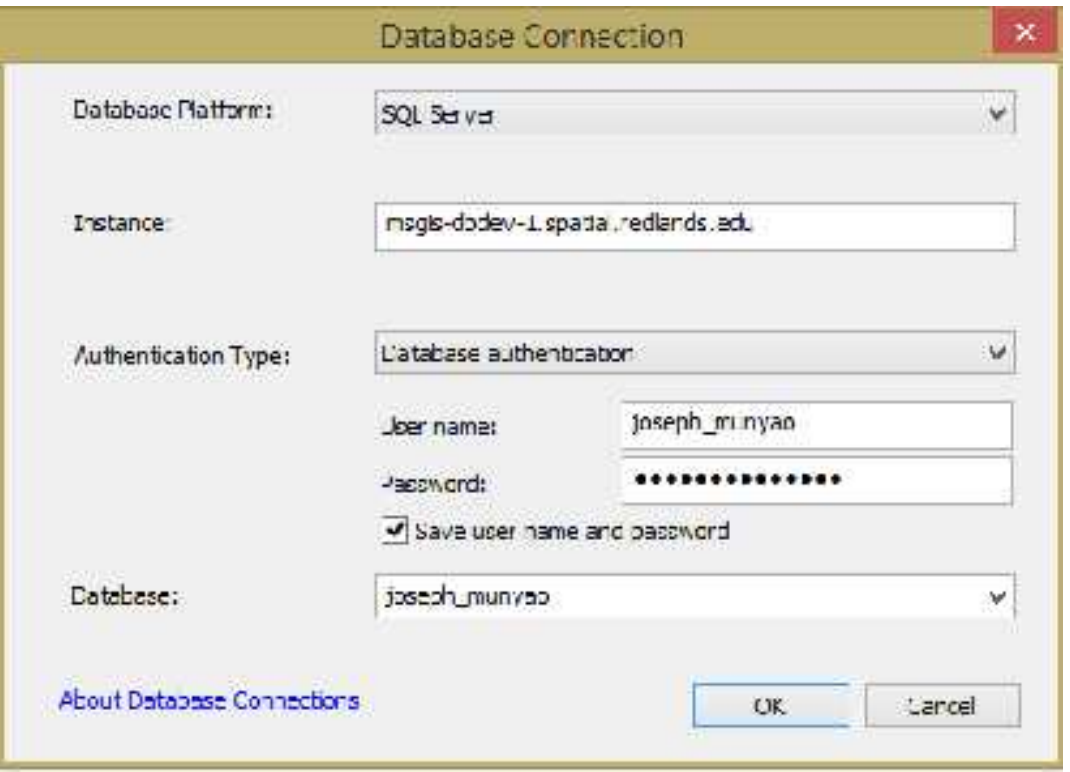

Figure 5.2: Database connection to the enterprise database server

\subsubsection{Map Service}

Map service publishing involves designing a map document (MXD) in ArcMap and then publishing it to the Web as a map service. The project was comprised of two map services: dynamic and cached map services. The dynamic map service consists of six feature layers: Ethnicity, English Language Proficiency, Poverty, Population density, Census County Division (CCD), and the Coachella Valley regions. These layers represent population distribution and characteristics within the project area. These layers were put together to constitute the Social Demographics map document in ArcMap.

The cached map service consists of only one layer: public water lines. The data source for this dataset requires the water lines not to be exposed with high accuracy to the public. However, the dataset use restriction does not apply to the dataset if it is used within the University of Redlands. Thus, cache was developed to enable drawing of the layer at the smallest unit possible for the application used by the clients, scale level 20 $(1: 1,128-1: 577,790)$. This made the layer lighter for the Web applications and supported fine zoom levels. For the public Web application version, this service was set to draw up to certain scale level, after which the service would disappear from the map.

Symbolization of the layers for all the map services was done within the desktop environment. This was due to the more options and capabilities offered in the desktop environment as opposed to the more limited ArcGIS Online (AGOL) environment. Upon the completion of all the necessary information on the map document, the MXD was published (Figure 5.3). 


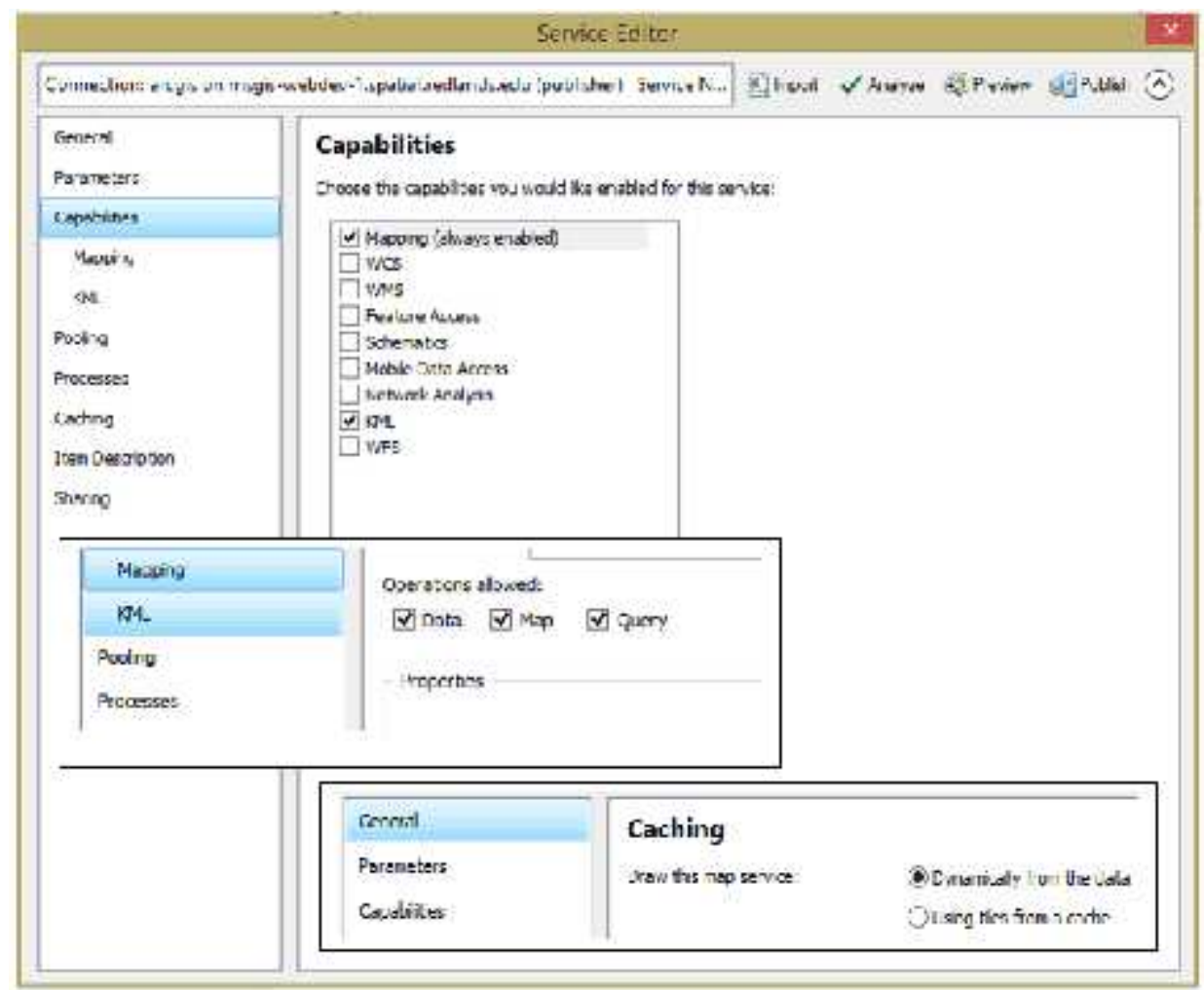

Figure 5.3: Map Service publishing configurations

On the Capabilities tab of the publishing window, Mapping and KML capabilities were enabled. Data, Query, and Map operations were enabled on the mapping sub-class from the publishing window. These three operations were crucial because the layers in the map service were to be used for geoprocessing processes in the advanced version of the application. In addition, the service was published as a dynamic map service rather than the cached service. Coupled with the three mapping operations enabled, the dynamic service enabled the opening up of the geometry and attributes of the individual feature layers on the browser side. After all the necessary service configuration settings were set, they were analyzed for errors and warnings to ensure there were no errors or high-level warnings that would affect the performance of the map services on the browser side. Any errors and critical warnings were fixed and the services re-analyzed until none of these were reported on the dialogue window. Finally, the service was published to the ArcGIS server.

\subsubsection{Feature Services}

Feature services publishing involves the feature classes that require edit capabilities on the Web. The feature services are comprised of the nine variables from the five themes considered in the project. A feature service usually entails opening up the feature for more operations on the Web platform. These operations include changing attributes, creating new features, updating information, and deleting features. These operations were important for the advanced version of the Web application built for the clients. The publishing was done from the ArcMap platform due to the comprehensive options offered 
in the desktop environment as compared to the AGOL environment. Figure 5.4 illustrates the feature service settings, which enables mapping service, feature access, and KML. Activating feature access makes the feature available for editing purposes.

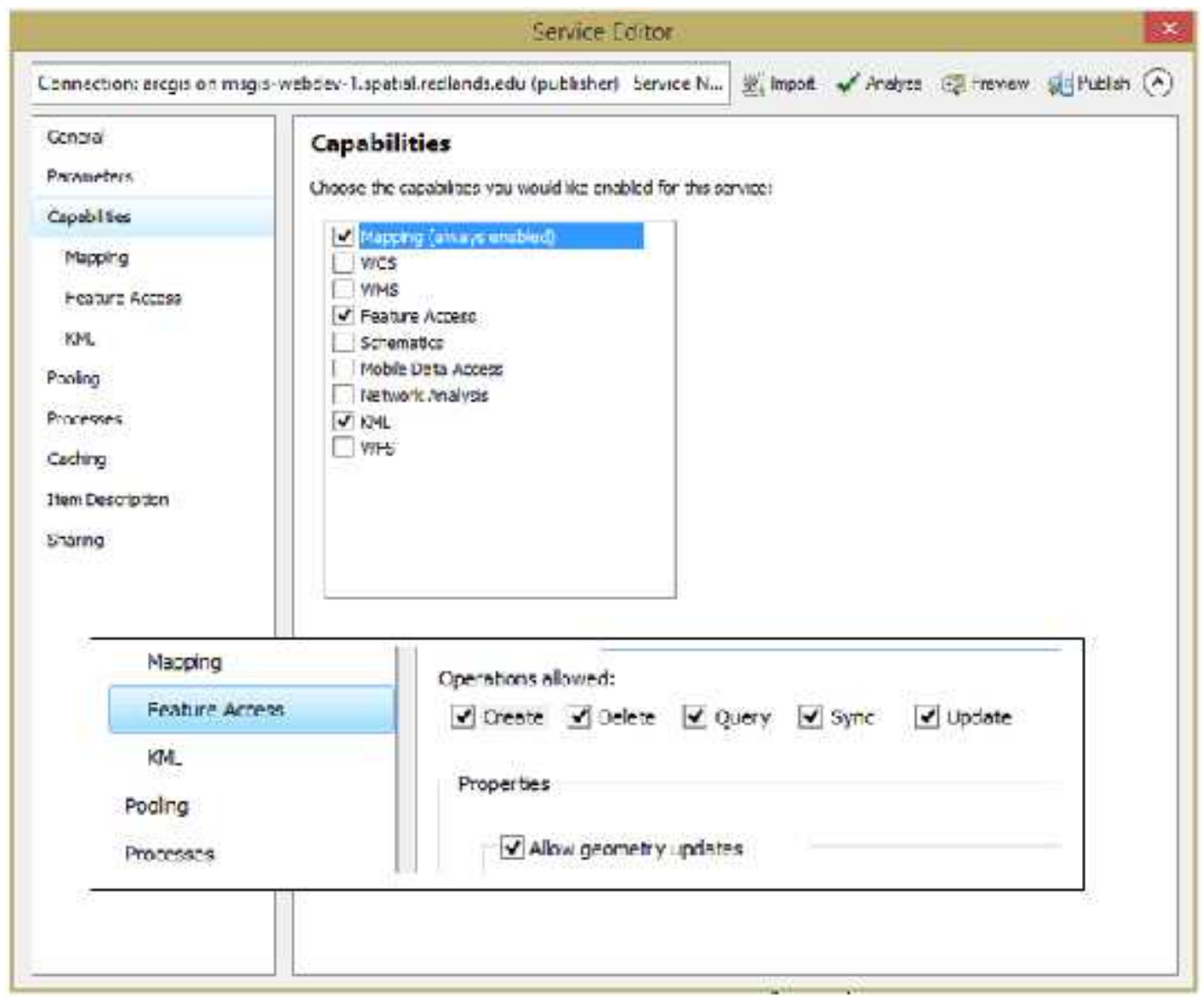

Figure 5.4: Feature service settings

In the Feature Access sub-class on the capabilities tab, five operations were enabled. These operations included Create, Delete, Query, Sync, and Update. These operations allow the feature service being published for deleting, querying, creating, and updating. The Sync operation was enabled to support editing from ArcMap and the Web application on the browser. The service settings were analyzed for possible errors and warning using the publishing toolbar.

\subsubsection{Geoprocessing Service}

Geoprocessing services enable the deployment of the powerful analytical capabilities of ArcGIS desktop suite to the Web. The advanced version of the Web application developed for this project was designed to allow the clients to perform spatial analysis from the Web browser. Based on the interests of the clients, this project implemented a tool for calculating the population that is under influence of selected environmentally hazardous sites. 
Two approaches were used to evaluate the impact of environmental hazards on population. One was to consider population of all the census tracts that intersect with the buffer of the environmental variables being investigated. For this first approach, polygon containment, the affected population was determined by dividing the tract population by the total population of the project area. The second approach involves determining the proportion of the intersecting tracts that fell within the buffer specified. To determine the affected population in the second method, area interpolation was used. To implement the area interpolation, it was assumed that the population was evenly distributed within the affected census tract. In this case, the portion of a tract within the buffer was determined and its proportion determined based on the area of the whole census tract. This proportion was then used to determine the percentage of population affected in reference to the project area population.

A Python script was developed to implement these two methods using the PyScripter Integrated Development Environment. ArcPy module was imported to call in the ArcGIS-built Arc Toolbox tools. There are four input variables from the user and three outputs. The input variables include the selected environmental variable feature class, selected social variable feature class, a SQL expression for making a selection from the environmental variable input, and a buffer distance for the environmental variables selected. The output variables include selected environmental variables, polygoncontainment feature class (the output of the first approach), and the buffer-containment feature class (the output of the second approach). The tools used in the script take in the input variables as feature layers as opposed to feature classes. Thus, the environmental and social indicator variables were converted to feature layer to be used in the tool. Various tools were used to perform the analysis, including Select by Attribute, Buffer analysis, Select by Location, and Copy features. Update cursor function was used to compute the percentage of the population affected by the selected environmental variables.

In the enterprise geodatabase, the script was converted into a toolbox - Population Influence Tool - to optimize its use for the user (Figure 5.5). This helped design a userfriendly interface for the users. 


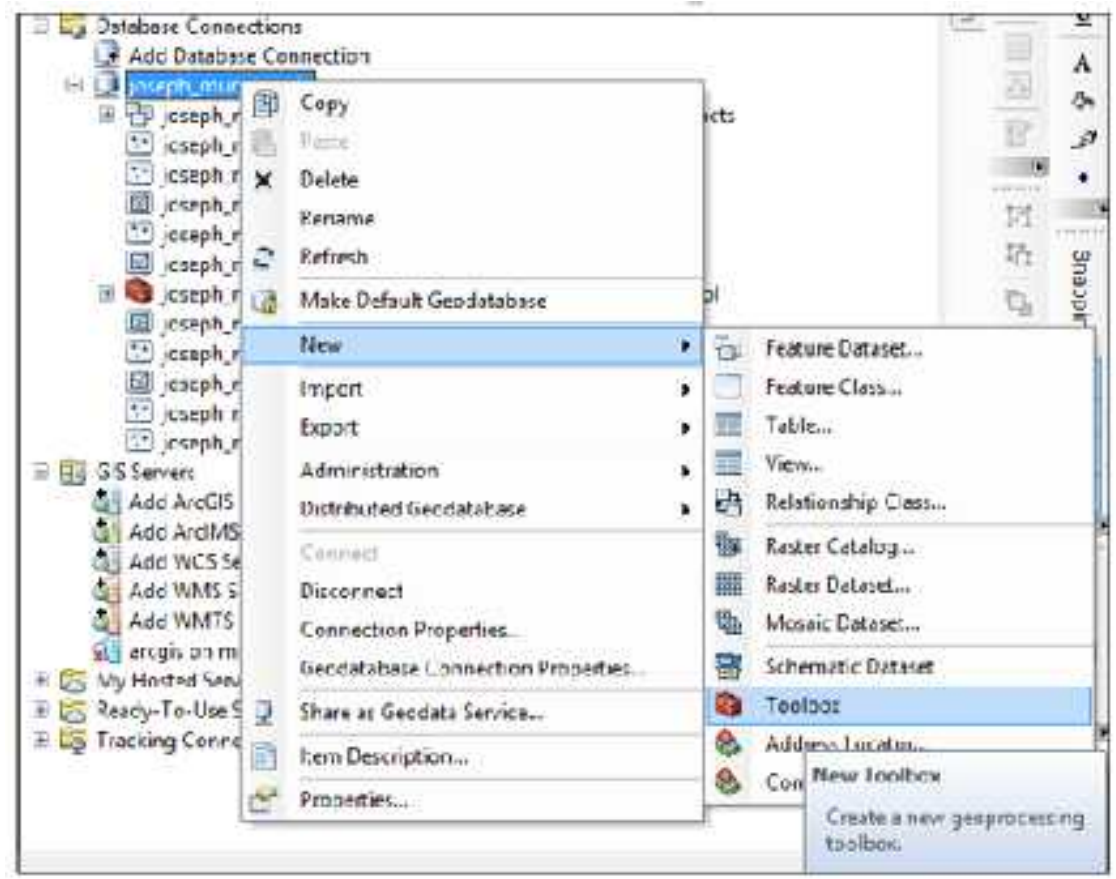

Figure 5.5: Creating a toolbox in the geodatabase

After creating the tool in the geodatabase, the Python script was imported into this tool. This connected the Python script with the toolbox so that the user would not need to open the PyScripter IDE to run the tool. Instead, the user would use this tool in the same way as any ArcGIS geoprocessing tool from Arc Toolbox. There were several properties to be set up for input and output parameters (Figure 5.6). 


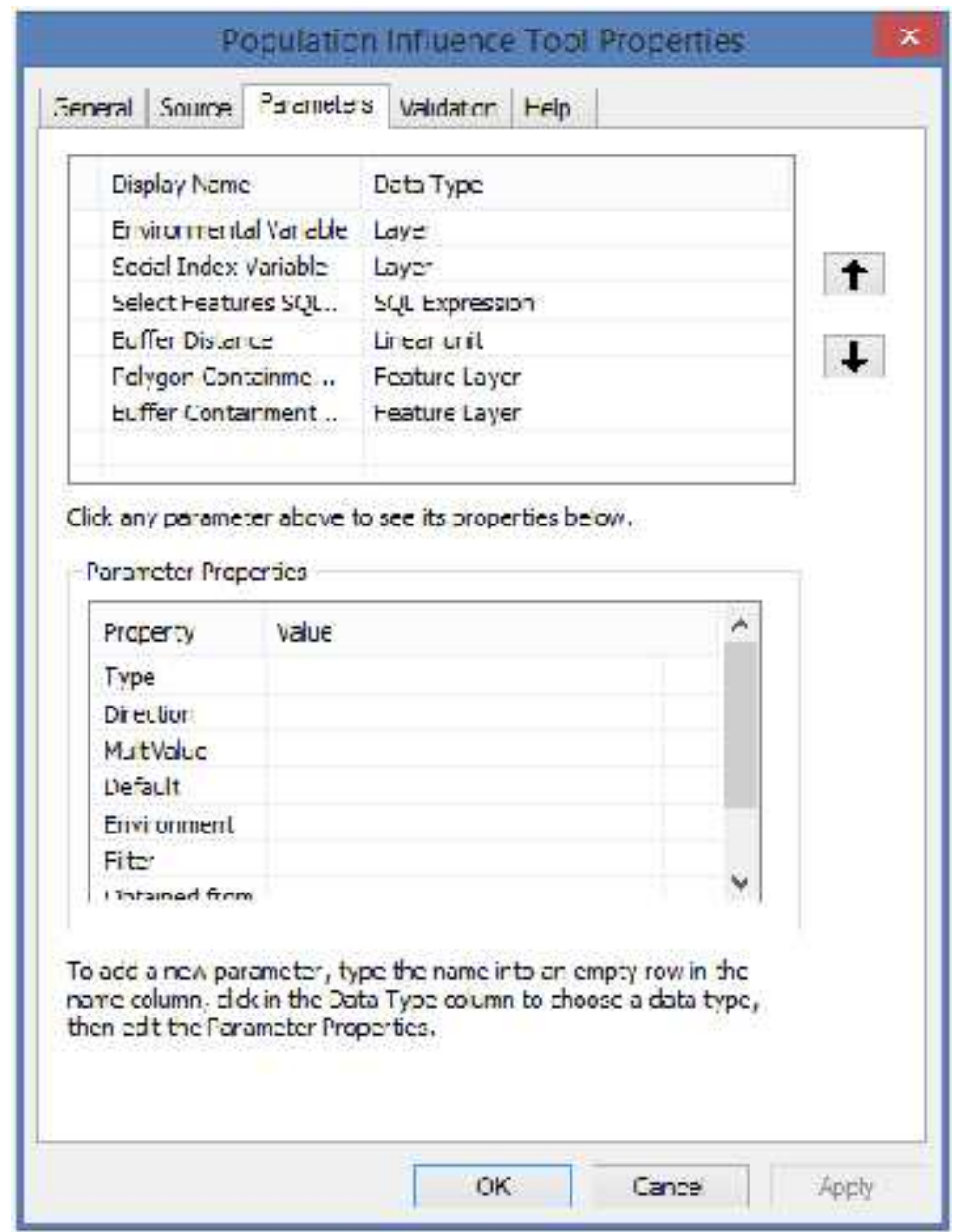

Figure 5.6: Setting up the tool parameter properties

In the parameter settings, each parameter was required as an input or output. A selfexplained name, data type, as well as the type of the parameter (input or output) was defined for each parameter.

Figure 5.7 illustrates the complete tool interface for the tool. In the tool interface, descriptive information was incorporated to guide the users as they enter the parameters on the right panel. The information describes each parameter required in the tool as well as the data type. 


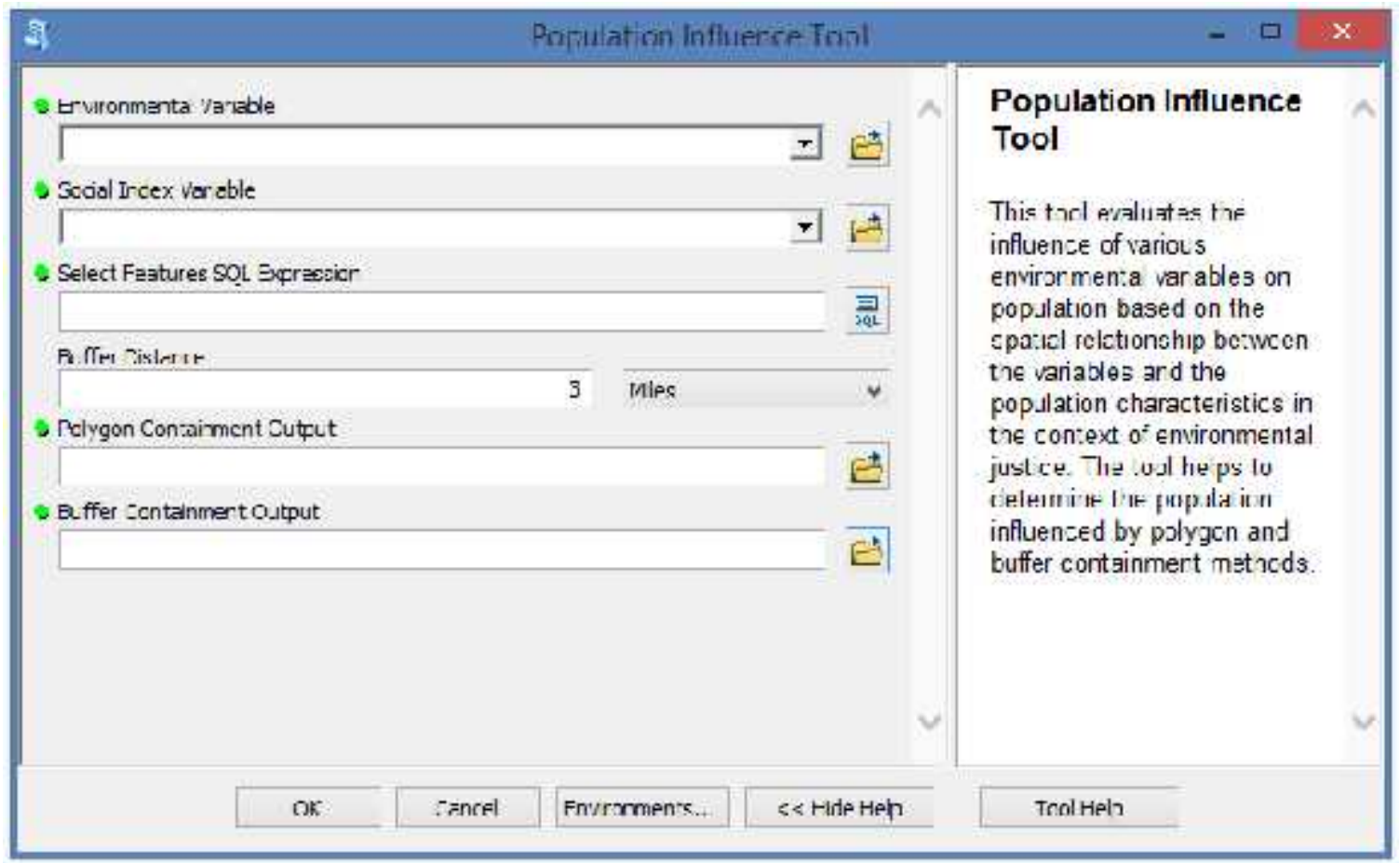

Figure 5.7: Tool user interface

To publish the tool, the tool was shared as a geoprocessing service. This popped up the publishing window where the necessary information was populated (Figure 5.8). Asynchronous execution mode was chosen to perform the analysis on the background, which allows the users to perform other tasks as the tool executes. 


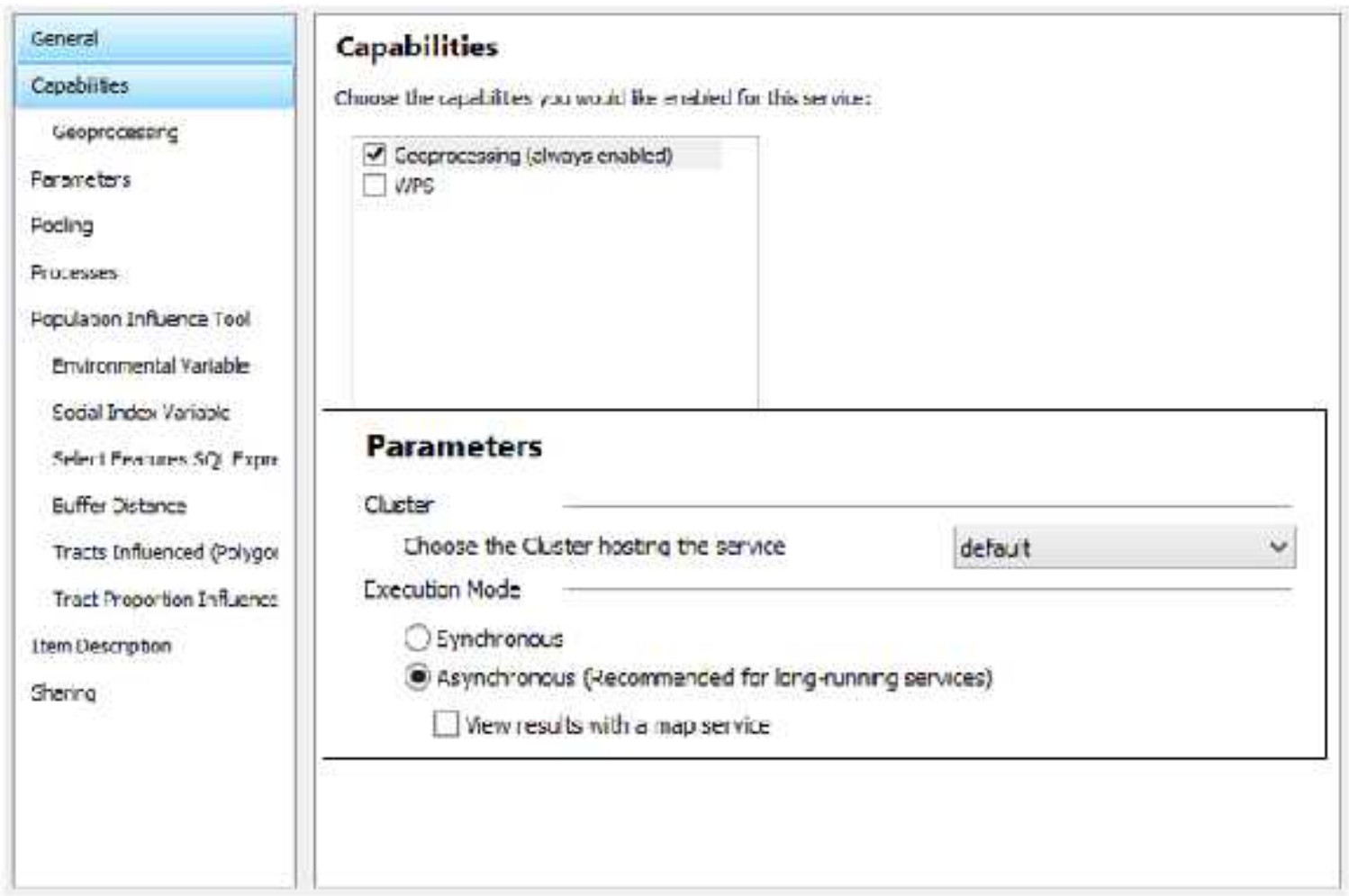

\section{Figure 5.8: Setting up the geoprocessing service}

The geoprocessing service settings were analyzed for possible errors and warnings using the publishing toolbar. After that, the service was then published to the ArcGIS Server.

All the published services were listed in the folder dedicated for this project on the ArcGIS server. The services were listed with a comment in parentheses detailing the service type: MapServer, FeatureServer, or a GPServer (Figure 5.9). 


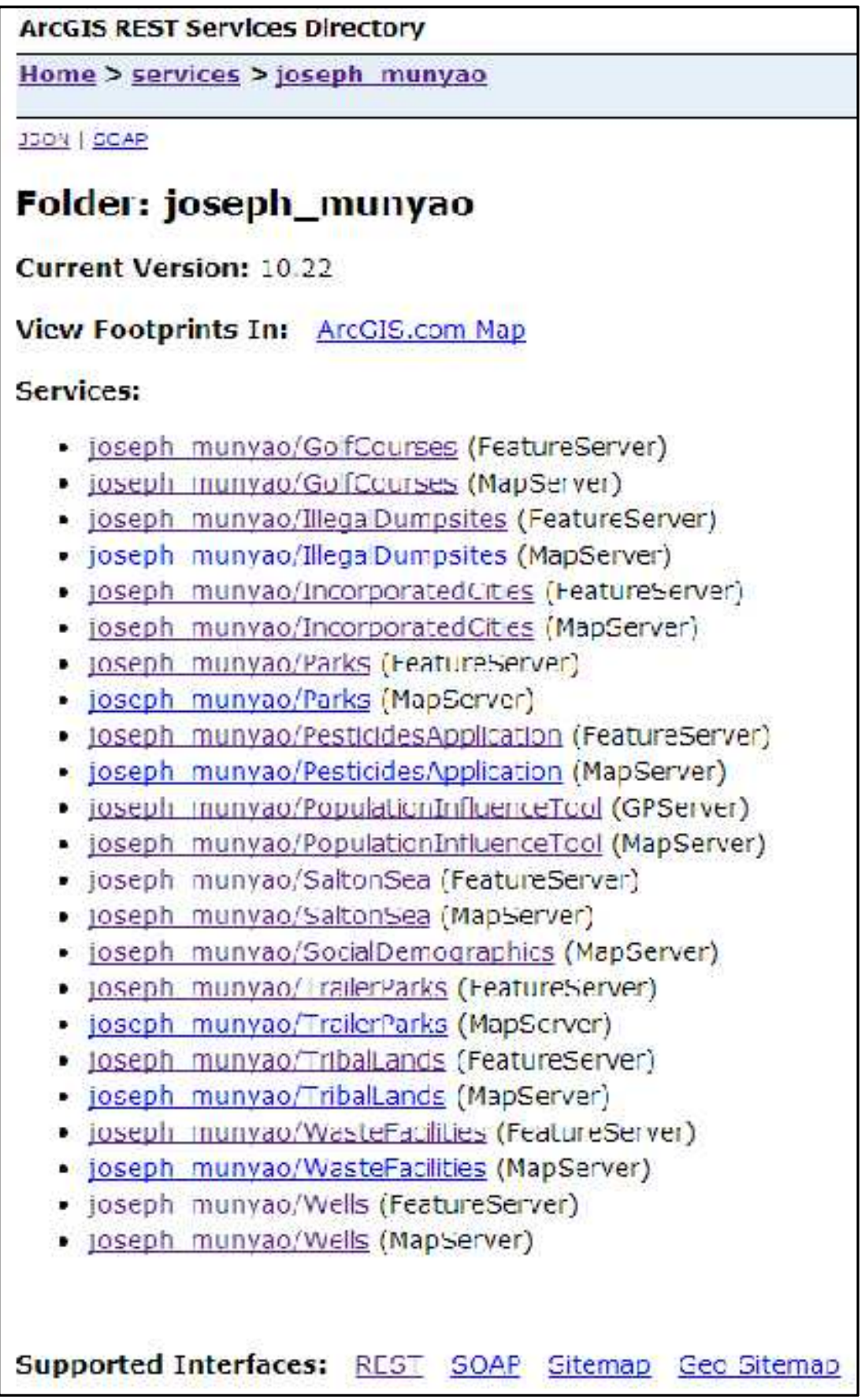

Figure 5.9: ArcGIS Server services directory

\subsection{Authoring Web Maps}

Four Web maps representing the three social indicators (Ethnicity, English Language Proficiency, and Poverty) and project area overview were authored. These four maps were put in the Web application for the public. The fifth map comprised of the three social indicators and the nine environmental variables was created for the Web 
application intended for the clients. This was because the clients' version of the Web application required centralization of all the variables for easy geoprocessing analysis.

Each of the social indicator maps in the public Web application consists of one social indicator and the nine environmental variables representing the five environmental themes considered in the project (Table 5.1).

Table 5.1: Project themes and respective feature services

\begin{tabular}{|l|l|}
\hline Environmental Theme & Feature Services \\
\hline \multirow{4}{*}{ Water Access and Distribution } & Public water lines \\
\cline { 2 - 2 } & Water wells \\
\hline \multirow{4}{*}{ Waste Disposal } & Unregulated dumpsites \\
\hline Pesticides Application & Licensed waste facilities \\
\cline { 2 - 2 } Green Spaces & Tribal lands \\
\hline \multirow{3}{*}{ Housing Infrastructure } & Pesticides usage \\
\hline
\end{tabular}

The maps were authored by integrating an AGOL basemap service, environmental feature services, and map services. For example, Figure 5.10 shows an example of Web map built by combining the published map and feature services.

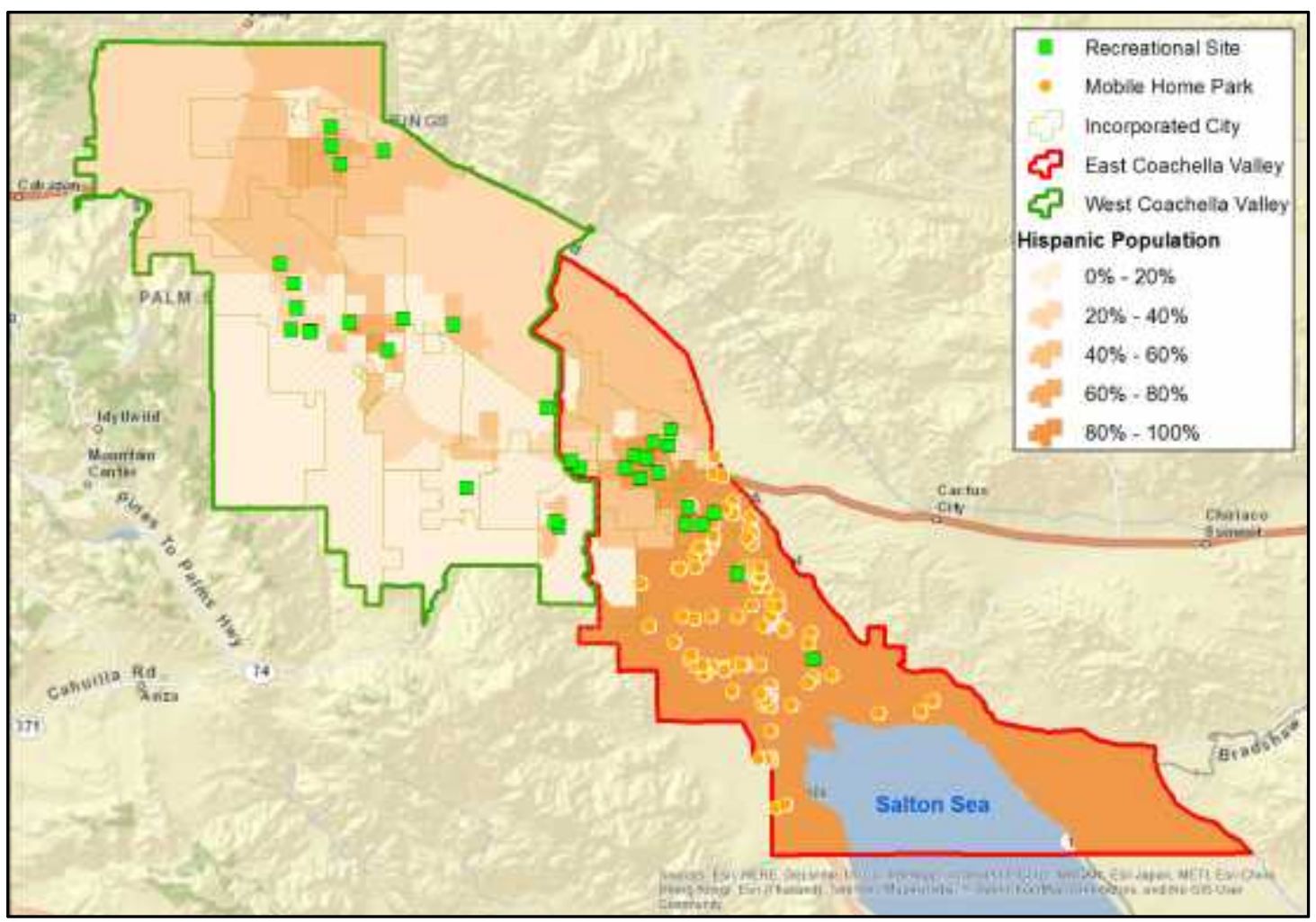

Figure 5.10: Environmental justice issues based on Hispanic population percentages 
The feature services in the map (Figure 5.10) are recreational sites and Mobile home parks while the map service layers are Coachella Valley regions and the Hispanic population distribution. Upon full completion of the map authoring and polishing, the maps were shared for public access. Each maps' Description, Use Constraints, Tags, and Map extent were also completed before it was shared. This set stage for the consumption of these Web maps in the Web application.

\subsection{Web Application Development}

Two versions of the Web application were built: public and clients' versions. The public version was built using ArcGIS API for JavaScript, and the second was built using ArcGIS Web App Builder to provide more advanced geoprocessing functions.

\subsubsection{Public Web Application Version}

Aptana Studio 3 was used for the Integrated Development Environment (IDE) given its advantages in supporting JavaScript (JS), HTML, CSS, and Dojo toolkit. These were key components for building the application to suit the clients' needs. In addition, Aptana Studio 3 provides a platform with error and warning notifications, as well as integrated documentation, which eases debugging processes.

The public Web application version adopted the Esri's Basic Web application template, downloaded from GitHub. The local machine was then Web-enabled through configuration of Microsoft's Internet Information Services (IIS) in the Inetpub folder. This platform allows configuration a computer for Web development purposes by enabling a local Web server to host the Web application. This was necessary before the Web application was deployed to the audience via the University of Redlands Web Server. The application has different folders for the codes of the three languages: HTML, JS, and CSS. The separation of these development language elements facilitated coding and debugging processes while building the application. The JS was used to design the application functionality, HTML used to design the Web page interface, and the CSS was used for styling the HTML elements. The modules and functions used in the application followed the Dojo framework and legacy module format. These three languages were set to communicate effectively to deliver the application on the browser to the audience.

Figure 5.11 provides an overview of the interface. Using HTML, a Web page was created, on the top of which is the title area of the Web atlas. Four tabs below the title link to the various social indicator maps (Hispanic population, Poverty status, English proficiency) and the overview map of the project area. The user can choose one kind of map at a time. All the widgets were arranged in a horizontal ribbon below the theme tabs. Widgets are important tools that the user would use to explore the maps on the Web. A button represents each widget. 


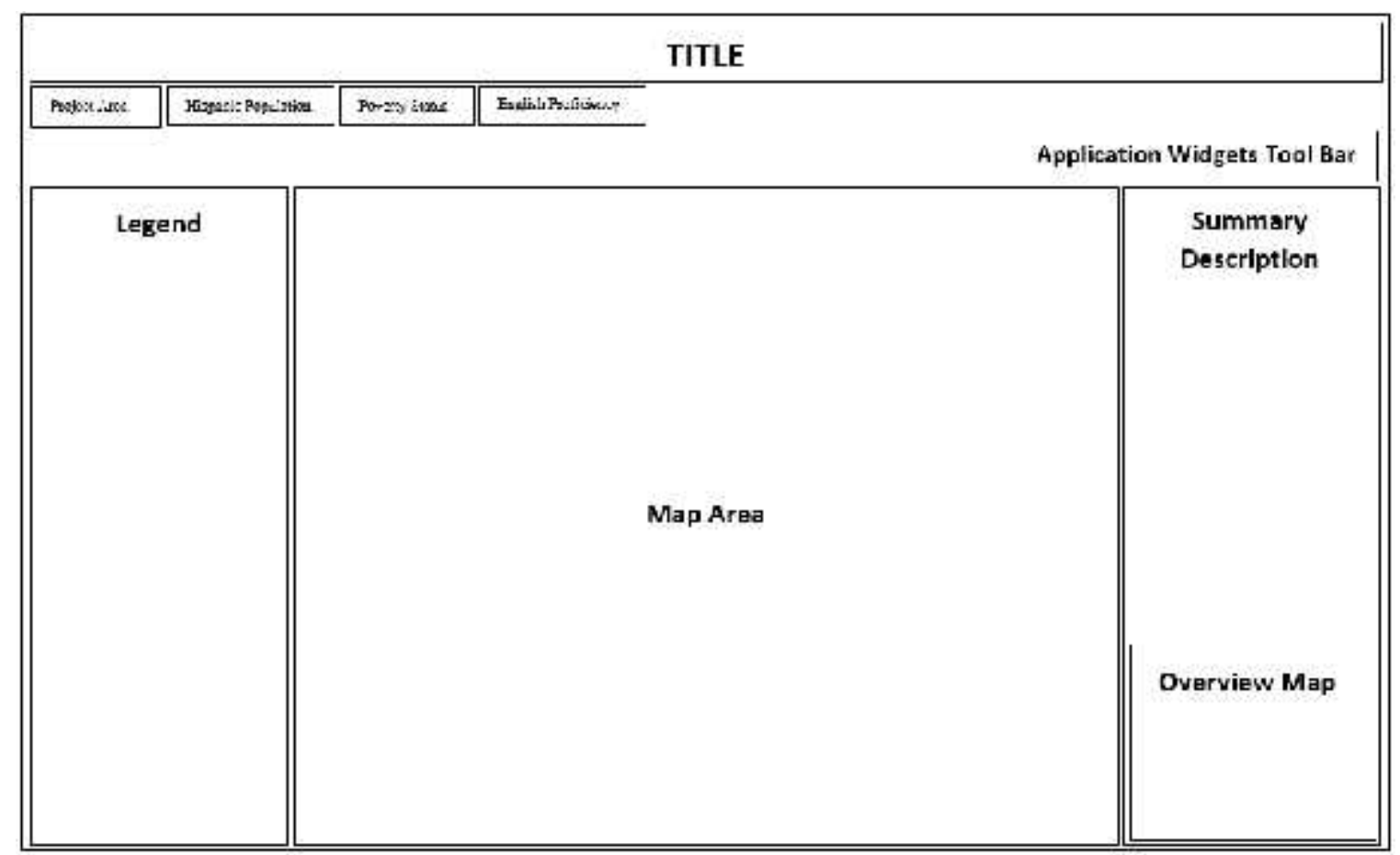

Figure 5.11: Public Web App interface design

The measurement widget would enable users to measure distances, areas, and coordinates. These measurements (distance or area) would help estimating proximity to a certain environmental hazard or feature (Figure 5.12).

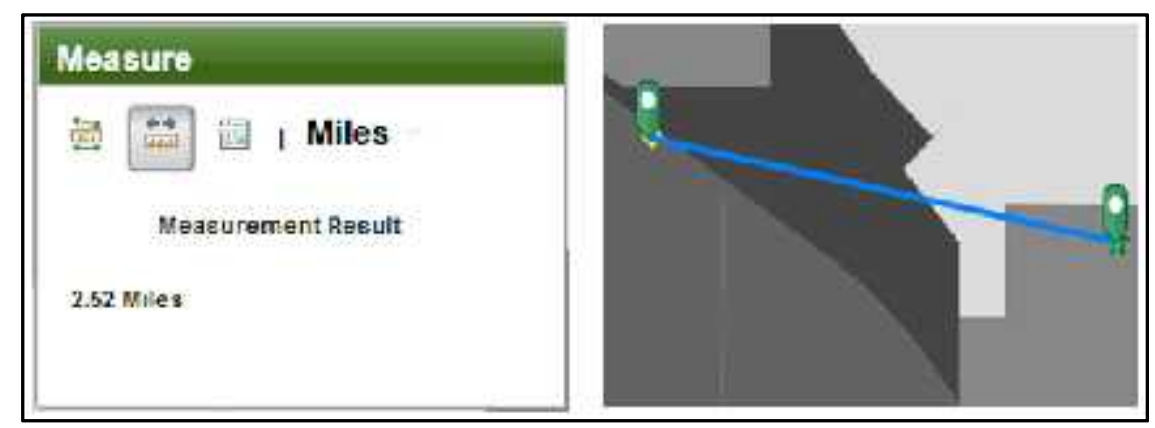

Figure 5.12: Using the Measurement widget on the application

The list layers widget was provided to help the users toggle on and off the layers. This function allows the users to overlay different environmental variable layers to explore spatial relationships among social indicators and these variables. A basemap widget provides the option of changing the basemap layer. In addition, a bookmarks widget is available to record an area of interest. In addition, the user can print and share the maps through the print and share widgets. Last, a geocoder widget provides the users the capability of searching places of interest through the addresses or place names.

To provide more details of the population characteristics, information windows were enabled. Figure 5.13 illustrates an example of an information window for the distribution of Hispanic and White populations. 


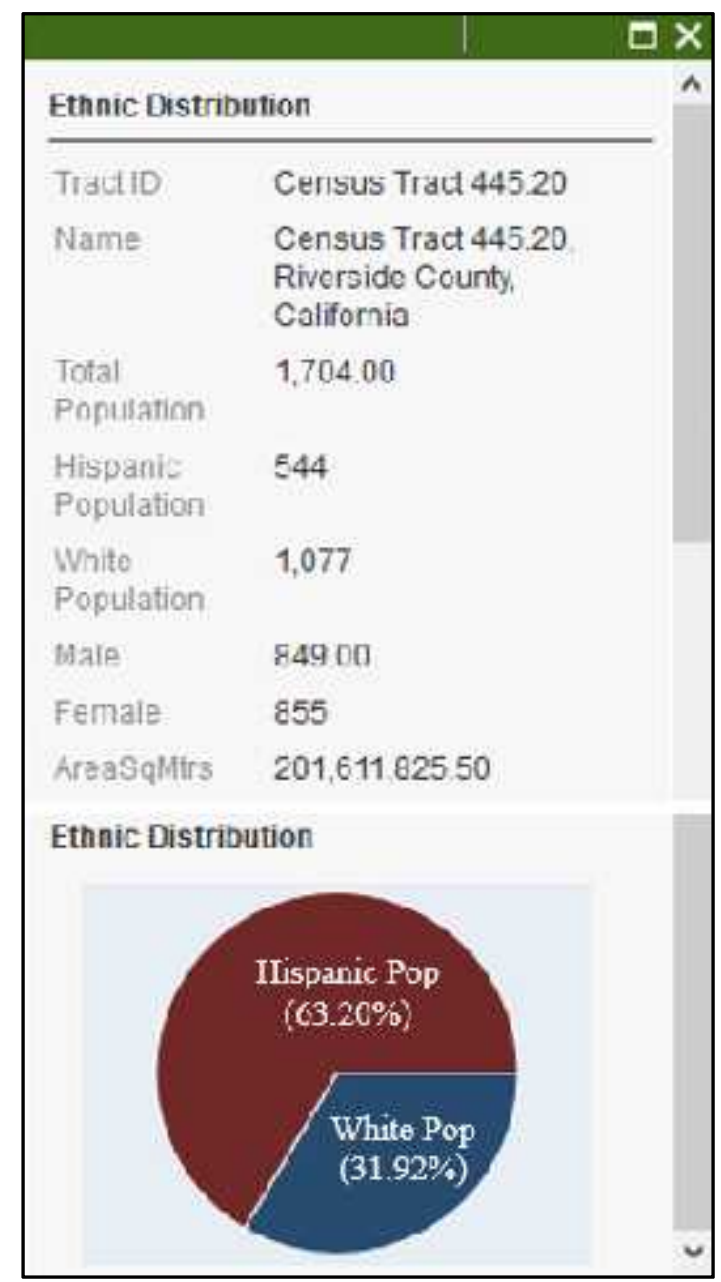

Figure 5.13: Characteristics of population based on ethnicity in a Tract

The information window provides descriptive information about the population as well as a chart showing the various population characteristics. The information window for environmental variables only includes the descriptive information, as many of these variables did not have numeric fields.

The left and right panes in the Web interface were designed to provide the users with information needed for map interpretation. In the left pane, the legend for each layer shown in the map will be displayed and updated when the layers are changed. On the right pane is the summary description for the map on the view, with which the audience can better understand the map content in the context of environmental justice. This information is obtained from the description section of each Web map as entered during the map authoring stage. This pane updates the description upon the change of the thematic map displayed on the map area.

\subsubsection{Clients Web Application Version}

The ArcGIS Web App Builder (AWAB) was used to build the advanced application. The AWAB provides an interactive user-friendly environment for building custom Web Applications. The developed Web map was shared from the AGOL environment. Various 
widgets necessary for the application were added and configured at this level. Besides the widgets that are available in the first Web application, there are two additional widgets: editing and geoprocessing. The edit tool widget allows for editing the environmental feature services on the browser end, and the geoprocessing widget enables the users to conduct analysis on impacted population by environmental hazards. The interface for this version was a little different from the public Web application. Figure 5.14 illustrates the interface of the clients' Web application.

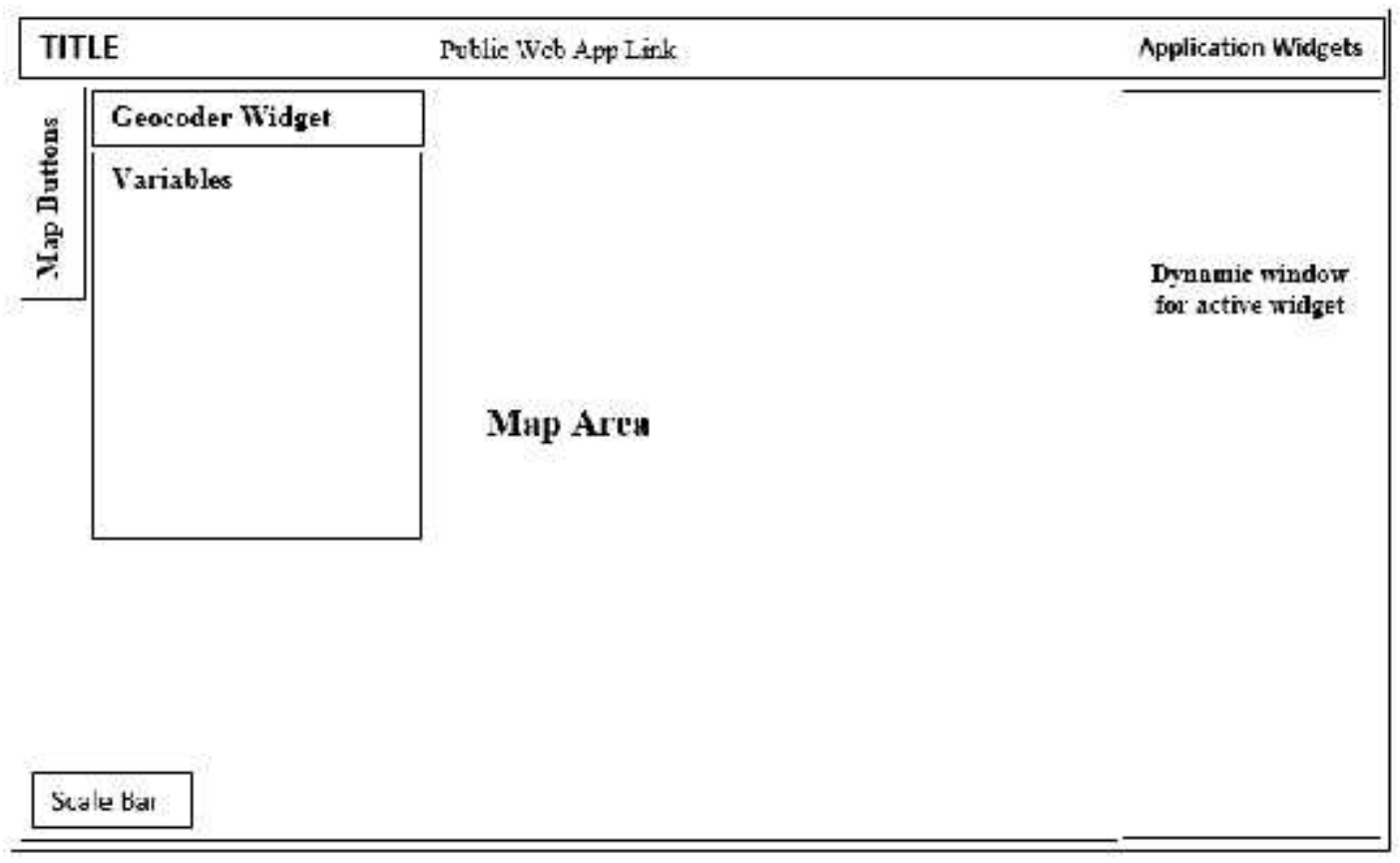

Figure 5.14: Clients' Web application interface

To perform edits on the Web application, the clients are required to activate the edit widget from the toolbar. This would activate an edit session through an editing window filled with edit-enabled feature services (Figure 5.15). 


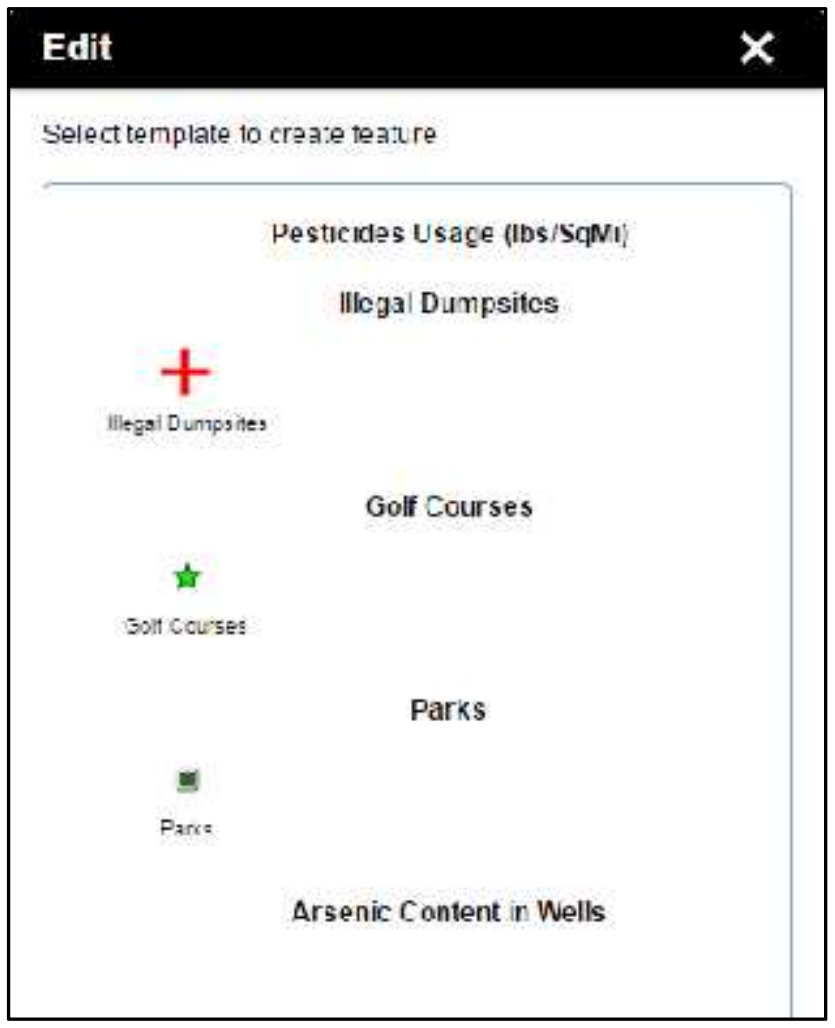

Figure 5.15: Edit window for the feature services

Depending on the operations enabled for each feature service, the editing capabilities vary among layers. If the feature service supports creation of new features, a symbol would be activated on the edit window. If the feature service only supports updating of the attributes, this feature service would be listed without a symbol next to it. In the case that the clients want to edit the features in the geodatabase directly, relevant settings were configured to allow for the editing of the feature classes in the enterprise geodatabase. Figure 5.16 shows the editing set up window in ArcMap, which includes edit options from the edit toolbar. 


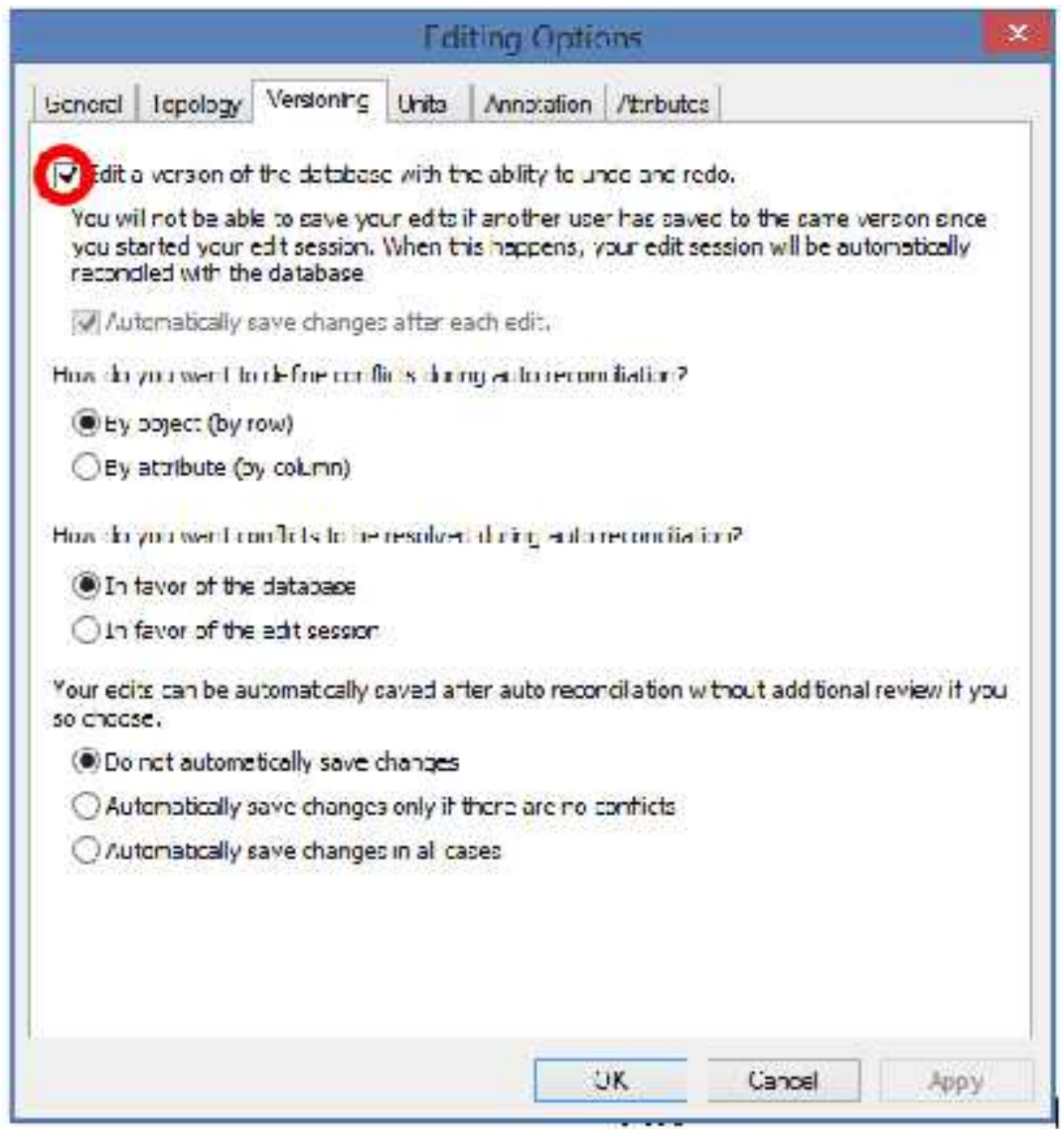

\section{Figure 5.16: Edit settings window in ArcMap}

The project geodatabase is not versioned. The default settings of ArcMap for enterprise geodatabase are set to allow edits on versioned geodatabases. Thus, the clients need to open up the edit options from the editor toolbar and uncheck the "edit a version of the database" radio button. This enables the editing of the feature classes in the geodatabase. When the edits are saved from ArcMap, the Web services are synchronized with these edits.

Geoprocessing analysis is also supported on this Web application, which is activated by clicking on the geoprocessing service widget on the toolbar (Figure 5.17). 


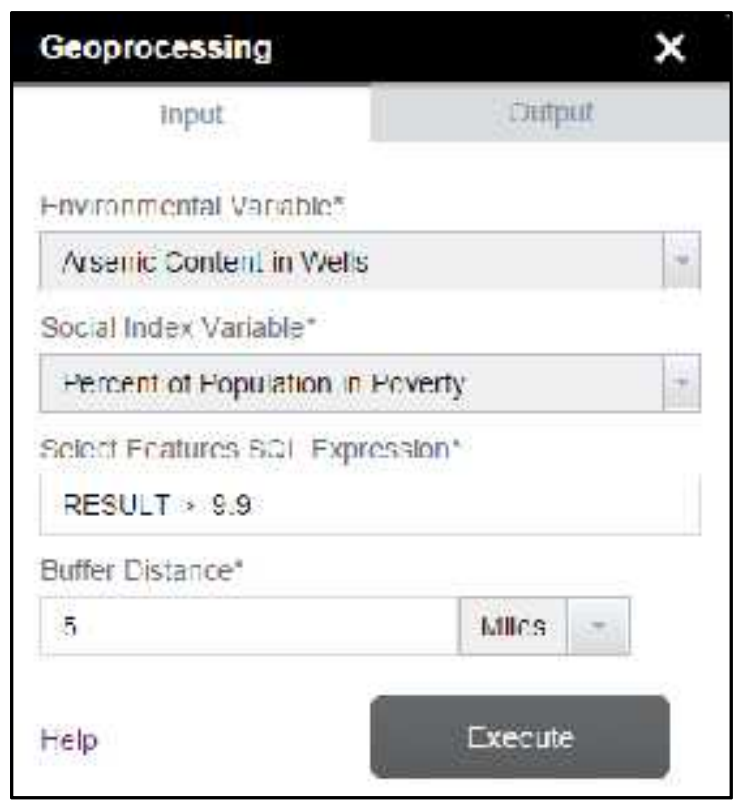

Figure 5.17: Geoprocessing service interface to enter parameters

The user enters in the parameters: environmental variable, social variable, SQL expression to select the environmental variables, and the buffer distance of operation. Upon clicking on execute, the tool would run and perform the two methods of evaluating the population influenced by the environmental variables as described in Section 5.1.3. The analysis results are displayed on the map as temporary map service layers.

\subsection{Summary}

Chapter 5 discussed the implementation procedures of this project. These procedures are comprehensive details of the tasks performed for the development of the desired project products. The project used three types of Web services: map, feature, and geoprocessing services. Thematic Web maps were then developed on AGOL platform. Finally, two Web applications were developed: a Public and client version. These were developed using JS and $\mathrm{AWAB}$ respectively 


\section{Chapter 6 - Results and Analysis}

This project was implemented to help users visualize environmental justice questions in the Coachella Valley. Two Web applications were developed to meet the clients' requirements. Compared to the public Web application that will be used by public to browse different maps of interest, the clients' Web application includes advanced functions such as data editing and spatial analysis. Sections 6.1 and 6.2 elaborate on the interface of the two Web applications, while Section 6.3 focuses on interpretation of some of the maps as examples of how the Web applications may be used to raise important questions. Data limitation is discussed in Section 6.4, and the chapter ends with a summary.

\subsection{Public Web Application}

The public Web application followed a simple, easy-to-use interface design, which allows users to map distributions of social and environmental variables related to environmental justice questions. Figure 6.1 illustrates the interface of the public Web application.

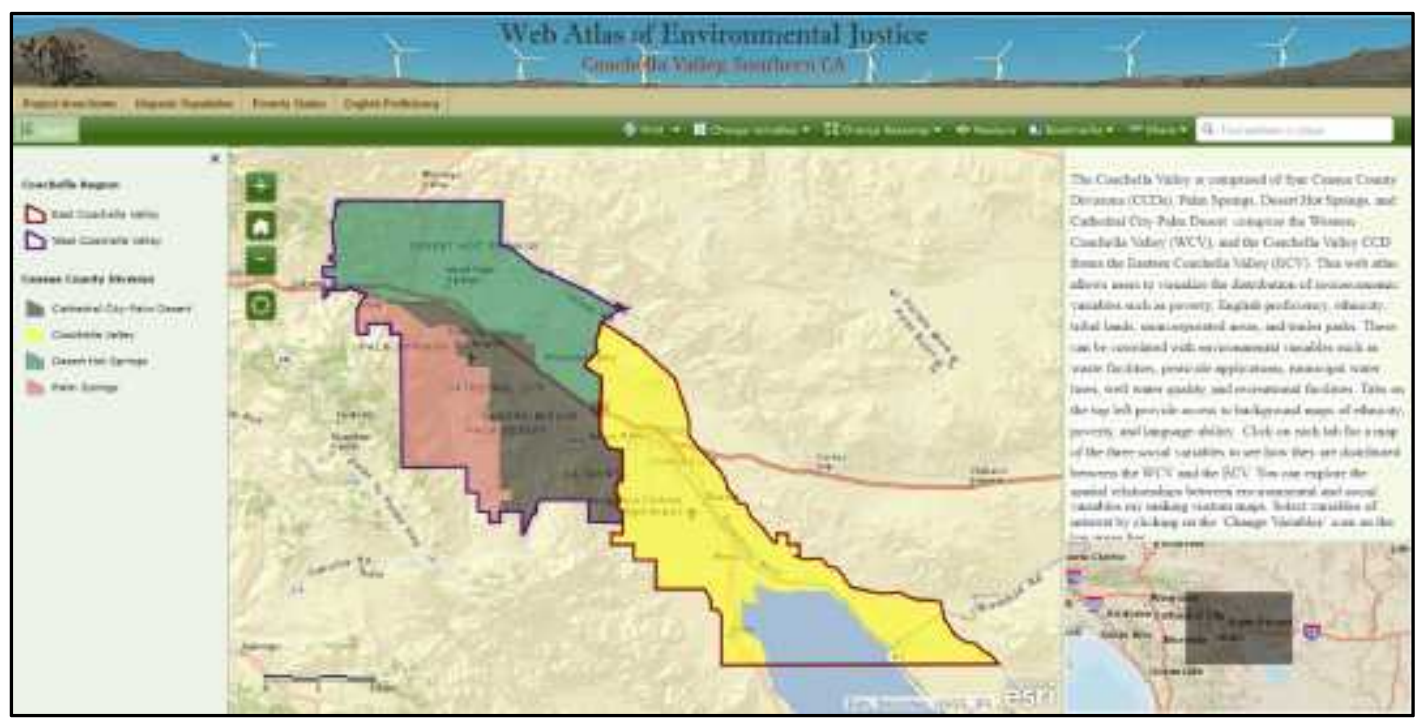

Figure 6.1: Public Web application interface

Four tabs on the top allow the user to select a social indicator of interest or overview the project area. Once a social indicator map is displayed, the user can overlay selected environmental variables on top of it. There are a few tools that allow the user to better explore and share the map. These tools are centralized in a ribbon for easy access and use. Figure 6.2 shows the toolbar of the application.

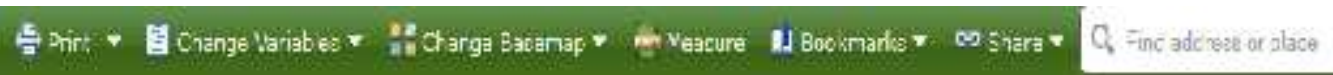

\section{Figure 6.2: Widget toolbar}


The tools include Print, Change Variables, Change Basemap, Measure, Bookmarks, and Share. In addition, the user can enter an address or a place name in the text box far right on the ribbon to map it. Among the main requirements for the Web application was the ability to toggle layers on and off. The user would click on "Change Variables" and choose the layers they want to see on the map (Figure 6.3).

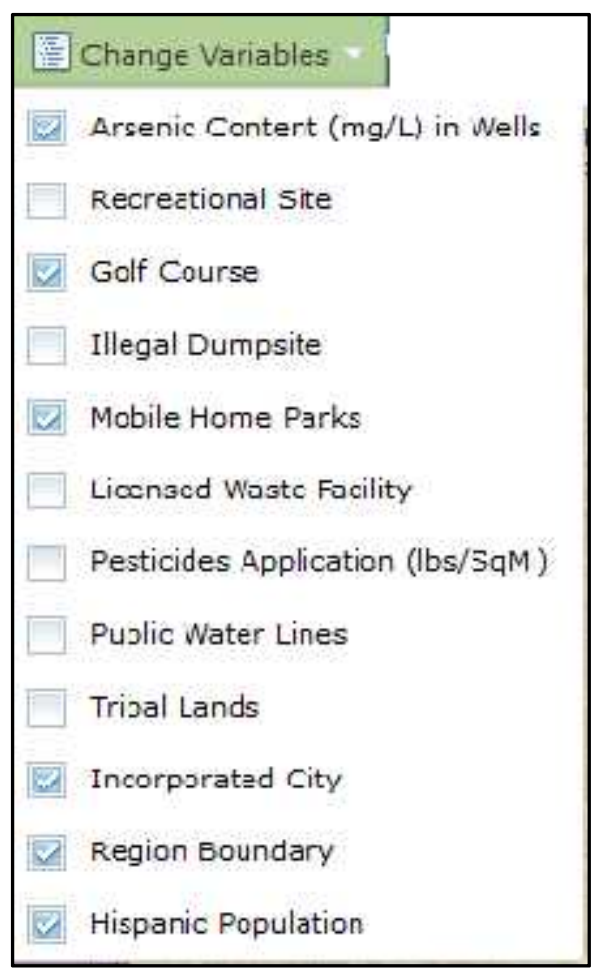

Figure 6.3: Change variables widget

This ability to change the variables helps the users to visualize the spatial relationships of the different social and environmental variables. Thus, the audience could gauge the vulnerability levels of different populations to environmental hazards.

The application was built to run on all the main Web browsers. Thus, the Web application was tested on Firefox, Chrome, Safari, and Internet explorer. The application response was the same across the four platforms. In addition, the application was tested outside the University of Redlands to ensure that the public could access it and use it comfortably. The students from Desert Mirage High School were chosen to perform the test guided by their teacher. Positive responses were received from these tests. Other areas where the application was tested include Kenya, Egypt, the United Kingdom, and the Netherlands. The people who participated in the testing exercise reported minor bugs but the application responded well for them. The minor bugs reported included slow loading of some layers like the public water lines. This layer is slow because many water line segments (131,261 segments) are stored in the dataset. The service of the water lines was then optimized for better performance. 


\subsection{Clients' Web Application}

The interface for the clients' Web application is illustrated in Figure 6.4.

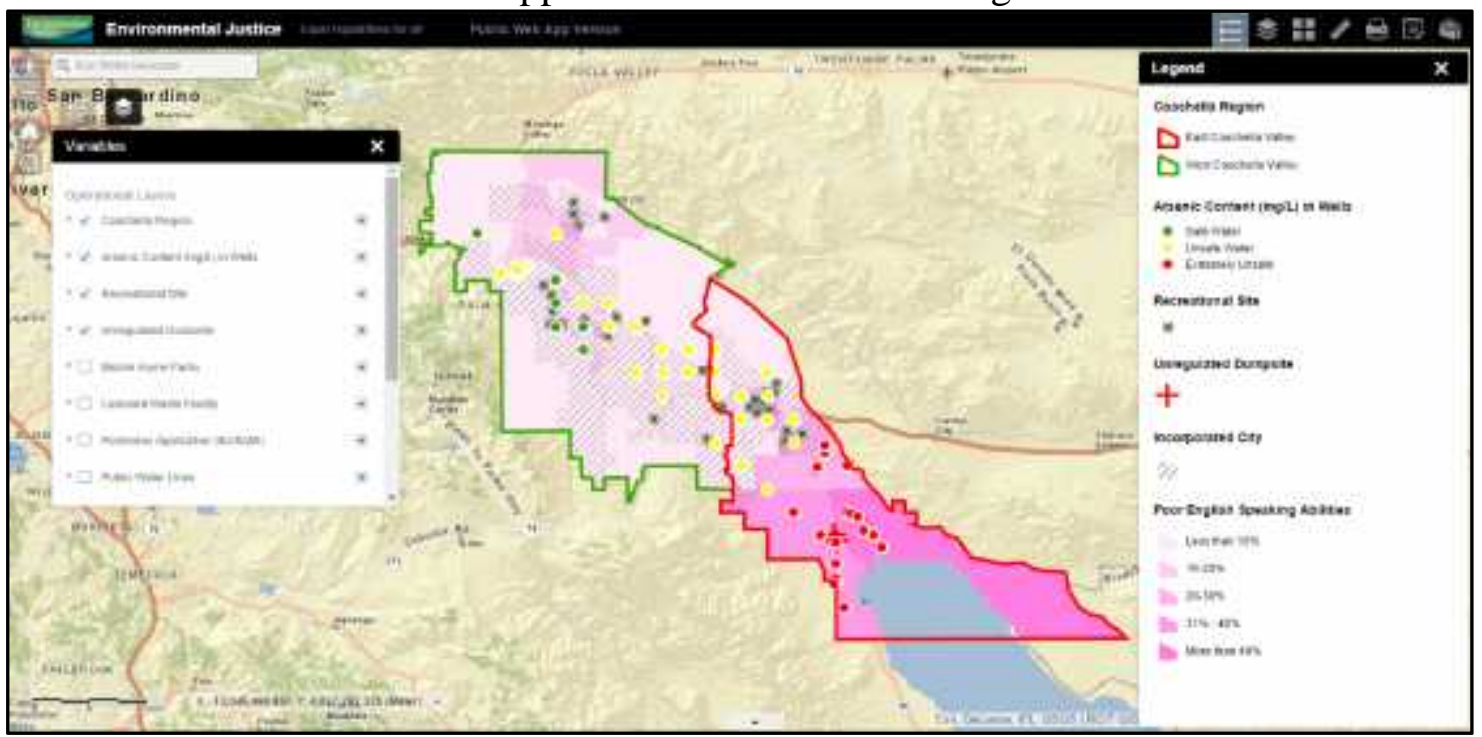

\section{Figure 6.4: Clients' Web application interface}

In this application, the clients are able to perform a geoprocessing task. The geoprocessing tool can execute the analysis based on the input choices (environmental and social variables) and display the results on the browser. These outputs include the selected variables from the environmental factors, the tracts influenced by the selected environmental variables, and the tract proportions within the buffer distance specified by the user. For example, the user may want to examine how many people are influenced by selected contaminated wells and the corresponding poverty level of these people. He would follow the geoprocessing interface to perform this task (Figure 6.5).

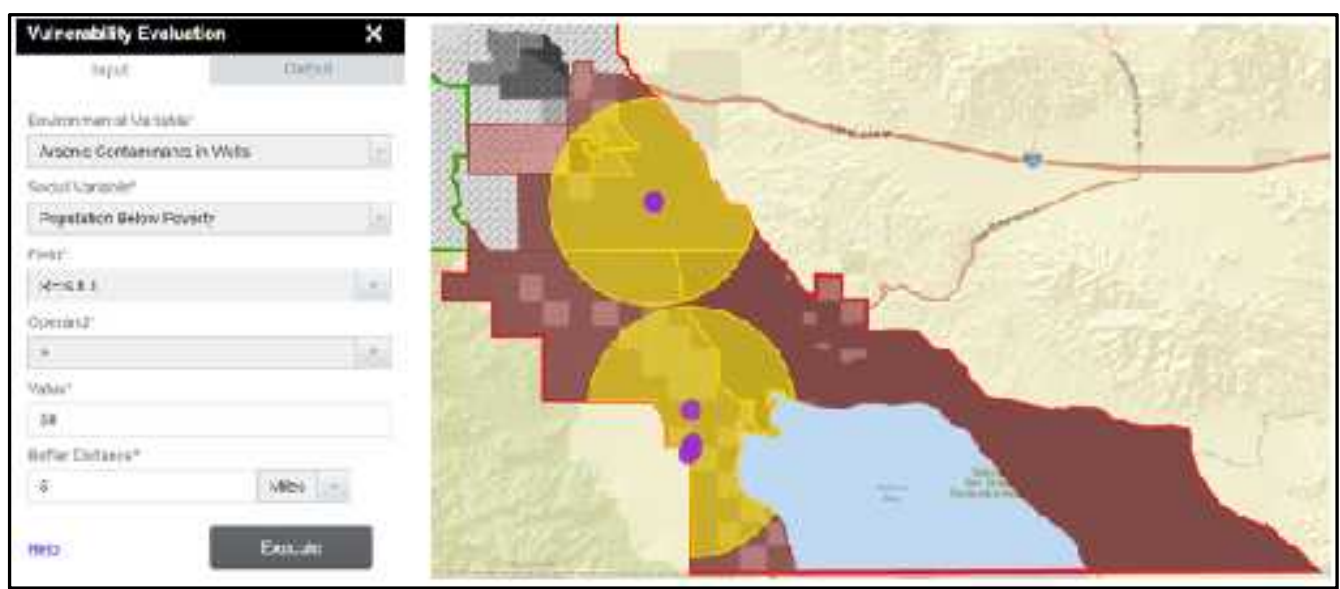

Figure 6.5: Geoprocessing input and results

In this case, the user would select Wells as the environmental variable to examine. This would be followed by selecting Percent of Population in Poverty as the social variable. A SQL expression such as "Result > 50" would be put to define the selection 
criteria. In this example, the user may be interested in examining the wells that have arsenic contaminants greater than $50 \mathrm{mg} / \mathrm{L}$. Finally, the user can specify a buffer distance, 5 miles, for the analysis. After these variables are entered, the tool will generate the results and render them on the map.

The purple solid circles in Figure 6.5 represent the selected wells, based on the SQL expression defined by the user where the arsenic levels are above $50 \mathrm{mg} / \mathrm{L}$. The tracts affected by these wells are shown as the maroon color, which are the results of the first method of determining the population influenced. The tract portions represented by the yellow color represent the second method output. The results are generated with attribute information at census tract level. The user can click on the features on the map to display an information template window with this demographic information (Figure 6.6).

\begin{tabular}{|l|}
\hline Population Characteristics $(1$ of 2 ) \\
Tract ID: Census Tract 456.05 \\
Tract Name: Census Tract 456.05 , Riverside County, California \\
Area Sq Mi: 74.43 \\
Total Population: 10543 \\
Non English Speakers $(\%): 38.1$ \\
Own Occupancy: 1907 \\
Rent Occupancy: 654 \\
Educated White Population: 1397 \\
Educated Hispanic Population: 3658 \\
English Speakers in Poverty $(\%): 13.94$ \\
Spanish Speakers in Poverty $(\%): 28.93$ \\
Influenced Population (\%): 2.49 \\
Zoom to
\end{tabular}

Figure 6.6: Influenced population characteristics

These two Web applications enable the clients and audiences to visualize the Web atlas and perform spatial analysis on a browser. The audience could also gauge the vulnerability levels of different areas to environmental hazards. A few examples will be provided in the following section.

\subsection{Use Cases}

The Web applications allow the users to explore different thematic maps with both social indicators and environmental variables overlaid. In this section, two use cases are provided to show how the user might gain insight into the distribution of the variables of interest and the relationships among these variables. In doing so, important questions with regard to environmental justice may be raised.

Before exploring different environmental factors, it is helpful to have an understanding of the socioeconomic characteristics of the study area. Therefore, the first use case is about analyzing the thematic maps of the three social indicators. Although the project area was divided into ECV and WCV regions following the previous study (London, Greenfield, \& Zagofsky, 2013), the interpretation of the maps may not be limited by this division. One of the reasons is that population is unevenly distributed across the whole project area with a very high concentration in the middle stretch of the Valley. Figure 6.7 is a dot density map developed with the population data at the census 
tract level. The population clusters in the middle stretch can be explained by the presence of cities and market centers there. The uneven distribution of population may directly affect the distribution of some environmental variables, such as public water lines. In addition, the socioeconomic characteristics of the tracts represented by percentage or ratio may become unstable due to the small populations. The four CCDs are provided in the map as a background information in this project; however, they could be used as analysis unit in future research.

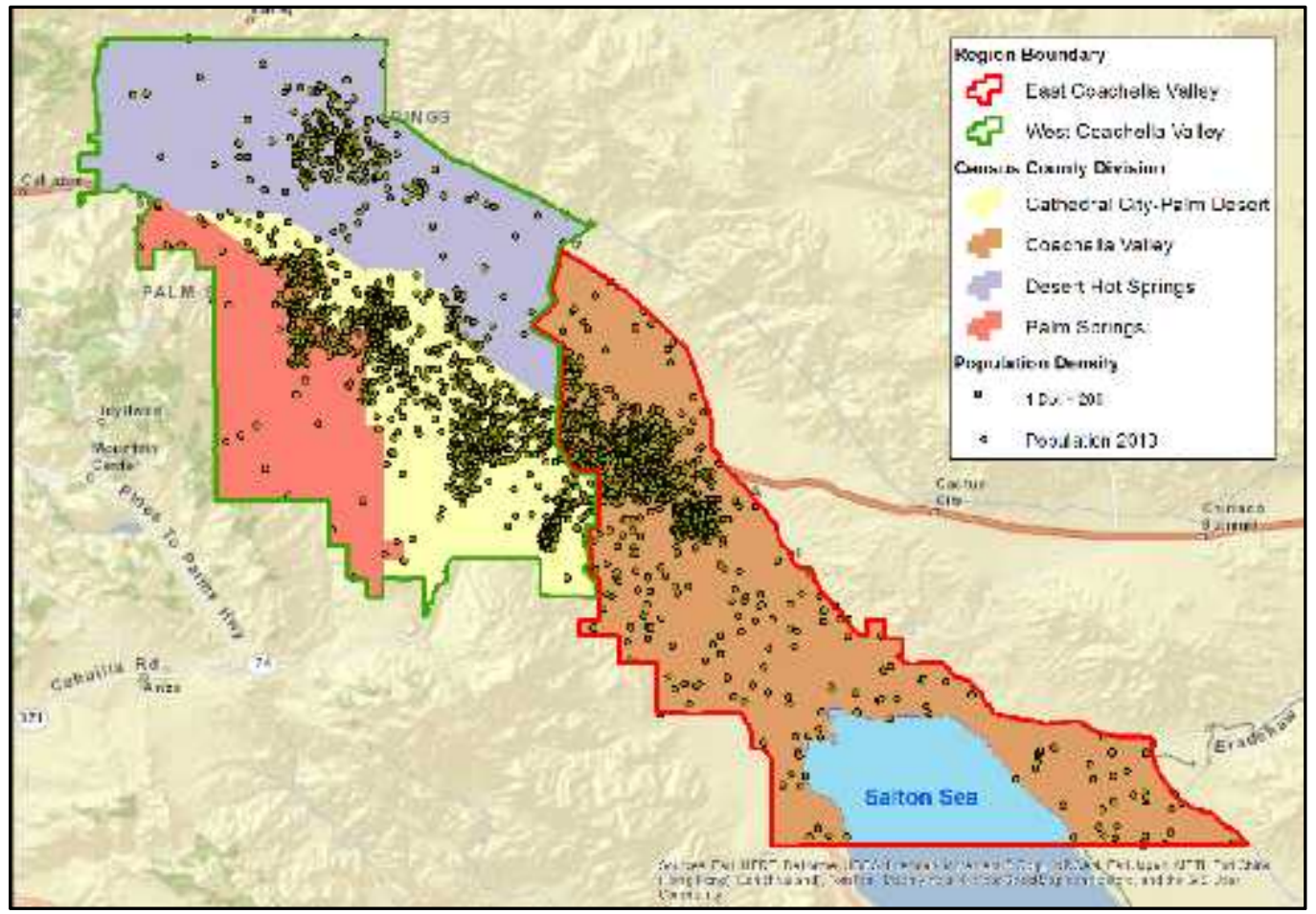

Figure 6.7: Population density in Coachella Valley

At the census tract level, the spatial distributions of the three social indicators are similar in the project area. As shown in Figure 6.8, most tracts in the ECV consist of higher percentages of Hispanic populations as compared to the tracts in the WCV that have higher percentages of non-Hispanic populations. Although Hispanic population dominates the southeast of ECV, the total Hispanic population is still relatively low given the uneven population densities in the project area. 


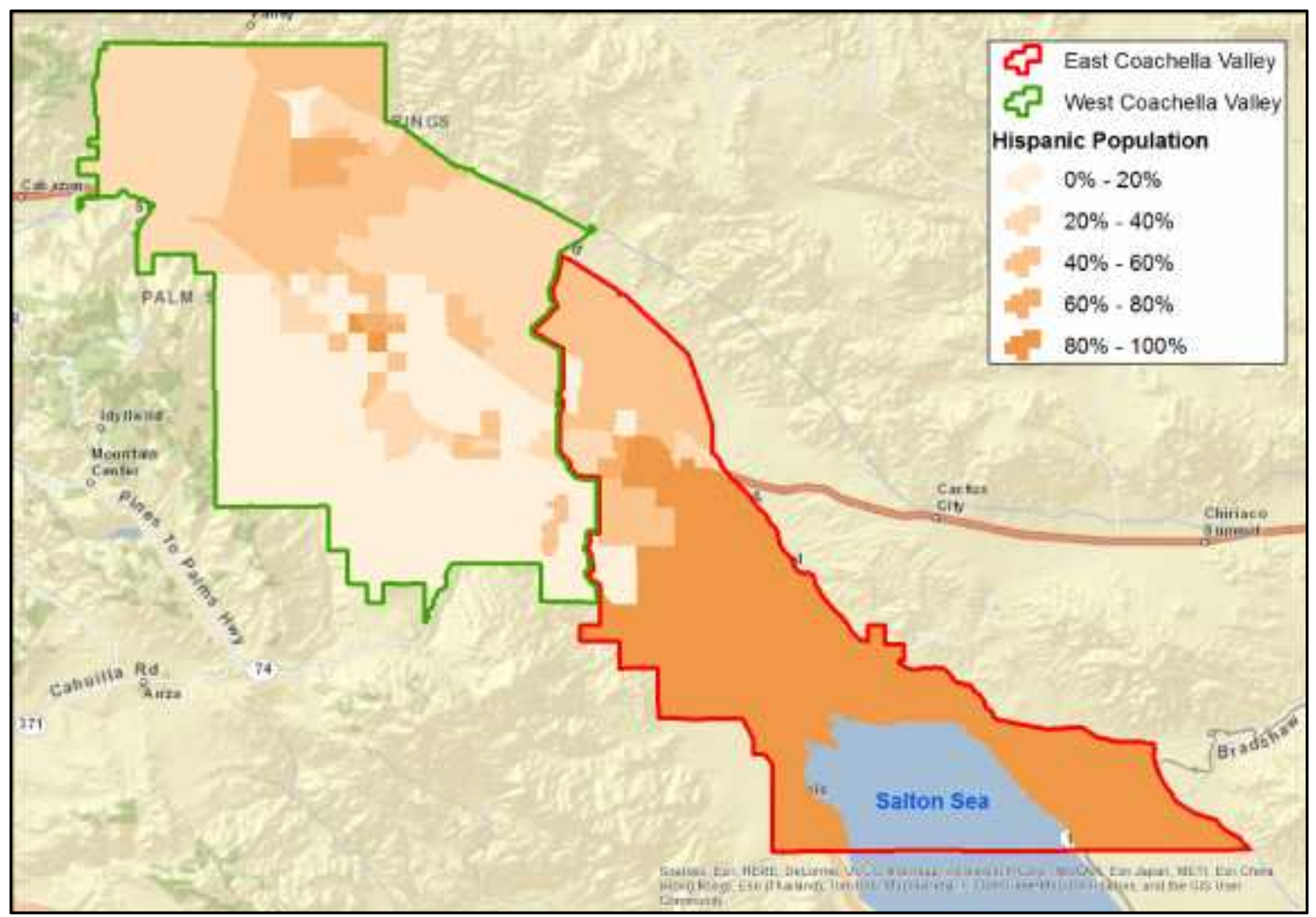

Figure 6.8: Percentages of Hispanic population per tract in Coachella Valley

Compared to the share of Hispanic population, distribution of population in poverty exhibits a rather similar pattern (Figure 6.9). The ECV has a higher percentage of tracts with high poverty rates ( $40 \%$ or more) as compared to the WCV tracts. The ECV tracts near the border of the WCV and the ECV have lower poverty rates as compared to those south of the ECV. The poverty rates in the WCV are relatively high in the northern tracts of the region. 


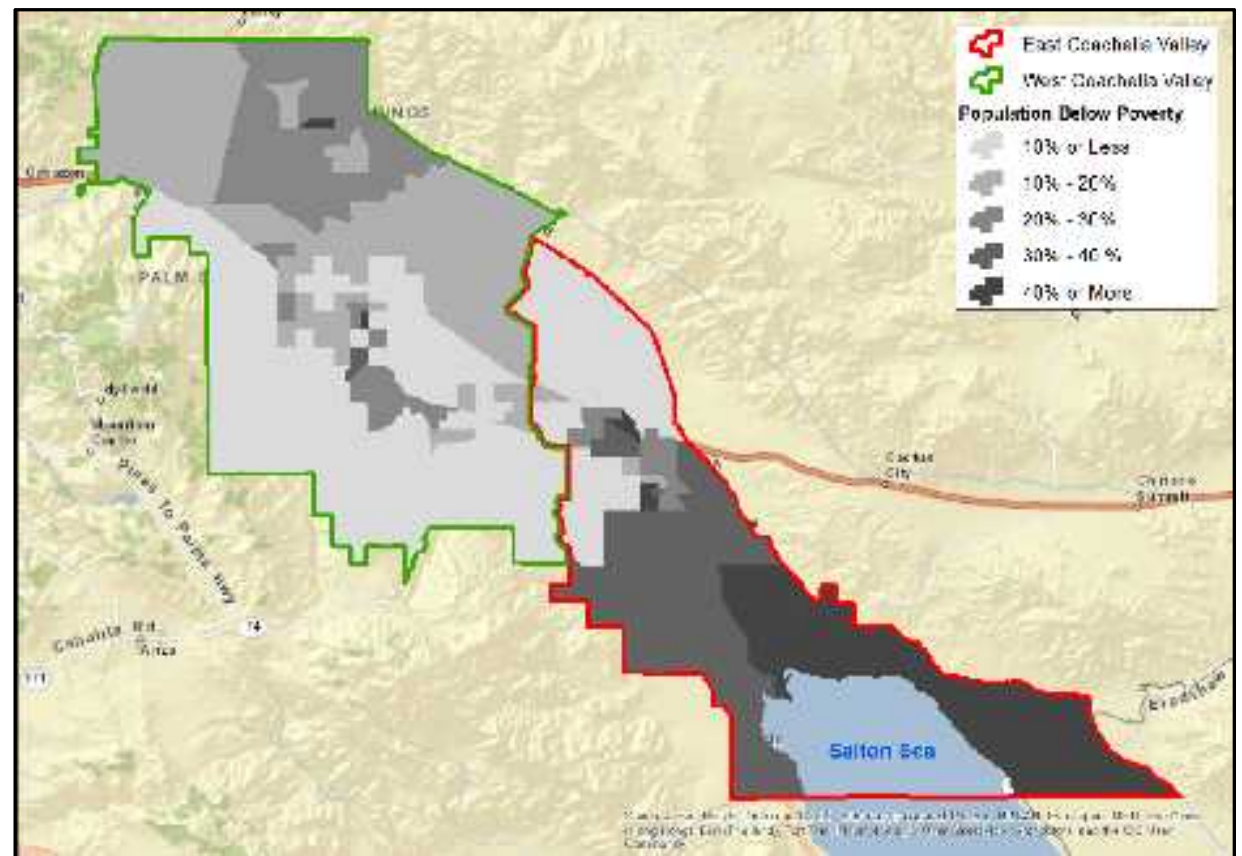

Figure 6.9: Poverty in the Coachella Valley

Lastly, the proficiency with English is mapped. Figure 6.10 illustrates how the populations are distributed based on their capabilities of speaking English.

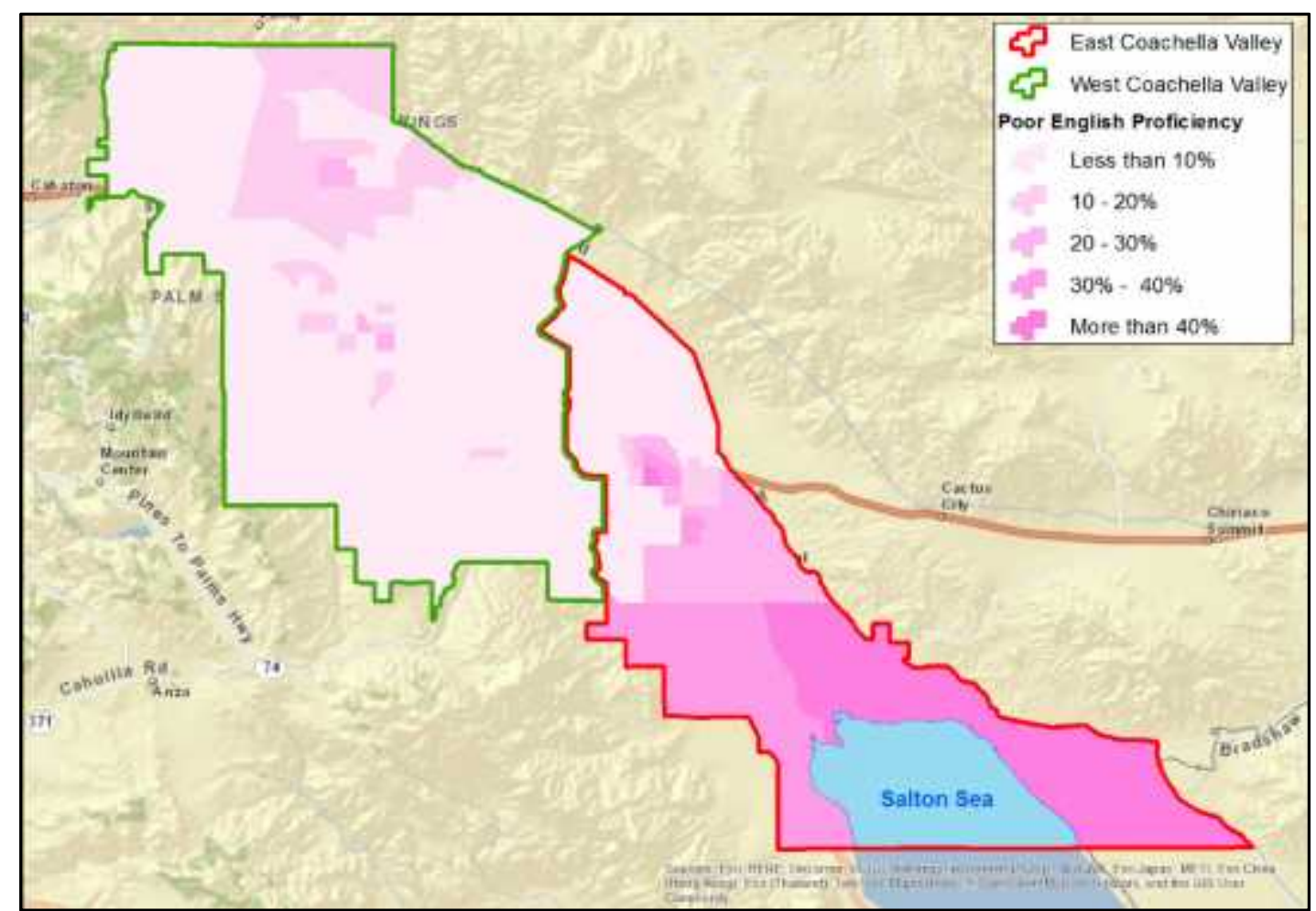

Figure 6.10: Poor English speaking abilities by the population 
Figure 6.10 suggests a higher percentage of population with limited English skills in the south of ECV. In particular, the area bordering the Salton Sea has the highest percentage of population whose English abilities are very limited.

In summary, the three social indicator maps suggest that the populations who are poor Hispanics with low English proficiency characterize the south of ECV. On the contrary, the WCV seems to be dominated by non-Hispanic populations who are in better financial status and English proficiency. These population characteristics would help the audience compare the distributions of environmental hazards among different places in the project area.

The second use case is an example of how a user would analyze various environmental variables in relation to the socioeconomic characteristics of the region. The five environmental themes considered are waste disposal, water distribution, pesticides usage, housing infrastructure, and green spaces. Multiple layers represent each of these themes. In this example, the user is interested in exploring whether water infrastructures and resources are equally accessible to all communities in the Valley. $\mathrm{He}$ may choose to map percentage of Hispanic population with public water lines and wells (Figure 6.11).

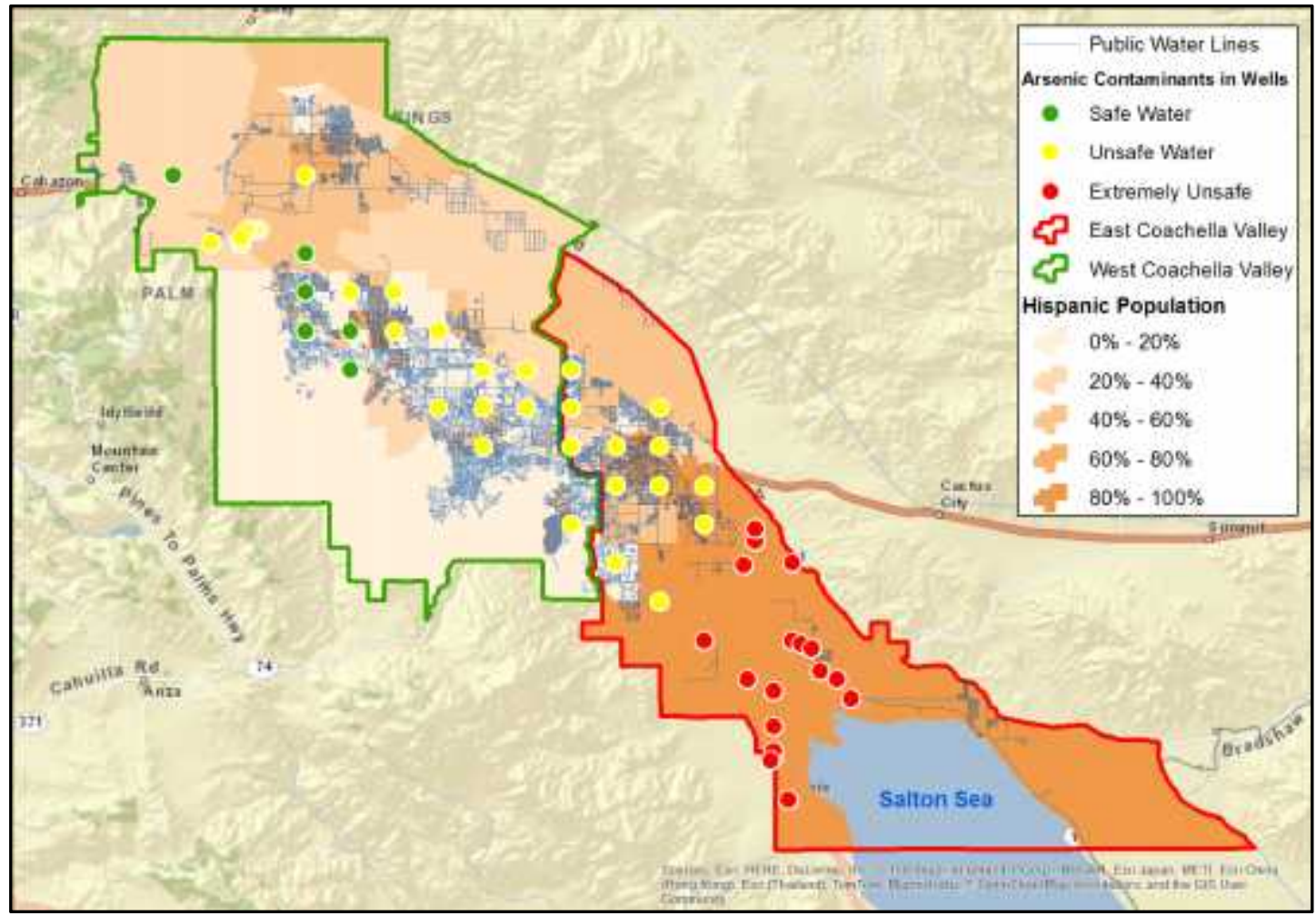

Figure 6.11: Water distribution based on percentages of Hispanic population

The municipal water lines are concentrated in the areas with high population densities. However, it may also suggest the residents in the south of the ECV have inadequate public service as relatively fewer water line are found in that area. Two questions can be raised based on this observation. One is whether the dataset of public water lines is complete, and the other one is whether residents in that area are truly 
underserved, given the very low population density in that area. This first question will be discussed later in Section 6.4. The second question needs more in-depth analysis. For example, density of water lines accounted by households from different tracts can be compared to identify tracts that have low densities of water infrastructures.

Meanwhile, water wells are another important resource in the Coachella Valley. According to the EPA, the maximum level of arsenic material contamination in water wells is $0.00998859 \mathrm{mg} / \mathrm{L}$ (US EPA, 2001). Based on this standard, all water wells in the ECV are unsafe (exceeding the standard), while the WCV has six water wells that meet the standard. In particular, the southern tracts of the ECV dominated by low-income Hispanic populations seem to have very polluted wells with arsenic contamination ranging from $2 \mathrm{mg} / \mathrm{L}$ to as high as $71 \mathrm{mg} / \mathrm{L}$. The contaminated water wells may expose the residents of the ECV to a higher environmental hazard risk. Other maps showing the spatial distribution of environmental variables against the social indicators are included in Appendix D.

\subsection{Data Limitations}

Although the Web applications provide good platforms for audiences to explore different environmental justice topics, users should carefully consider data limitations in their interpretations. Since data acquisition was not within the scope of this project, the data provided by the clients were used, and problems associated with some of the datasets were identified. For instance, the WCV was represented as an area without any mobile home parks. This is not true because the data of mobile home parks were only collected for the ECV through a field survey. In addition, the illegal dumpsites might not be accurate as these sites were identified through a limited survey of local people's knowledge, and the dataset may not include a complete list of illegal dumpsites. In addition, disconnected water lines are observed in the study area, which indicates that the data might not be complete nor accurate.

The clients may continue improving data quality for a better understanding of the environmental injustice in the Coachella Valley. The client can improve the maps by updating the new features into the features services via two platforms: the clients' Web application, and the ArcMap environment. These data edits are automatically synchronized and displayed on the applications. To add new variables to the maps, the client would publish them as feature services and add them as layers to the Web maps on ArcGIS online. Since the applications are reading these Web maps, the new variable added will be shown as well.

\subsection{Summary}

Chapter 6 discussed the results of the project. The focus of the chapter was the interface of the two Web applications, examples of how the Web application may be used to examine spatial correlations of social and environmental variables that might be interpreted as environmental injustice, and a discussion of data limitations. The public Web application was tested in variety of places including the Coachella Valley, Kenya, Egypt, the United Kingdom, and the Netherlands. The Web application allows users to overlay social and environmental variables often deployed in arguments about environmental justice. It permits them to easily develop maps which can help them pose 
environmental justice questions and defend or refute environmental justice arguments. Despite data limitations, the Web application facilitates users' analysis of potential disparities of environmental hazards among different local communities. Furthermore, the tool allows the clients to update datasets as environmental justice questions evolve and as better data become available. 


\section{Chapter 7 - Conclusions and Future Work}

The primary goal of this project was to build a platform that helps audiences to visualize the environmental justice issues in the Coachella Valley. GIS and Web technologies were implemented to deliver these complex environmental spatial relationships to broader audience. To execute the task as per the requirements of the clients, two Web applications were developed: public and clients Web application versions. The public application was developed using ArcGIS API for JavaScript, while the clients' version was developed using ArcGIS Web App Builder (AWAB). Diversity of the audience in relation to GIS expertise and the need for the clients to perform spatial analysis and edit the data were the main reasons behind the two Web application approach.

To develop the solution, various tasks were done. The process began by publishing of Web services: Feature, map, and geoprocessing services. The feature services were comprised of the project variables that required frequent updating by the clients. These services included mobile home parks, water wells, pesticides usage, recreational sites, incorporated cities, tribal lands, unregulated dumpsites, and licensed waste facilities. Map service was comprised of social demographics datasets that needed no frequent updates. The layers in this map service were ethnicity, English speaking abilities, poverty, population density, Coachella Valley region, and county census divisions (CCD's). The public water lines were published as cached map service due to the structure and use constraints of the dataset. The geoprocessing services were published python scripts to help the clients perform customized spatial analysis to identify how various populations were influenced by the environmental variables.

The feature and map services were put together to author Web maps based on the three social indicators. The maps were authored on ArcGIS Online platform. These Web maps were set to be accessible by the public. The public version of Web application development involved four languages namely JavaScript, Dojo, HTML, and CSS. These languages were used to build the application and deliver the results on a web page, which was accessible via a Web browser like Firefox, Chrome, Safari, and Internet explorer. The clients' version was built using the AWAB.

The product developed realized the clients' requirements. However, the project could be furthered in the future. To begin with, the project variables could be increased. The project dealt with three social indicators to gauge the vulnerability levels of the communities in the project area. Increasing the number of social variables would educate the communities better and call the responsible agencies to quicken response to the injustices. In addition, increasing the environmental variables would help the audience know more environmental hazards they are exposed to. Opening up the geoprocessing analysis to the public would help the audience perform basic spatial analysis and generate reports, which they can use to implement preventive measures against the hazards. This would also increase the environmental awareness of the audience. Developing a mobile application could assist in reaching more people. This is because the developed Web application was more usable on a desktop or iPad sized screen for better results. The mobile application would help the audience more, considering that most people have basic phone devices which can accommodate basic applications. 



\section{Works Cited}

Faber, D. R., \& Krieg, E. J. (2005). Unequal Exposure to Ecological Hazards 2005:

Environmental Injustices in the Commonwealth of Massachusetts. Boston:

Northeastern University. Retrieved February 15, 2014, from

http://nuweb9.neu.edu/nejrc/wp-

content/uploads/final_unequal_exposure_report_2005_1012051.pdf

Fu, P., \& Sun, J. (2011). Web GIS: Principles and Applications. Redlands, CA: Esri Press.

Kraak, M.-J. (2004). The role of the map in a Web-GIS environment. Enschede: Journal of Geographical Systems. Retrieved February 14, 2014, from

http://link.springer.com/article/10.1007\%2Fs10109-004-0127-2

London, J., Greenfield, T., \& Zagofsky, T. (2013). Revealing the Invisible Coachella Valley: Putting Cumulative Environmental Vulnerabilities on the Map. Davis, CA: UC Davis Center for Regional Change. Retrieved February 10, 2014, from http://regionalchange.ucdavis.edu/ourwork/publications/ceva-ecv/revealing-theinvisible-coachella-valley-putting-cumulative-environmental-vulnerabilities-onthe-map

Longley, P. A., Goodchild, M. F., Maguire, D. J., \& Rhind, D. W. (2010). Geographic Information Systems \& Science (Third ed.). Danvers, MA: John Wiley \& Sons, Inc.

Massey, R. (2004). Environmental Justice: Income, Race, and Health. Medford, MA: Global Development and Environment Institute. Retrieved February 15, 2014, from http://www.ase.tufts.edu/gdae/education_materials/modules/Environmental_Justic e.pdf

Mennis, J. (2002, March 01). Using geographic information systems to create and analyze statistical surfaces of population and risk for environmental justice analysis. Social Science Quarterly, 81(1), 281 - 295. Retrieved September 02, 2014, from http://astro.temple.edu/ jmennis/pubs/mennis_ssq02.pdf

Morello-Frosch, R., Pastor, M., Porras, C., \& Sadd, J. (2002, April). Environmental Justice and Regional Inequality in Southern California: Implications for Future Research. Environ Health Perspect, 110 (Supplement 2), 149 - 154. Retrieved Sept 30, 2014, from http://www.ncbi.nlm.nih.gov/pmc/articles/PMC1241158/

Okembo, C. O. (2012). Web Maps for Environmental Learning at Highland Sam J. Racadio Library \& Environmental Learning Center. Redlands: University of Redlands. Retrieved February 12, 2014, from http://inspire.redlands.edu/gis_gradproj/161

Swarthmore College. (2006). Mapping Environmental Justice in Delaware County, PA. Swarthmore, PA: Swarthmore College. Retrieved February 15, 2014, from http://www.ejnet.org/chester/delco-swat.pdf

US EPA. (2001, January 30). Fact Sheet: Drinking Water Standard for Arsenic. Retrieved June 14, 2014, from United States Environmental Protection Agency: http://water.epa.gov/lawsregs/rulesregs/sdwa/arsenic/regulations_factsheet.cfm 
US EPA. (2014, February 4). Environmental Justice. Retrieved August 19, 2014, from U.S. Environmental Protection Agency: http://www.epa.gov/environmentaljustice/ 


\section{Appendix A. Sample Code in Aptana Studio 3}

This is a sample of the code used during the development of the application.

Downloaded from GitHub...starts here

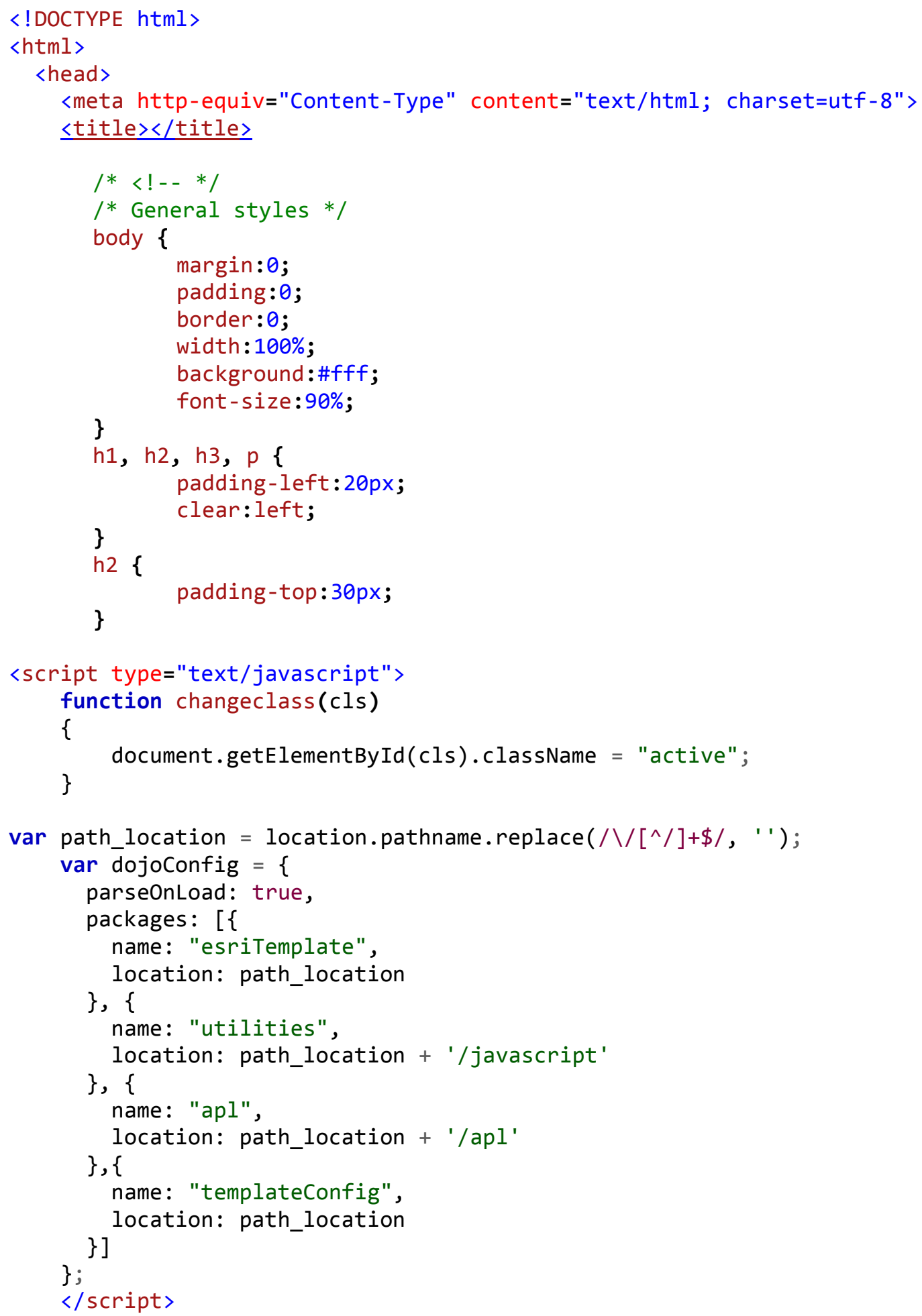




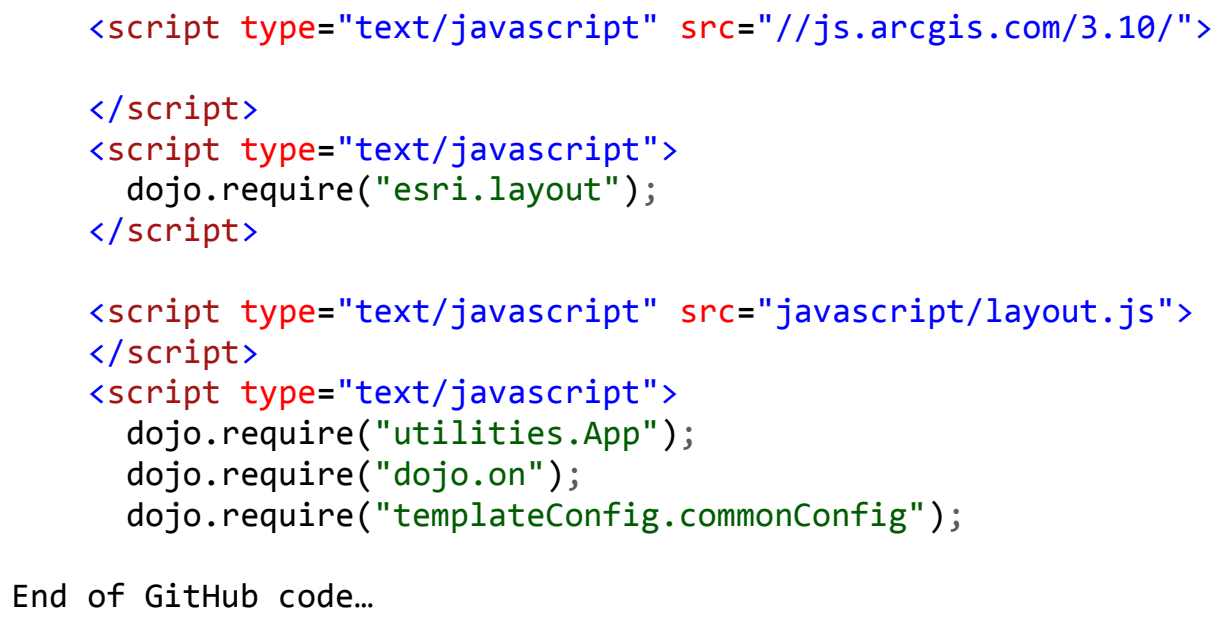

End of GitHub code...

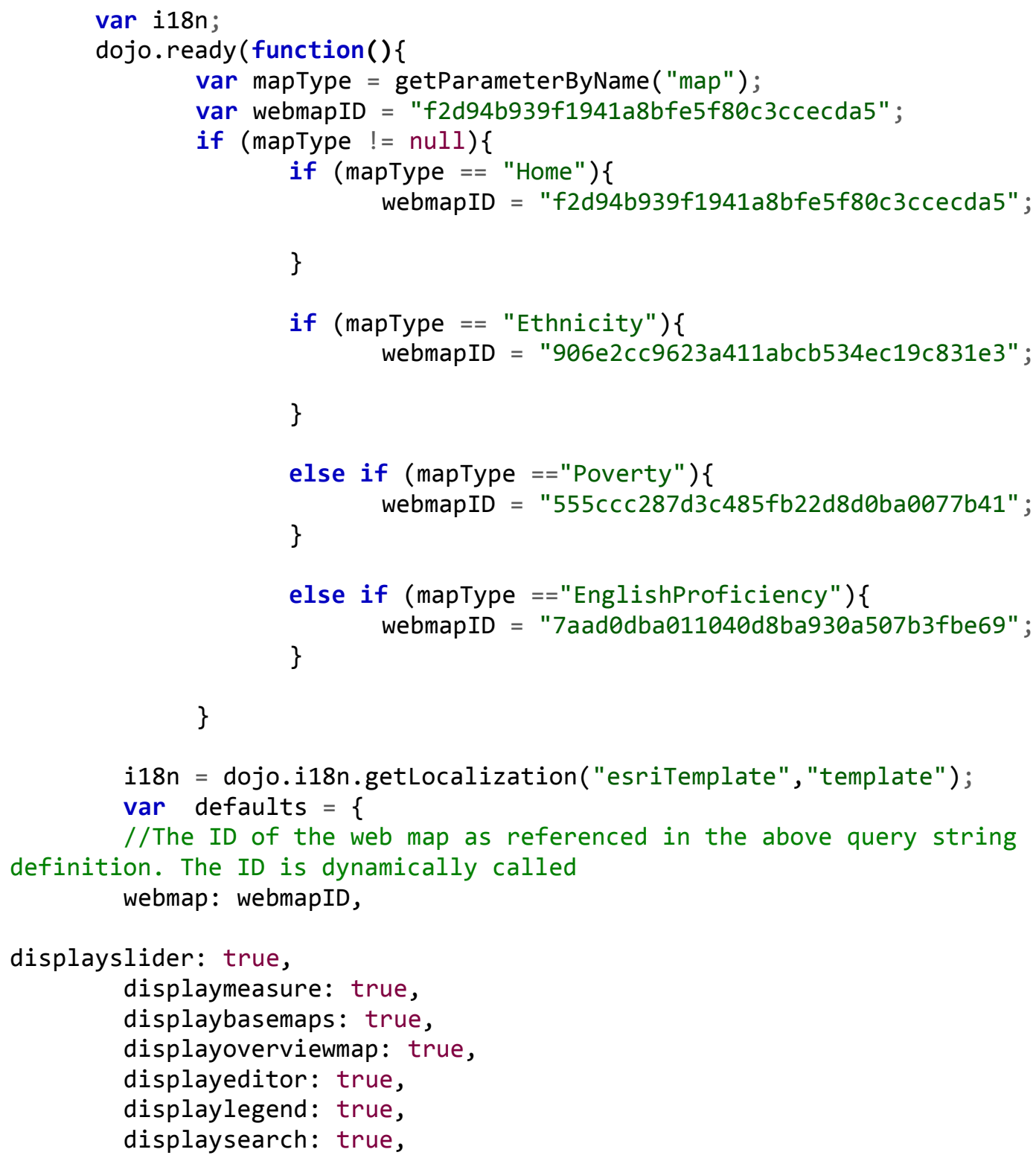


displaylayerlist: true, displaybookmarks: true, displaydetails: false, displaytimeslider: false, displayprint: true, displayprintlegend: true, displayeditortoolbar: false, displaymapwidgets: false,

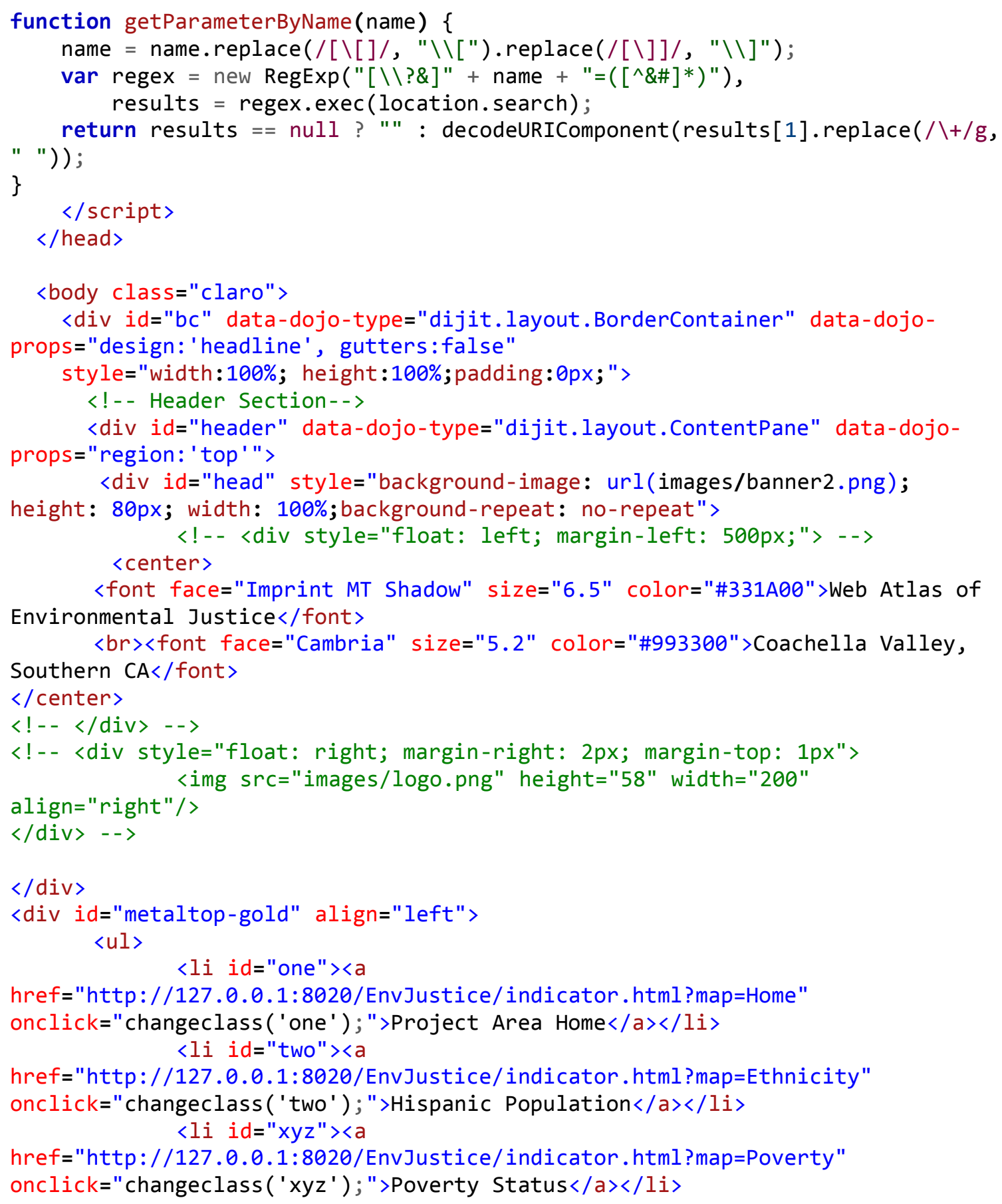


$<$ li id="three" $><a$

href="http://127.0.0.1:8020/EnvJustice/indicator.html?map=EnglishProficiency"

onclick="changeclass('three');" $>$ English Proficiency $\langle/ a\rangle\langle/ l i\rangle$

$<$ li id = "four" $>\langle a$

href="https://www.youtube.com/watch?v=WXmGIcPYOuI" target="_blank">Show Me How? $\langle/ a\rangle$

$\langle/$ ul $\rangle$

$\langle/$ div $\rangle$

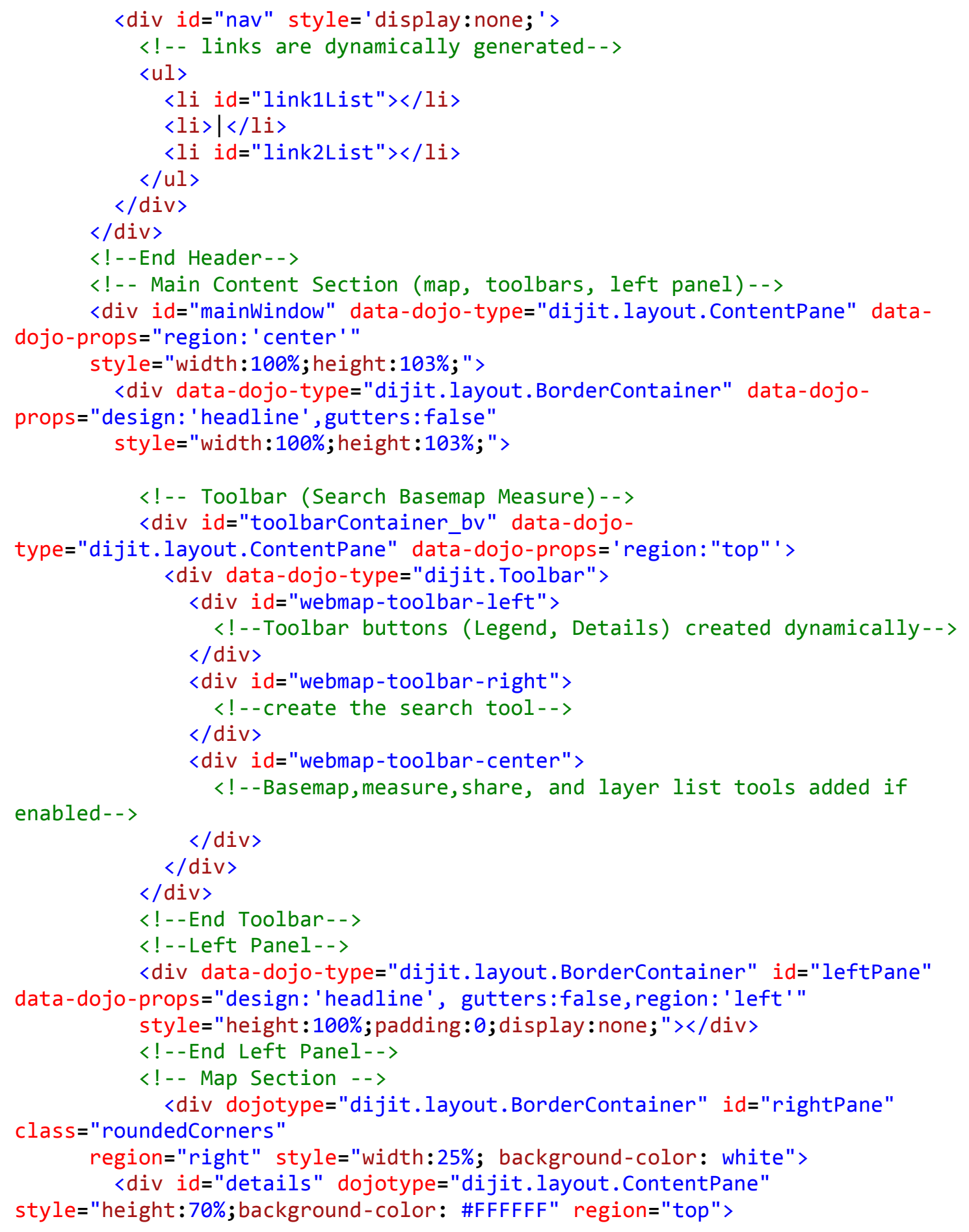




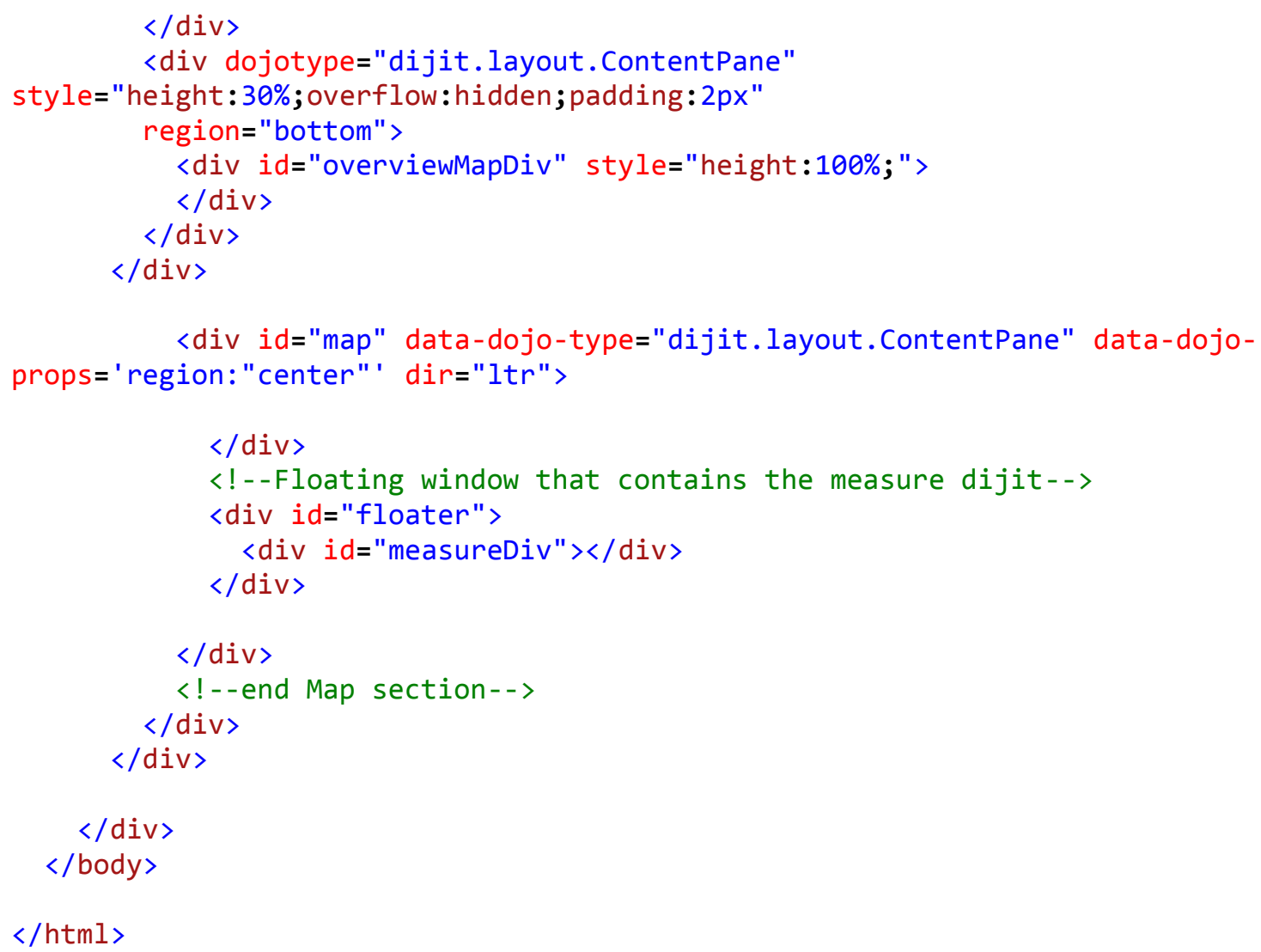

$</$ html $>$ 


\section{Appendix B. Sample CSS}

This is a sample of the CSS used to style the application interface. body \{ \} background:url(../images/green/body_bg.png) repeat-x \#666666;

\#leftPane \{

background-color:\#ecf4e9;

\}

.HomeButton .home\{

\}

background-color: \#4a6f1c;

. LocateButton .zoomLocateButton \{

background-color: \#4a6f1c;

\}

.HomeButton .home:hover \{

background-color: \#b5d19a;

\}

. LocateButton .zoomLocateButton:hover \{

background-color: \#b5d19a;

\}

/*override claro background and other props*/

\#toolbarContainer_bv .dijitToolbar \{ \}

background:url(../images/green/toolbar_bg.png) repeat-x \#4a6f1c;

/*Measure toggle button*/

.claro .dijitToolbar .dijitButtonNode:hover \{

background:url(../images/green/sidebar_header_active_bg.png) repeat-x \#b5d19a;

\}

.claro .dijitToolbar .dijitToggleButtonchecked .dijitButtonNode \{ background:url(../images/green/sidebar_header_active_bg.png) repeat-x \#b5d19a;

\}

/*Attribute Inspector button styling (delete buttons)*/

.esriAttributeInspector div.atiButtons span.dijit span.dijitReset \{ background:url(../images/green/toolbar_bg.png) repeat-x \#4a6f1c; color:\#fff;

\}

border: none;

.esriAttributeInspector div.atiButtons span.dijit span.dijitReset:hover background:url(../images/green/sidebar_header_active_bg.png) repeat-x \#b5d19a;

\} color:\#000;

.dojoxFloatingPaneTitle\{ \}

background:url(../images/green/toolbar_bg.png) repeat-x \#4a6f1c;

.esriPopup .titlePane\{ 


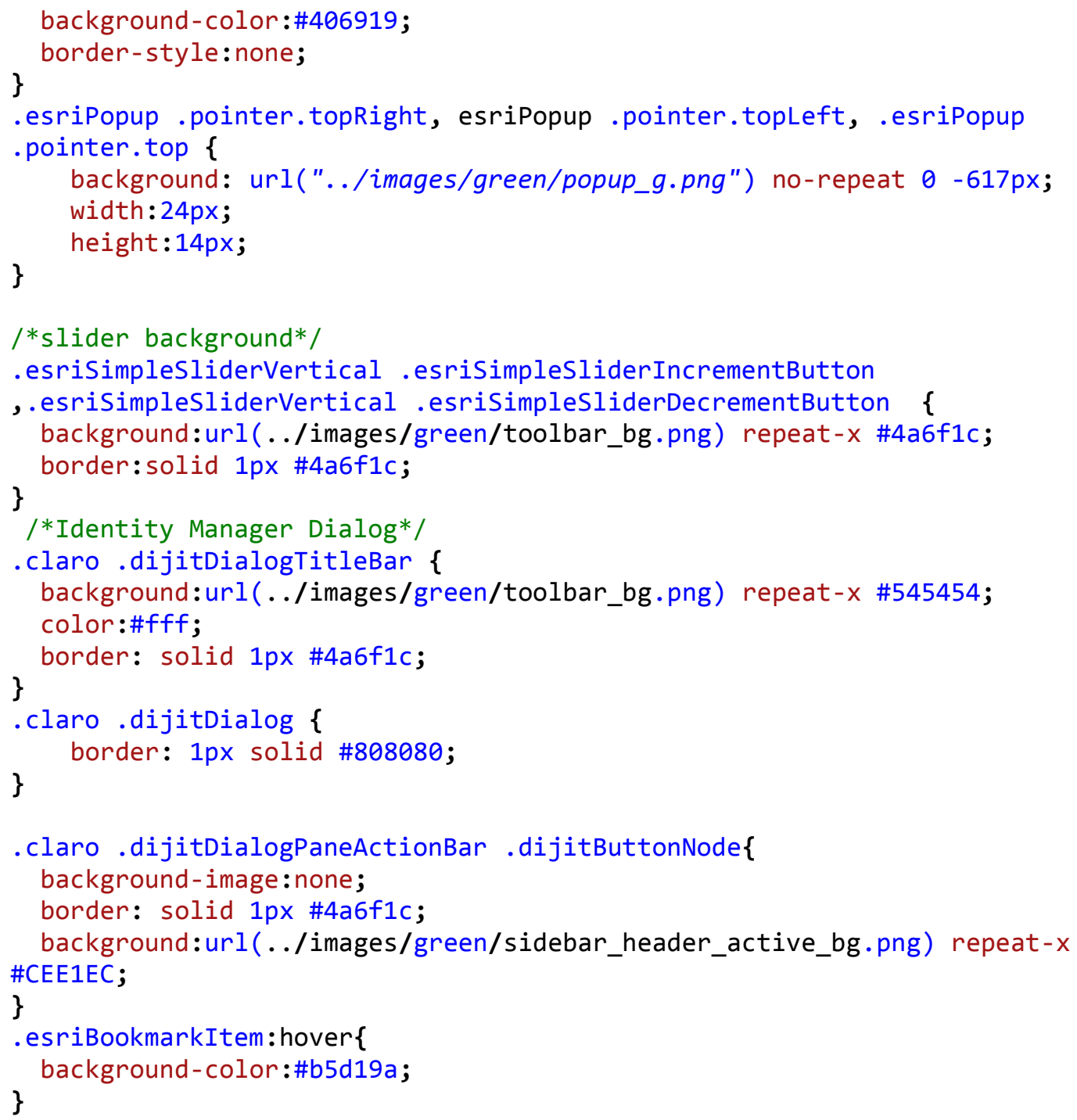




\section{Appendix C. Geoprocessing Code}

This is the Python code for the geoprocessing tool.

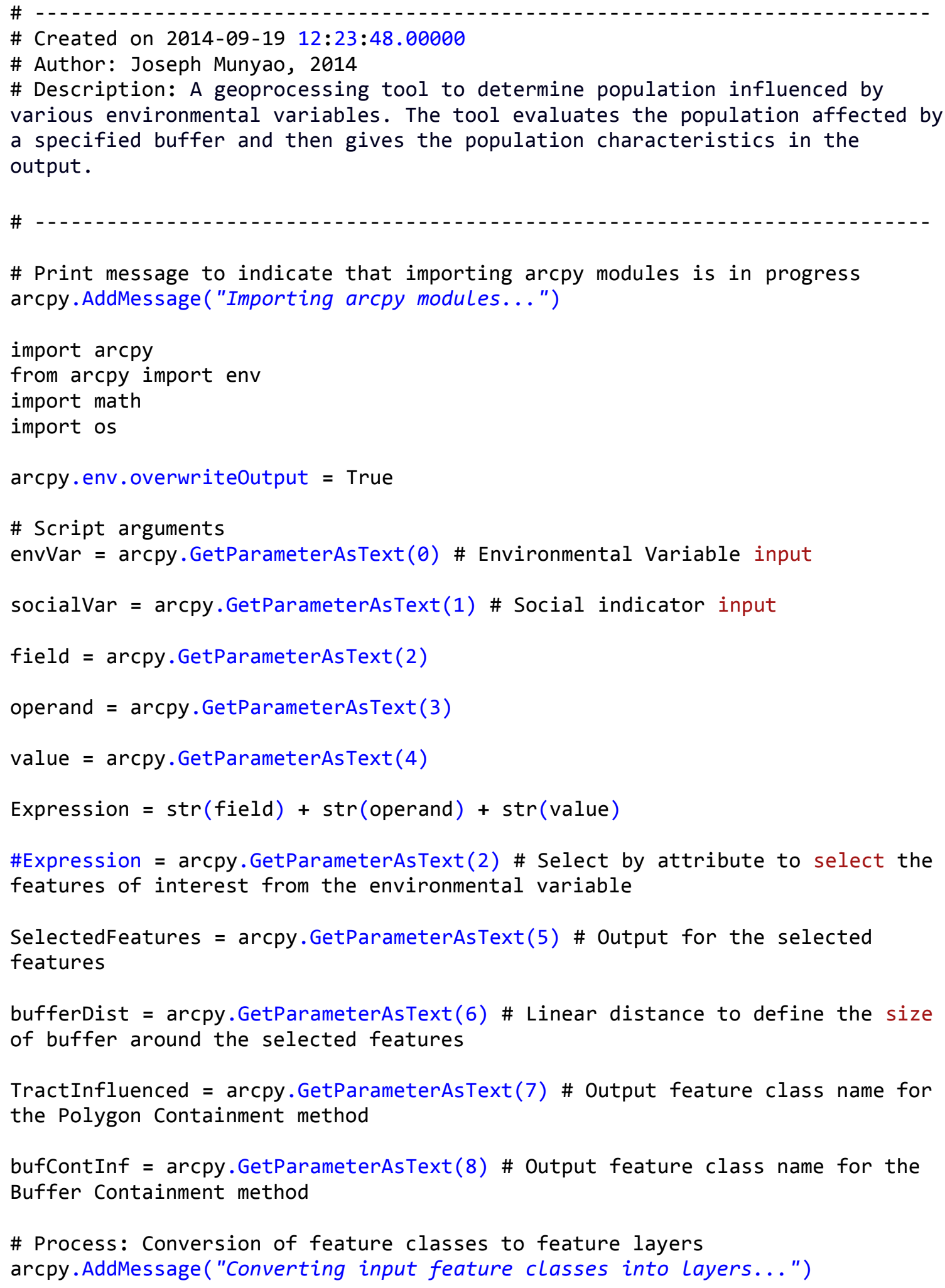


envVarLyr = arcpy.MakeFeatureLayer_management(envVar) \# Environmental variable conversion

socialVarLyr = arcpy.MakeFeatureLayer_management(socialVar) \# Socal indicator conversion

\#Process: Select Layer by attributes (Performed on the environmental variable input)

arcpy.SelectLayerByAttribute_management(envVarLyr, "NEW_SELECTION", Expression)

\#Process: Write out the selected features as output arcpy.CopyFeatures_management (envVarLyr, "\%scratchGDB\%/features") arcpy.MakeFeatureLayer_management("\%scratchGDB\%/features", SelectedFeatures)

\# Print message to indicate the process of buffer creation is in progress arcpy.AddMessage( "Buffering...")

\# Process: Buffering the environental variable using the user's parameters envVarBuffer = arcpy.Buffer_analysis(SelectedFeatures, "\%scratchGDB\%/buffer", bufferDist, "FULL", "ROUND", "ALL")

\# Process: Select Layer By Location arcpy.SelectLayerByLocation_management(socialVarLyr, "INTERSECT", envVarBuffer, "", "NEW_SELECTION")

\# Print message to indicate that the generated output are being written to disk arcpy.AddMessage ("Generating outputs...")

\# Process: Write polygon containment results to disk

arcpy.CopyFeatures_management(socialVarLyr, "\%scratchGDB\%/pol")

arcpy.AddField_management( "\%scratchGDB\%/pol", "TractPctPop", "DOUBLE")

\#Process: Calculate the new area proportion for the new features created by the buffer containment method

with arcpy.da.UpdateCursor("\%scratchGDB\%/pol", ["pop2010", "TractPctPop"]) as cursor:

for row in cursor:

TractPop $=\operatorname{row}[0]$

wholePop $=421860$ \#Total project area population

row $[1]=($ TractPop/wholePop $) * 100$ \# Proportion of the tracts within

the buffer zone

cursor.updateRow(row)

del row

arcpy.MakeFeatureLayer_management("\%scratchGDB\%/pol",TractInfluenced)

\#Process: Intersect analysis to determine buffer containment influence arcpy.Intersect_analysis([envVarBuffer, socialVarLyr], "\%scratchGDB\%/buf") 


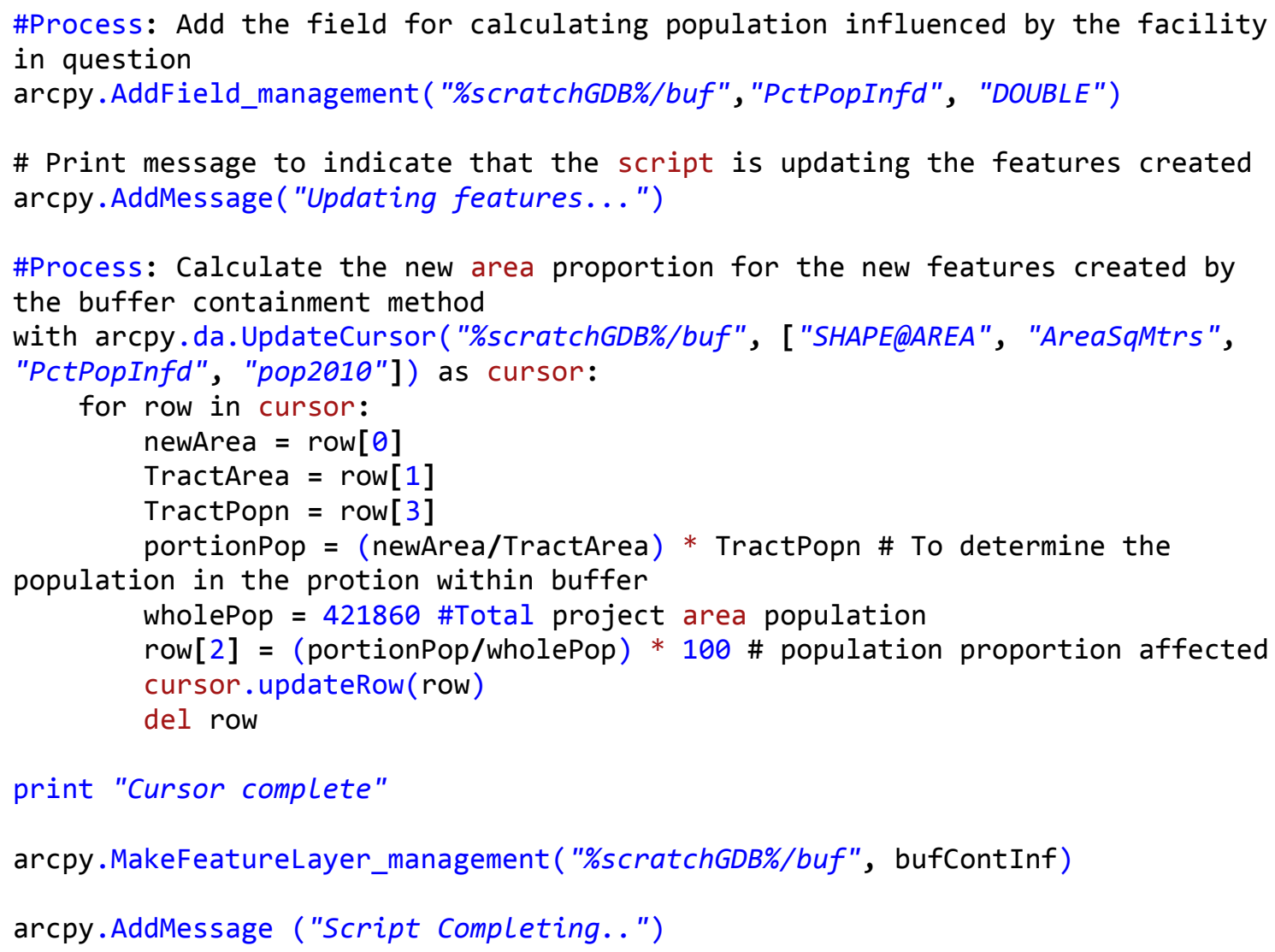




\section{Appendix D. Environmental Justice Maps}

Various maps were generated to visualize environmental justice issues in the Coachella valley. These maps could be generated by overlaying the environmental variables on the social indicators.

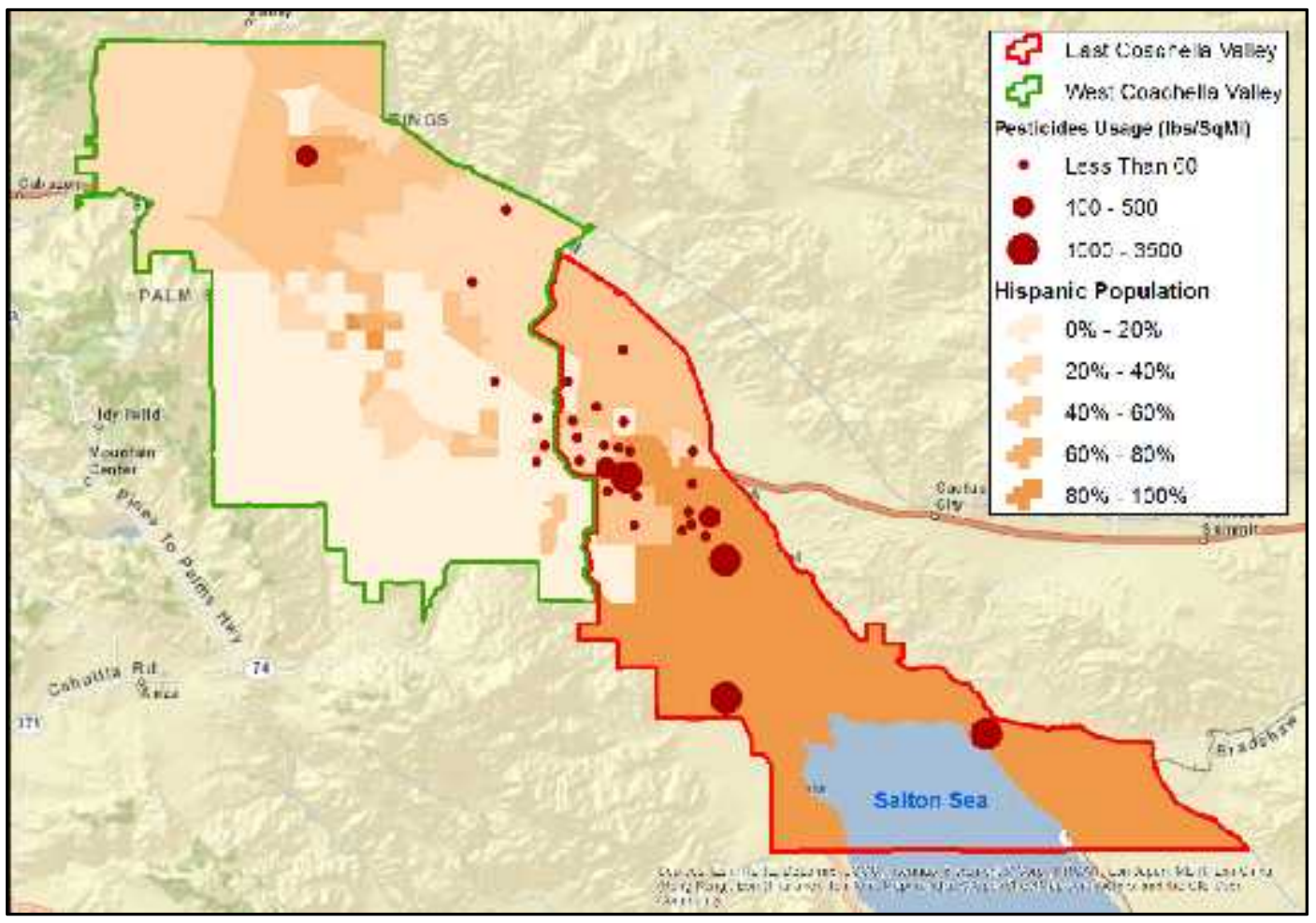

Map 1: Use of pesticides against percentages of Hispanic population 


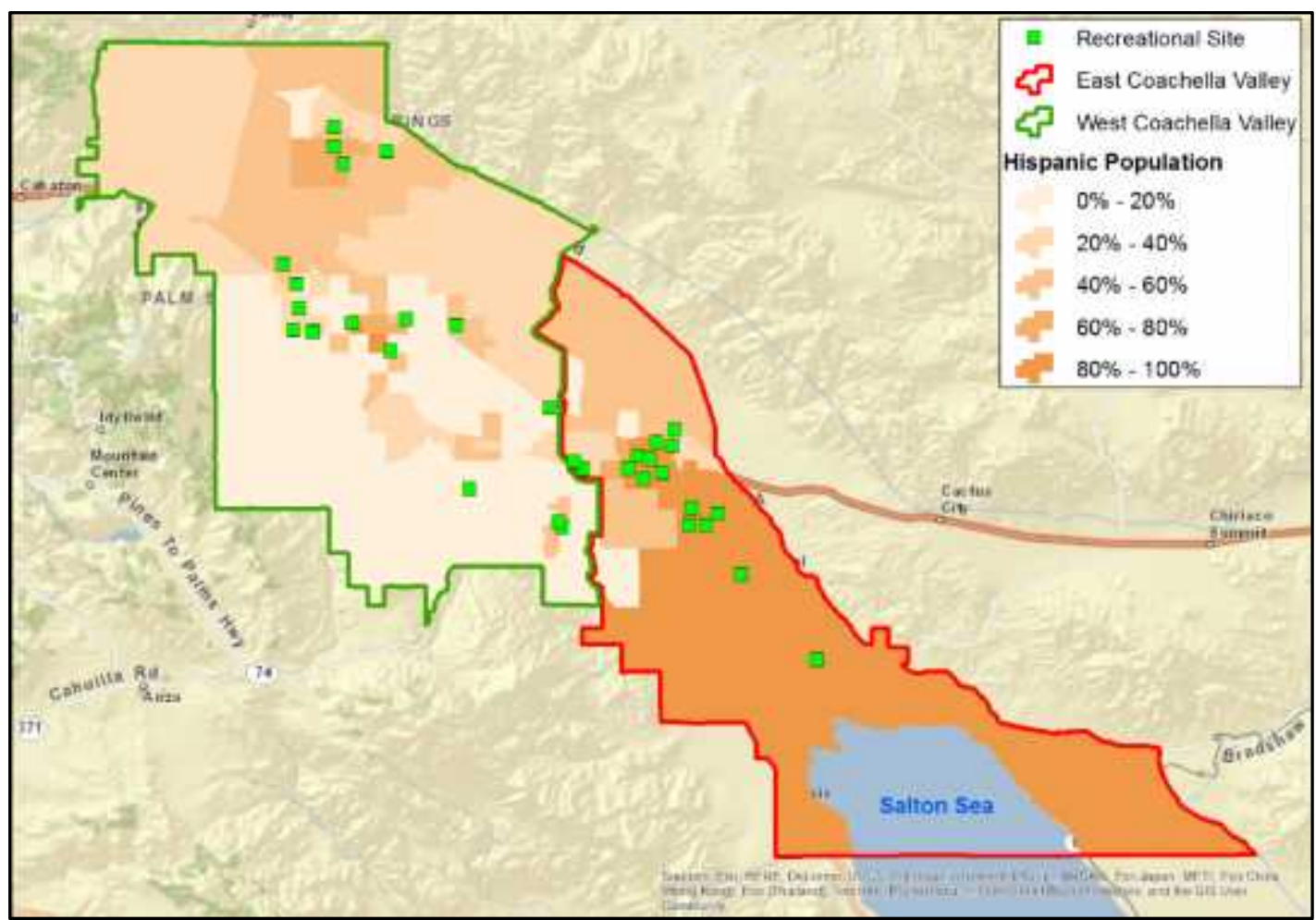

Map 2: Distribution of green spaces against percentages of Hispanic population

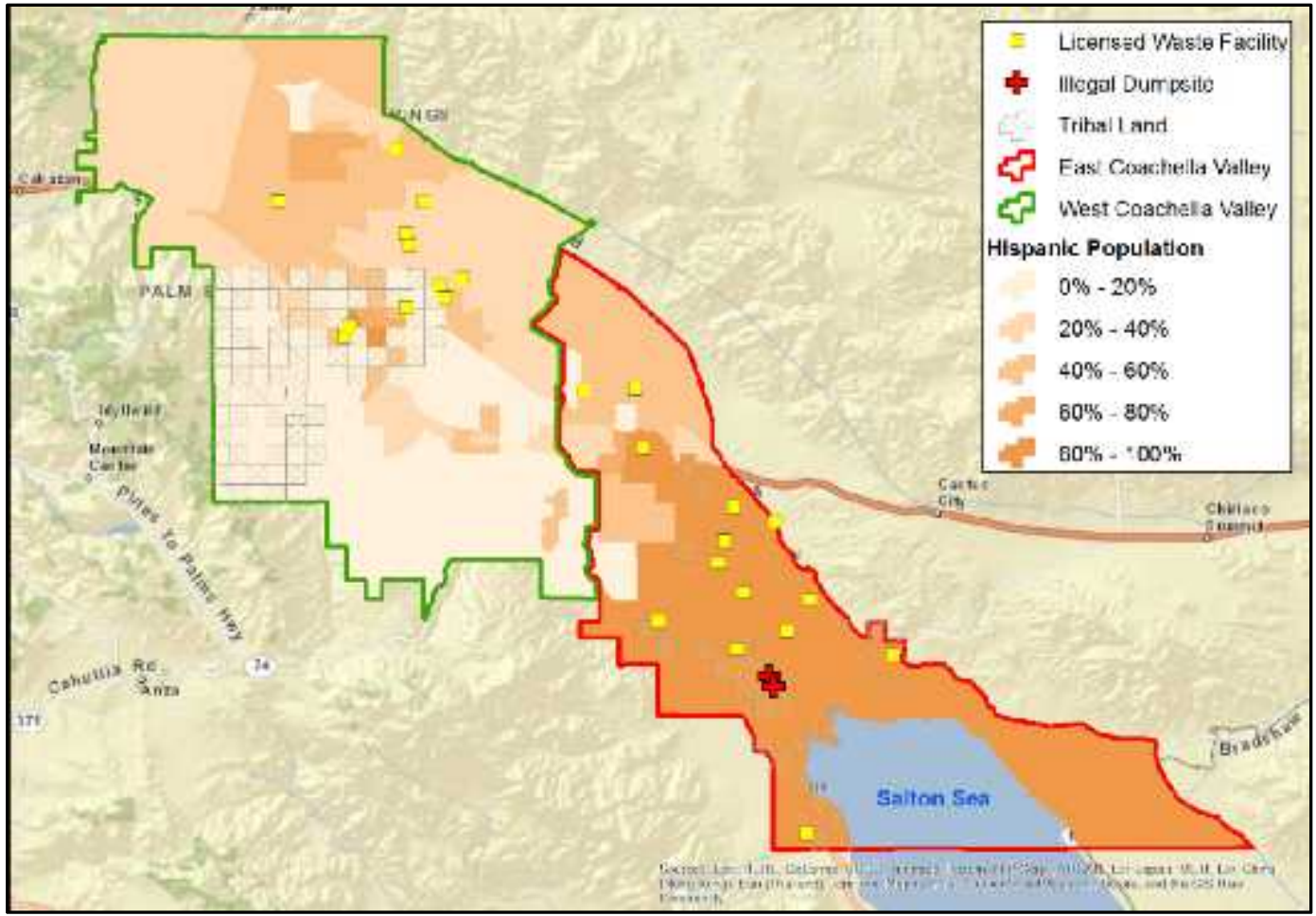

Map 3: Waste disposal practices against percentages of Hispanic population 


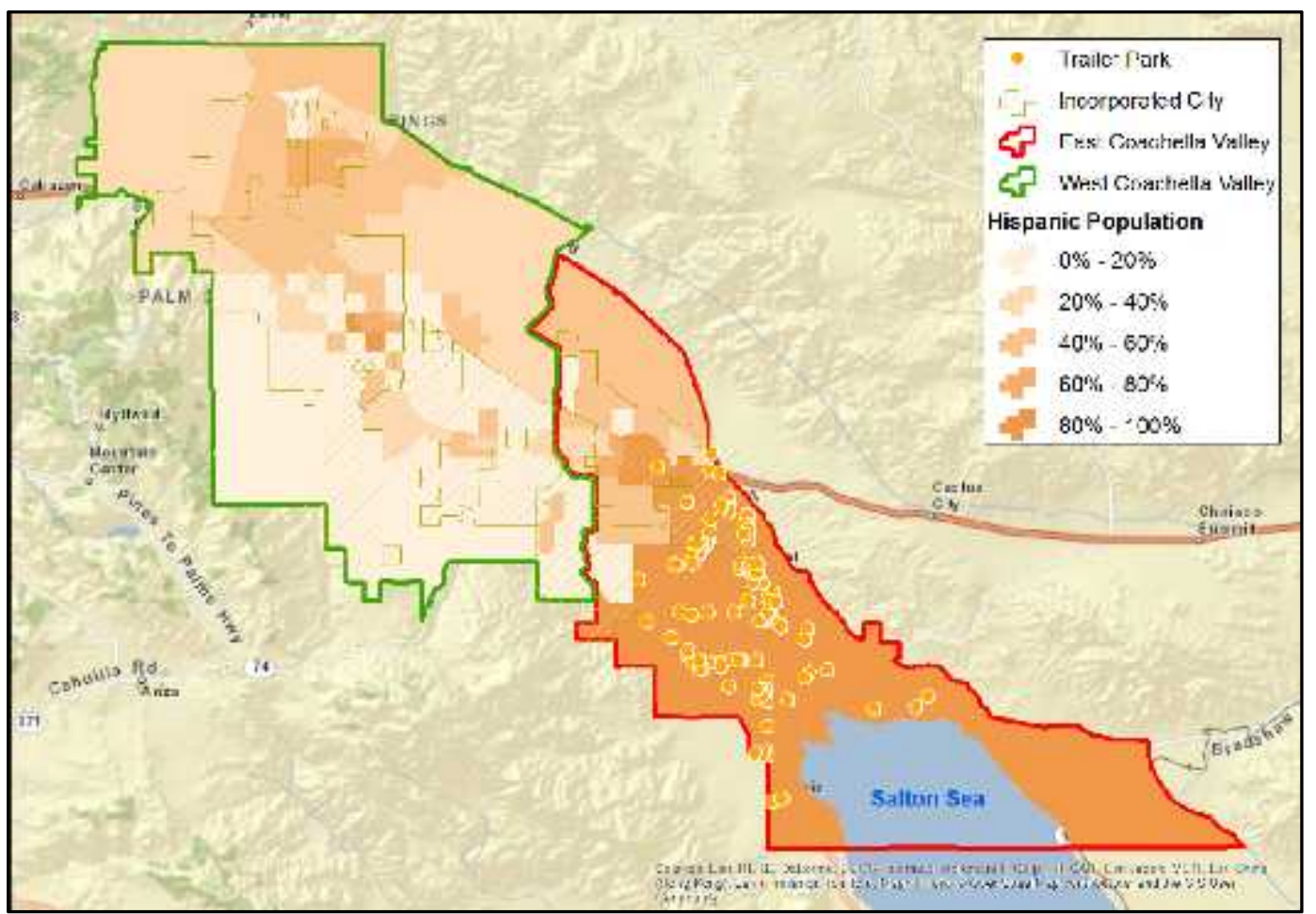

\section{Map 4: Housing infrastructure against percentages of Hispanic population}

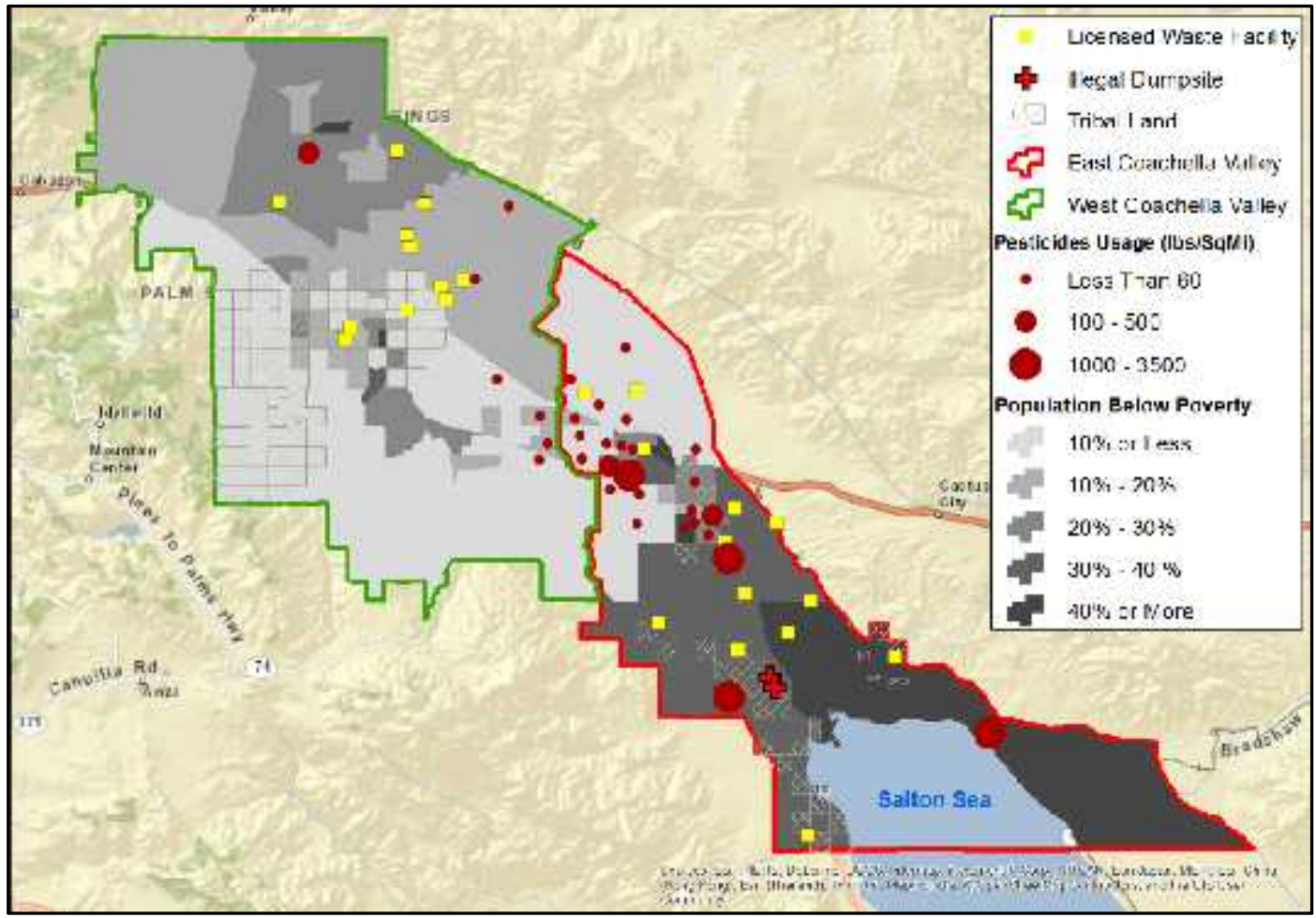

Map 5: Pesticides and waste disposal facilities against poverty levels 


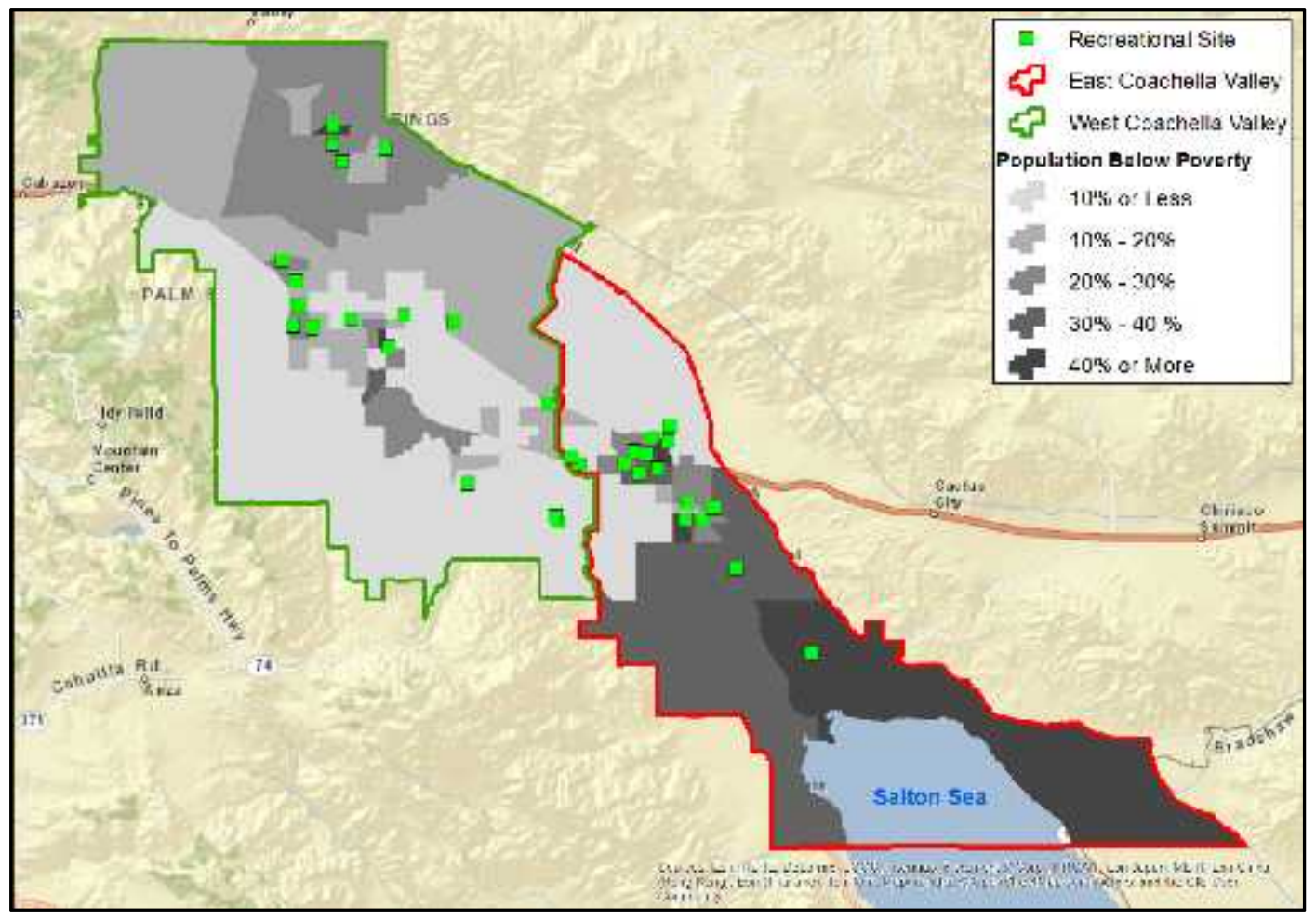

Map 6: Distribution of green spaces against poverty levels

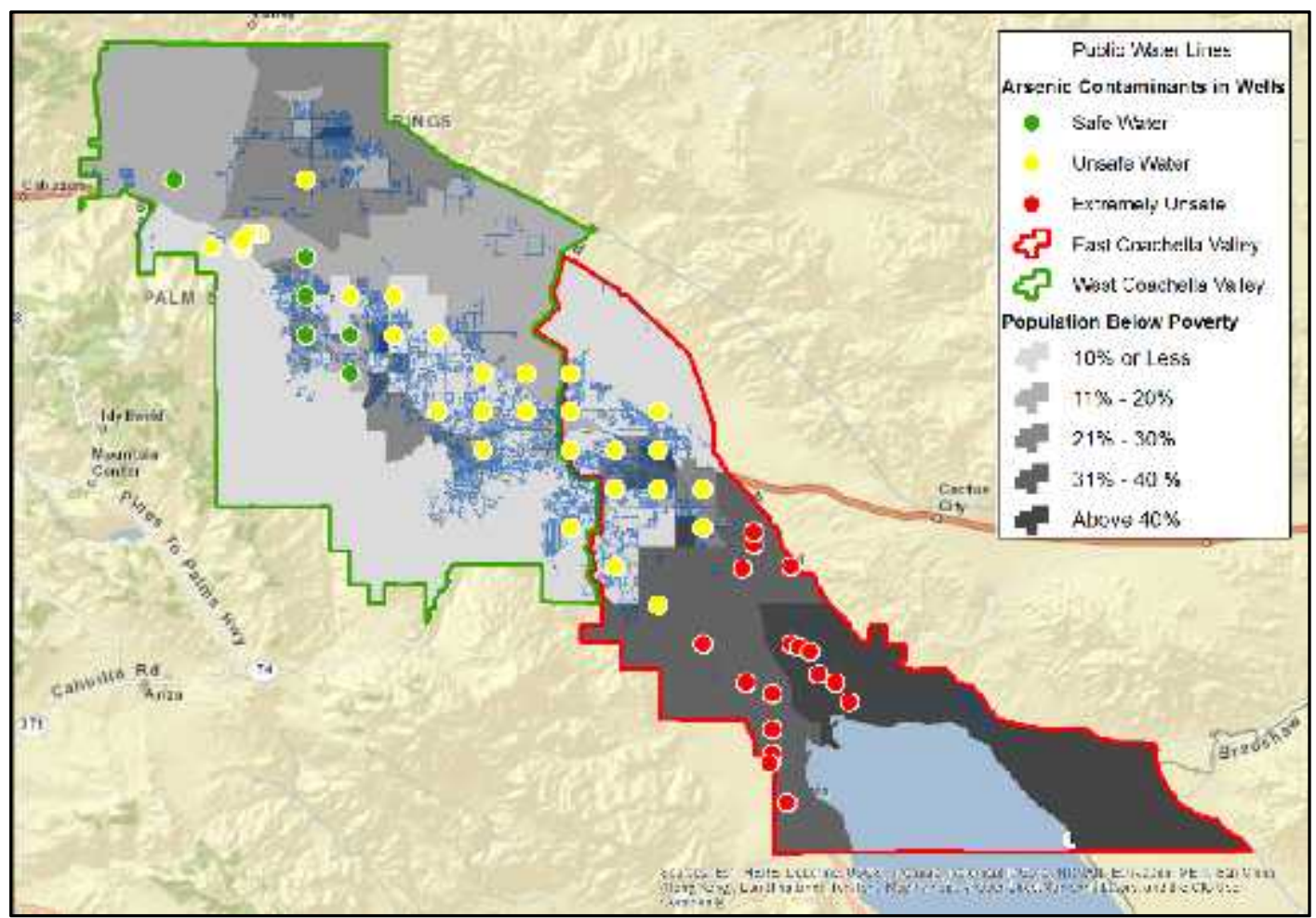

Map 7: Water distribution and access against poverty levels 


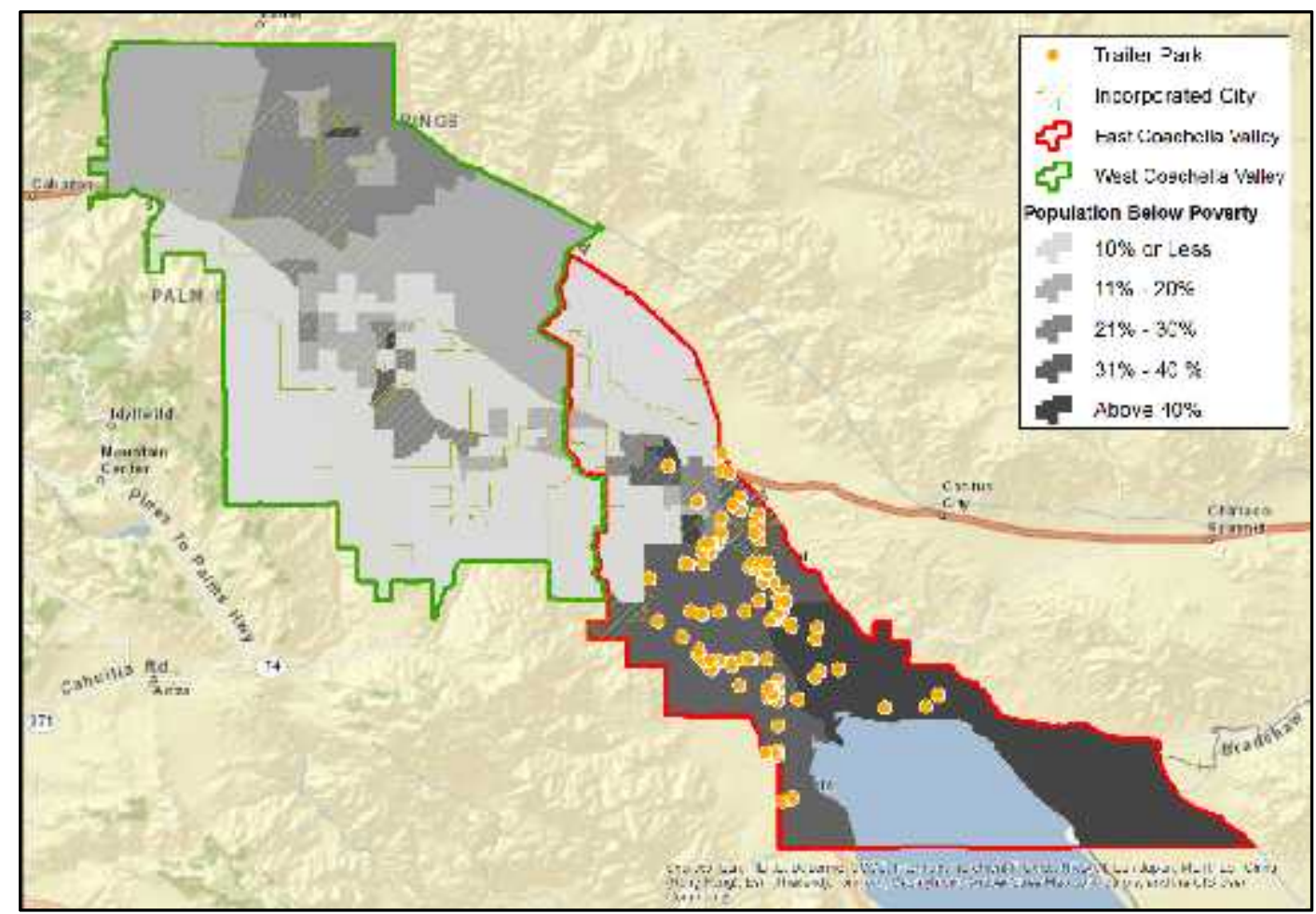

\section{Map 8: Housing infrastructure against poverty levels}

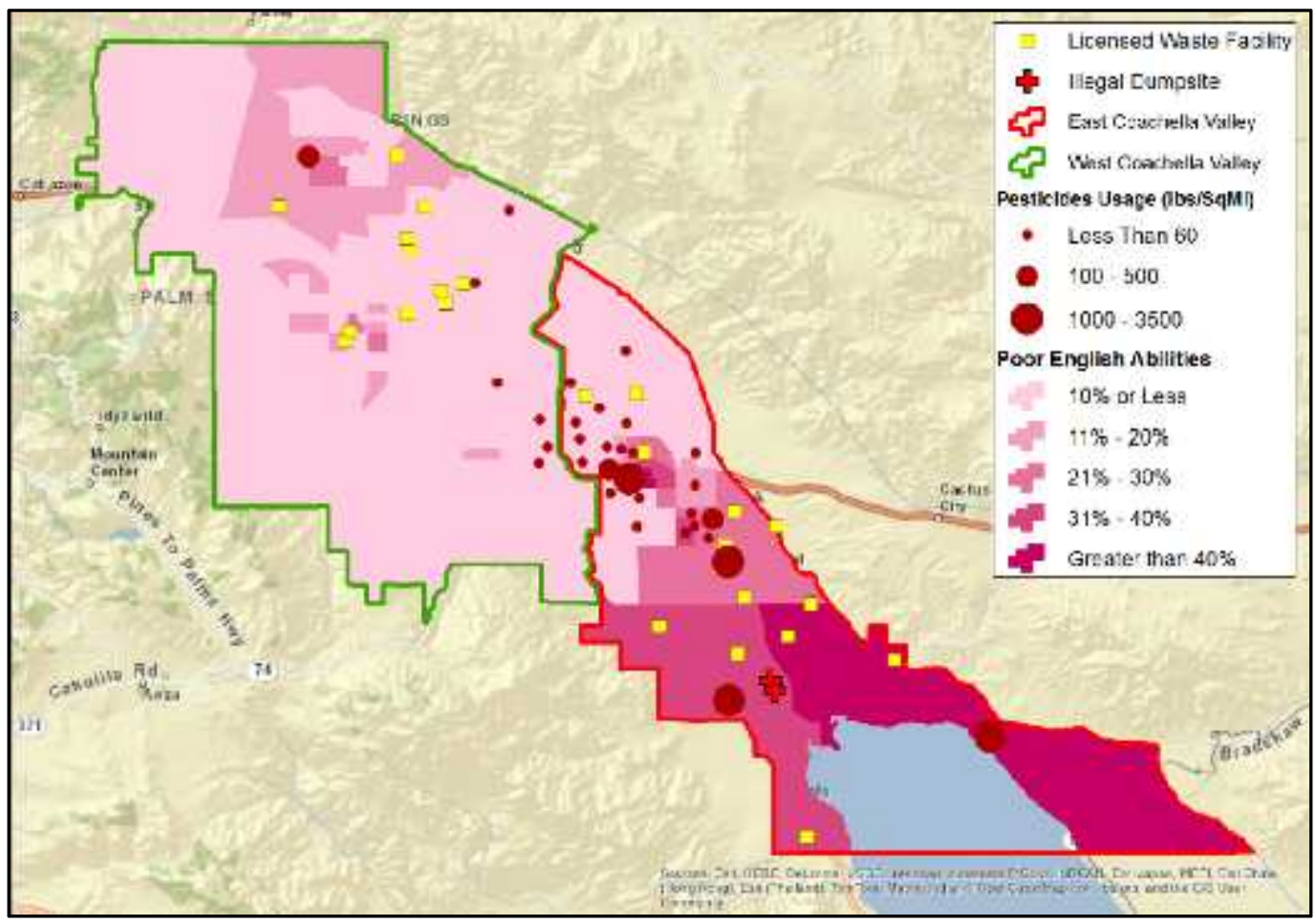

Map 9: Waste disposal facilities and pesticides usage against English speaking abilities 


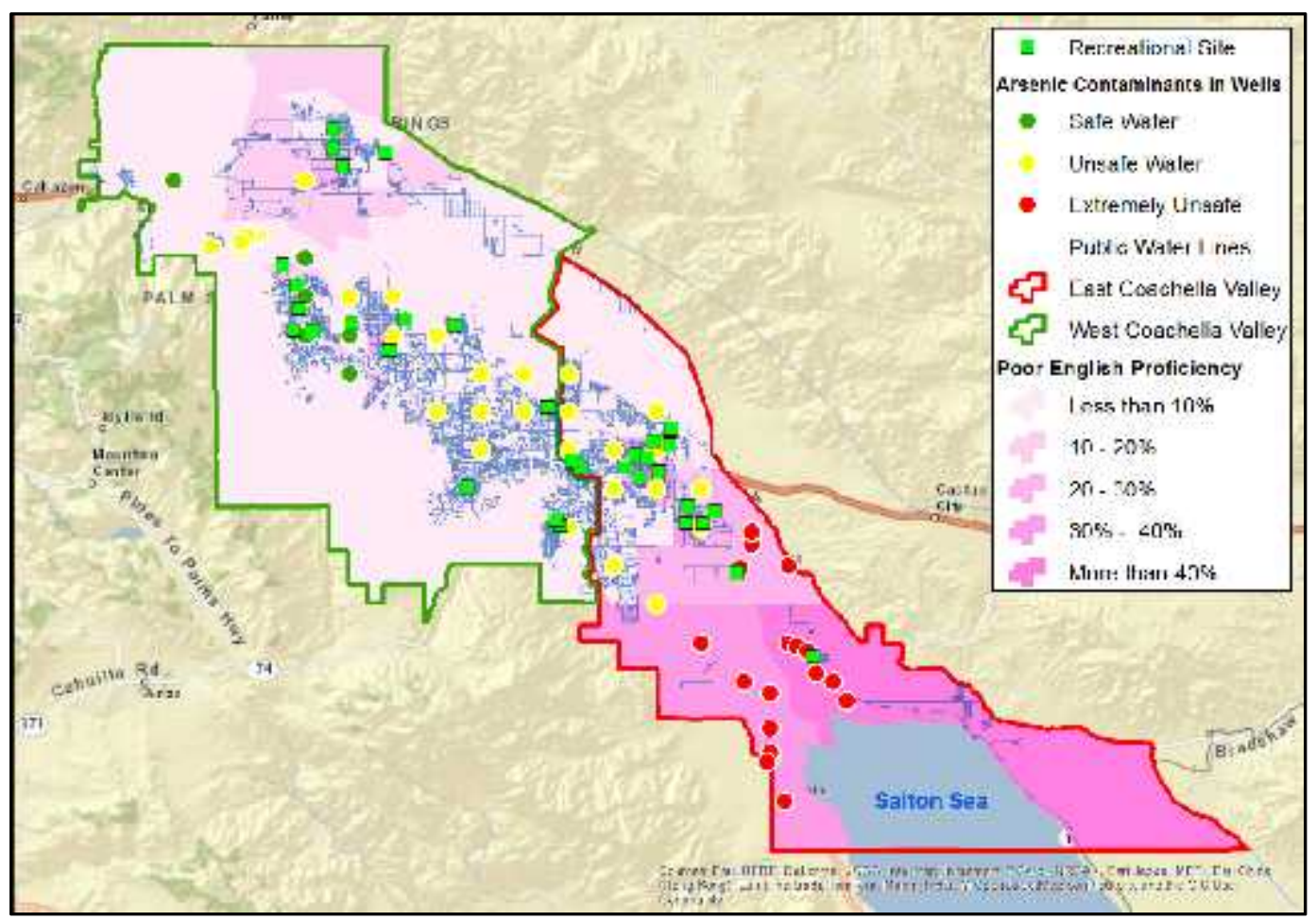

Map 10: Water infrastructure and green spaces against English speaking abilities

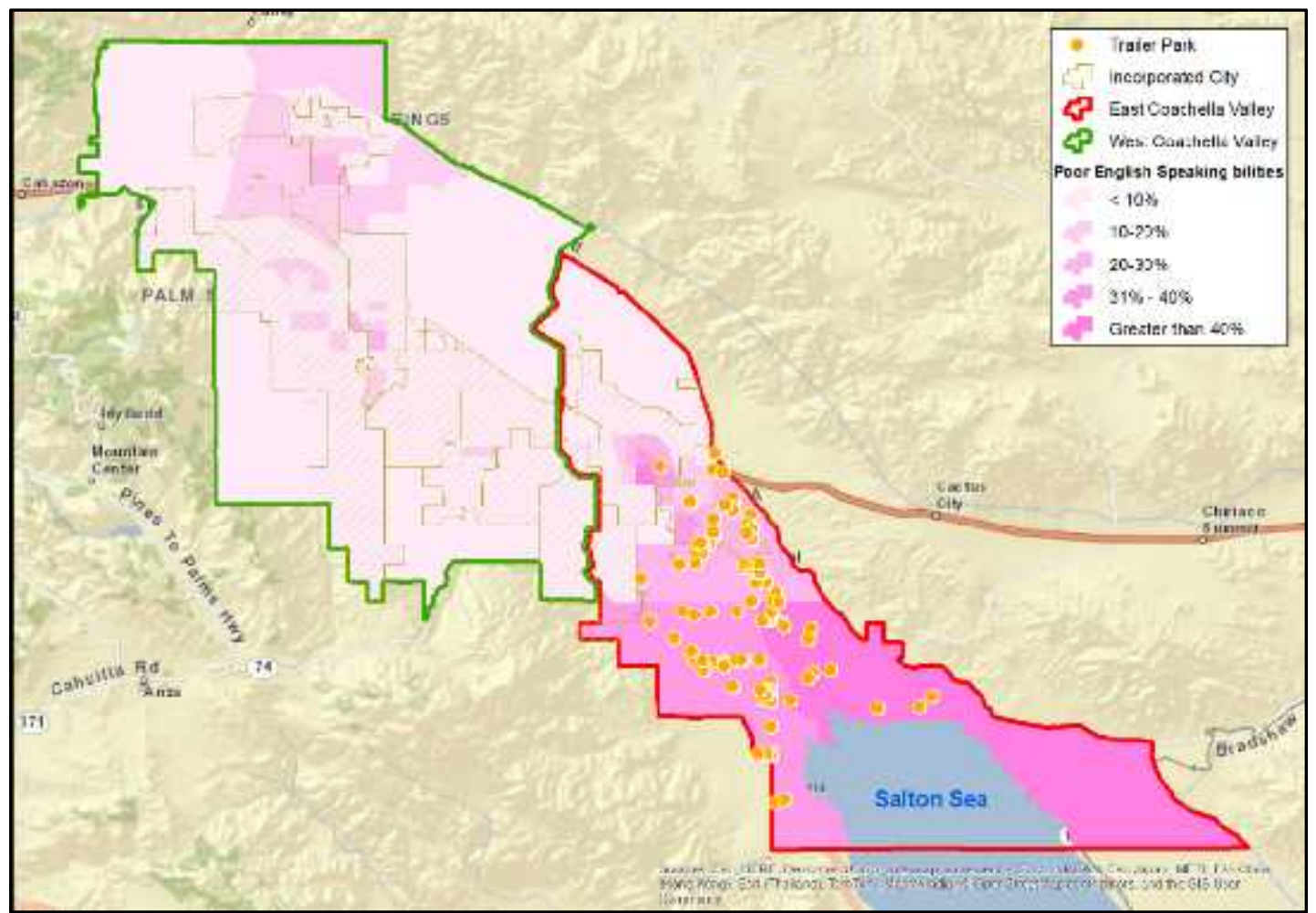

Map 11: Housing infrastructure against English speaking abilities 